(Aus dem embryologisehen Institut der Wiener Universität, Vorstand: Prof. Dr. A. Fischel.)

\title{
Über den Zellteilungsrhythmus und seine Regelung.
}

Von

Dr. Werner Kornfell, Assistent am Institute.

Mit 29 Textabbildungen und 7 Tabellen.

(Eingegangen am 15. August 1921.)

Inhaltsiibersicht.

I. Die gegenseitigen Beziehungen der einzelnen Entwicklungsvorgänge innerhalb des Individuums nach den in der Literatur vorliegenden Befunden.

a) Ubber die Regelung von Entwicklungsvorgängen im allgemeinen. .................. 526-540

b) Utber die Regelung zellulärer Entwicklungsprozesse . . . 540-548 II. Eigene Untersuchungen.

a) Fragestellung, Material and Methodik . . . . . . . 548-556

b) Abhängigkeit der Zellteilungstätigkeit von der Ernährung . 556-562

c) Vergleich der Zellteilungstïtigkeit zwisehen zwei gleichartigen Zellkomplexen eines Individuums:

1. Der Grad der Ubbereinstimmung in der Zellteilungstätigkeit 562--571

2. Die Eälle von abweichenden Zellteilungsrhythmen . . 571-577

3. Die Bedeutung der ungleichen Zellteilungsrhythmen für die Analyse der Zellteilungsfaktoren und die in der Literatur vorliegenden Befunde über Zellteilungsrhythmen und Zellteilungsfaktoren . . . . . . . . . 577- 587

III. Zusammenfassung. . . . . . . . . . . . . 587-590

Literaturverzeichnis. . . . . . . . . . . . . 591-592

Die Tatsache, daß bei der Lntwicklung jedes Lebewesens eine Anzahl von Vorgängon in gesetzmäßig geregelter Weise nebeneinander hergeht, so daß einem bestimmten Stadium des einen Entwicklungsprozesses stets auch ein bestimmtes Stadium des anderen entspricht, erscheint der naiven Naturbetrachtung selbstverständlich. Es scheint keiner weiteren Erklärung zu bedürfen, daß bei der Ontogenese gleichartige Organe (wie z. B. die beiderseitigen Ur- oder Nachnieren, Extremitäten $u$. a. m.) im allgemeinen stets den gleichen Entwicklungszustand aufweisen, daB ferner zwischen verschiedenartigen Organen bestimmte zeitliche Beziehungen des Ausbildungsgrades bestehen, daß also ein gewisser Entwicklungszustand des einen Organes stets auch mit einem ganz bestimmten Entwicklungszustande des anderen Organes zeitlich verknüpft ist.

Und doch lehrt eine genauere Erwägung der hierbei in Betracht kommenden Umstände, daß dieser fast mit gesetzmäßiger Strenge ge- 
regelte gleichzeitige Verlauf der Entwicklungsvorgänge, diese mehr oder weniger starre Synchronie der Entwicklungsschritte zahlreiche offene Fragen darbietet, deren Lösung nur auf mühevollen Wegen der Beobachtung und des Experimentes angestrebt werden kann.

Schon die Frage, inwieweit die Synchronie zwischen den verschiedenen Entwicklungsvorgängen im normalen Entwicklungsgeschehen eine bindende Gesetzmäßigkeit ist und wie weit andererseits eine Variationsmöglichkeit der gegenseitigen zeitlichen Beziehungen besteht, ist noch kéineswegs geklärt. Auf rein deskriptivem Wege ist K. E. v. Baer bereits im Jahre 1828 dem Problem von der Verbindung der verschiedenen Entwicklungsvorgänge untereinander näher getreten. Er findet an Hühnerembryonen bei verschiedenen Individuen die "Ungleichheiten im Nebeneinandersein der Erscheinungen" nicht sehr bedeutend. Man finde im allgemeinen, daß die Entwicklung der einzelnen Organe um so mehr in gleichem Maße fortschreite, je enger die physiologischen Beziehungen zwischen diesen Organen namentlich in der Entwicklung selbst ist. Gekröse- und Darmbildung bedingen sich gegenseitig so unmittelbar, daß sie einander nicht vorauseilen können. Dagegen stehe die Ausbildung des Hirnes und des Darmes weniger in Ubereinstimmung. Am unbestimmtesten scheine das Verhältnis der allgemeinen Körperkrümmung zur übrigen Ausbildung des Körpers zu sein. Endlich stellt Baer fest, daß augenscheinlich das Verschwinden von Teilen, deren Wirksamkeit aufgehört hat, den meisten Abweichungen unterworfen ist.

Später betont His (1874) die Bedeutung des gesetzlichen $\mathrm{Zu}$ sammenhanges aller der Körperentwicklung zugrunde liegenden Vorgänge: Jede einzelne Organentwicklung sei immer wieder nur eine abhängige Teilerscheinung eines großen, nach allen Richtungen sich verkettenden Gesamtprozesses. Diese Ausführungen sind bei $\mathrm{His}$ um so bemerkenswerter, als die von diesem Forscher aufgestellte Theorie der organbildenden Keimbezirke mehr auf eine weitgehende Selbständigkeit der einzelnen Teile in ihrer Entwicklung hinweist.

Aber nicht alle Forscher anerkannten das Bestehen eines bindenden Zusammenhanges der einzelnen Entwicklungsvorgänge. So schließt Mehnert (1895) aus einer Untersuchung der individuellen zeitlichen Unterschiede in ider Differenzierung des gleichen Organs innerhalb einer Spezies, daß keine konstante Wechselbeziehung der Organentwicklung bei gleich alten Embryonen besteht. Der oft eklatante Mangel an Korrelationen der Organentwicklung zeige, daB jeder Entwicklungsvorgang eines Organs gewissermaßen ein selbständiger Prozeß sei. Die Entwicklung des Wirbeltierembryos bestehe aus einer Reihe von nebeneinander nur durch phylogenetische Beziehungen geregelten Einzelvorgängen. 
Zwischen diesen schroffen Gegensätzen in der Auffassung des Zusammenhanges der Entwicklungsvorgänge finden wir auch vermittelnde Darstellungen. So zeigte Fischel (1896), daß bei Entenembryonen in allen Stadien zwischen dem Auftreten des ersten und des zwanzigsten Urwirbels Variationen in der Beziehung zwischen der Gesamtlänge des Embryos, der Länge der einzelnen Embryonalteile und der Differenzierungshöhe zu finden sind. Immerhin entspreche aber meist auch jedem Stadium ein bestimmtes Verhältnis der einzelnen Körperabschnitte zueinander. Die individuellen Variationen werden vorwiegend in den jüngsten Stadien gefunden. Je älter der Embryo wird, desto regelmäßiger wird das Verhältnis der einzelnen Strecken des Körpers zueinander. Aus diesen Tatsachen schließt Fischel auf regelnde Einflüsse, die sich während der Entwicklung geltend machen und die bewirken, daß sich allmählich ein gesetzmäßiger Aufbau des embryonalen Körpers einstellt. Auf die größere Variabilität jüngerer Stadien war auch schon von v. Baer hingewiesen worden und sie wurde später noch mehrfach bestätigt, so beispielsweise von Peter (1903) an Eidechsenembryonen.

Oppel (1891) und Keibel (1906) beschäftigen sich vor allem mit der Frage, wie weit die Beziehungen der Entwicklungsvorgänge zueinander durch die Stammesentwicklung bedingt und daher für phylogenetische Spekulationen verwertbar seien. Wir werden hier an die beiden Faktoren erinnert, die bei jeder entwicklungsgeschichtlichen Analyse untersucht werden müssen: Festhaltung von den Vorfahren überlieferter Eigentümlichkeiten durch Vererbung einerseits, Abänderung des Entwicklungsweges durch Anpassung an neue Entwicklungsbedingungen andererseits. Beide Faktoren können den direkten Weg der Entwicklung - das wäre die kürzeste Verbindung zwischen Fortpflanzungssubstrat und fortpflanzungsfähigem Individuum - abändern. Beide Falktoren können aber eine gesetzmäßige Verbindung verschiedener Entwicklungsvorgänge innerhalb des Individuums bedingen. Uberwiegt die Vererbung, dann finden wir eine "palingenetische" Verknüpfung von Zuständen entsprechend dem »biogenetischen Grundgesetz "; überwiegt die Anpassung an neuartige Entwicklungsbedingungen, dann sehen wir beispielsweise ein einzelnes Organ in der Ontogenie in einem viel früheren Stadium auftreten, als es seiner Stammesgeschichte entsprechen würde. In diesem Falle ist der stammesgeschichtlich ursprüngliche Parallelverlauf bestimmter Entwicklungsvorgänge gestört; es ist ein neuartiger, für das Individuum aber wieder bindender Zusammenhang bestimmter Entwicklungsschritte entstanden, der nun als "eänogenetisch" zu bezeichnen wäre. So verweist Keibel beispielsweise auf die frühzeitige Anlage des Amnions und auch der Allantois bei den Säugetieren. Ferner bespricht er die allerdings sel- 
teneren Verschiebungen in dem Auftreten der einzelnen Komponenten eines Organs: Beim Meerschweinchen trete beispielsweise die mesodermale Allantoiswucherung sehr frühzeitig und kräftig auf, während der phylogenetisch sicher ältere entodermale Anteil erst spät und nur rudimentär auftrete. Gerade aus solchen Verschiebungen zwischen den einzelnen Komponenten eines Organs leitet Keibel den Beweis dafür $a b$, daß eine solche Lösung des ursprünglichen Zusammenhanges zwischen verschiedenen Entwicklungsvorgängen eine Folge der Funktion ist, das heißt also, einer Neuanpassung an die besondere Entwicklungsart der Tiergruppe entspricht. Unabhängig von diesen Ausführungen gelangte später auch C. Rabl (1910) zu ähnlichen Auffassungen bei der Aufstellung des "Prinzips der prospektiven funktionellen Anpassung ". Die Frage, wie weit oder wodurch eine Regelung der verschiedenen nebeneinander einhergehenden Entwicklungsschritte gesichert ist, wird aber durch diese Erwägungen über den palingenetischen oder cänogenetischen Charakter der Verbindung gleichzeitig zu beobachtender Entwicklungsstufen von verschiedenen Organen nicht wesentlich berührt.

Während in dieser Weise auf deskriptivem Wege die Frage nach der gegenseitigen Abhängigkeit der Entwicklungsvorgänge nur wenig Klärung fand, erschlossen sich der Forschung neue Möglichkeiten in den experimentellen Untersuchungsmethoden. Der Kampf um die Grundfragen der Entwicklungslehre: Präformation oder Epigenesis? lebte in erneuter Form auf und die Anhänger von Rouxs Mosaiktheorie ebensowohl wie deren Gegner, mit O. Hertwig und H. Driesch an der Spitze, verwendeten die neugewonnenen Hilfsmittel der Untersuchung zur Stïtzung ihrer Ansichten. In diesem Kampfe sehen wir frühzeitig auch wieder Fragen gestreift, die den hier behandelten Problemen nahestehen. Denn soweit Selbstdifferenzierung von Teilen stattfindet, geht die Entwicklung dieser Teile eines Individuums unabhängig von der der anderen Teile vor $\operatorname{sich}^{1}$ ). Im Falle der nabhängigen Differenzierung " dagegen ist eine gesetzmäßige Verbindung bestimmter gleichzeitig ablaufender Entwicklungsschritte miteinander naheliegend. Aber auch die experimentellen Untersuchungsmethoden brachten bis jetzt keine eindeutige Antwort auf die Frage nach dem Zusammenhange der Entwicklungsvorgänge untereinander. Sie deckten vielfach wieder neue Probleme auf und zeigten immer nene Schwierig-

1) Es ist aber, wie Roux betont, daran zu denken, daß die Selbstdifferenzierung eines Organs selber nur durch abhängige Differenzierung seiner Teile entsteht, daß Selbstdifferenzierung nur ein topographischer, kein kausaler, kein Wirkungsbegriff ist. Er besagt bloB, daß die die Art der Differenzierung des Organs bestimmenden Faktoren in dem Organe selber gelegen sind; aber ihr Wirken geschieht natürlich durch gegenseitige Beeinflussung. 
keiten. Gerade die Auslegung der experimentell gewonnenen Resultate bot erst neue Streitobjekte und es kam vor, daß die Resultate eines Forschers von einem späteren Bearbeiter desselben Gebietes als Gegengrund gegen die theoretischen Ausführungen des ersten Forschers verwendet wurden. Als Beispiel mag gleich eine der ersten experimentellen Arbeiten dieses Gebietes dienen. Born (1897) schließt aus den Ergebnissen seiner Verwachsungsversuche mit Amphibienlarven, daB die Entwicklung der Amphibien von jenem Stadium an, in dem sich das Medullarrohr gerade geschlossen hat, wesentlich auf Selbstdifferenzierung seiner Teile beruht, ein Korrelationseinflu $\beta$ der Nachbarschaft wie des Ganzen lasse sich nirgends erkennen. Und doch weist schon Born selbst auf eine Gruppe von Tatsachen hin, welche später Uhlenhuth (1913) als eines der ersten Beispiele für experimentell nachgewiesene Abhängigkeit der Entwicklungsgeschwindigkeit einzelner Keimteile vom übrigen Organismus anführen konnte. Born stellte nämlich fest, daß künstlich vereinigte Teilstücke von Anurenlarven sich immer gleichzeitig verwandeln, auch wenn die Ernährungsbedingungen für die beiden Teile ungleich sind, was sich in verschieden starkem Wachstum und dadurch in verschiedener Größe der Teilstücke äußerte. Schon Born vermutete, daß es sich dabei um eine Beeinflussung auf dem Blutwege handeln dürfte.

Noch vor den Untersuchungen Borns batte auf botanischer Seite Vöchting (1892) den Nachweis erbracht, daß bei Pfropfungen die Lebensdauer des Pfropfreises verlängert werden könne. Er schrieb diese Beeinflussung den Ernährungsbedingungen zu, welchen das Pfropireis von seiten des Wirtes her ausgesetzt ist. Das stünde mit der bekannten Tatsache in Einklang, daß die Entwicklungsgeschwindigkeit durch Ernährungseinflüsse abgeändert werden kann. Speziell für den Entwicklungsvorgang des Alterns ist dies später auch von Child (1911) experimentell nachgewiesen worden.

Nach diesen ältesten Befunden von Vöchting und Born finden wir vereinzelte $\cdot$ hierher gehörige Angaben verstreut als Nebenbefunde in Arbeiten, deren eigentliches Ziel die Lösung anderer Fragen darstellt. So teilen Rehn und Wakabayaschi (1912) mit, daß bei Transplantation von Extremitätenknorpeln jugendlicher Säugetiere der Verknöcherungsprozeß am Transplantat synchron mit dem an den wirtseigenen Skeletteilen fortschreitet. Bedenkt man, daß hier ähnlich wie bei Borns Versuchen nach der Operation die Ernährungsbedingungen für die transplantierten Gewebe doch wesentlich von denen für die körpereigenen abweichen mußten, dann erscheint durch diese Tatsache die Abhängigkeit des Verknöcherungsprozesses im einzelnen Organ vom übrigen Organismus bewiesen.

Der erste, der die Frage nach der gegenseitigen Abhängigkeit der 
Entwicklungsvorgänge einer eigenen experimentellen Untersuchung zugrunde legte, war Uhlenhuth (1913). Er bewies durch die Resultate seiner Augentransplantationen an Salamanderlarven, daß eine für die Metamorphose charakteristische Teilerscheinung, nämlich das Verschwinden eines gelben Ringes in der Iris, in ihrem Ablauf von der Entwicklung des übrigen Körpers abhängig sei. Denn diese "Metamorphose des Auges" spielt sich am Transplantat stets gleichzeitig mit den entsprechenden Vorgängen an den körpereigenen Augen des Empfängers $a b-$ mit Ausnahme jener Fälle, in denen entweder der Spender oder der Empfänger des Transplantats zur Zeit der Operation in der larvalen Entwicklung schon besonders weit vorgeschritten sind: In dem Larvenendstadium hat offenbar normalerweise die Beeinflussung der Einzelorgane, z. B. der Augen, durch den übrigen Organismus im Sinne der Einleitung der Metamorphose bereits stattgefunden. Daher erfolgt die Motamorphose eines Auges, das einom im Larvenendstadium stehenden Tiere entnommen wurde, unaufhaltsam, auch wenn das Wirtstier noch weit von der Metamorphose entfernt ist. Andererseits wird das einer jüngeren Larve entnommene Transplantat, wenn es auf ein im Larvenendstadium befindliches Tier übertragen wird, mit den körpereigenen Organen des Wirtstieres nicht mehr Schritt halten können, da am Wirtstier der die Metamorphose auslösende Einfluß die einzelnen Organe schon vor der Durchführung der Operation erreicht hatte.

Im Anschluß an diese Befunde Uhlenhuths untersuchte ich (1914) mit der gleichen Methode eine andere Teilerscheinung der Amphibienmetamorphose, nämlich die Rückbildung der äußeren Kiemen. Meine Ergebnisse brachten im wesentlichen eine Bestätigung der Angaben Uhlenhuths: Auch an transplantierten Kiemen spielt sich ein als Metamorphose zu deutender RückbildungsprozeB gleichzeitig mit dem der körpereigenen Kiemen, unabhängig vom Alter des Spenders und des Empfängers ab. Auch die Kiemen erweisen sich dadurch in ihrer metamorphotischen Entwicklung als abhängig vom Gesamtorganismus. Ich betonte damals, daß die Augenmetamorphose und die Hautfärbungsmetamorphose eine relativ große Unabhängigkeit von dem Komplex: Häutung, Rudersaumrückbildung, Verlassen des Wassers, Kiemenrückbildung besitzen, bei relativ großer Abhängigkeit der in diesem Komplex zusammengefaßten Einzelerscheinungen untereinander. Ich folgerte weiter aus dieser Tatsache, daß die Einflußnahme des Gesamtorganismus auf die einzelnen metamorphosierenden Organe zu verschiedenen Zeiten, vielleicht auf verschiedene Weise erfolgt. Wir werden sehen, daß diese Annahme in späteren Arbeiten Uhlenhuths eine Bestätigung erfuhr.

Mit der Frage der Abhängigkeit der metamorphotischen EinzelArchiv für Entwicklungsmechanik Ld. bo. 
vorgänge vom Gesamtorganismus beschäftigte sich auch Weigl (1913). Er findet, daß sich bei Hauttransplantationen zwischen Amphibienlarven die Metamorphose der überpflanzten Haut gleichzeitig mit der des Wirtstieres vollzieht, wenn bei der Transplantation Spender und Empfänger in gleichem Alter standen. Beachten wir die unter normalen Umstïnden zwischen gleich alten Tieren zu beobachtenden beträchtlichen Differenzen im Termin der Metamorphose, dann dürfen wir wohl schon in dieser Beobachtung Weigls eine Bestätigung der Uhlenhuthschen Ergebnisse erblicken. War bei der Transplantation der Spender jünger als der Empfänger, dann setzte die Metamorphose des Transplantats später ein als die der Wirtstiere. Weigl faßt dies als Beweis dafür auf, daß ein gewisser Reifezustand in der Haut erreicht sein muß, damit die zur Zeit der Metamorphose vom übrigen Körper zur Haut gelangenden Reize hier die Metamorphoşe der Haut auslösen können. Es wäre aber auch daran zu denken, daß dieses Fehlen ider Synchronie bei Transplantation zwischen verschieden alten Tieren in den Versuchen Weigls durch Verwendung von Larvenendstadien im Sinne Uhlenhuths bedingt war. Diese Deutung könnte auch den Befund Weigls erklären, daß die Metamorphose des Transplantats früher als die des Wirtstieres einsetzte, wenn bei der Transplantation der Spender älter war als der Empfänger. Weigl dagegen deutete dieses Ergebnis dahin, daß die Metamorphose des Transplantats doch auch wirklich unabhängig von der des Wirtstieres erfolgen könne. Er stützt diese Annahme noch besonders durch die Mitteilung, daß ein früheres Metamorphosieren der transplantierten Haut auch dann stattfindet, wenn die Haut von einer jungen Larve auf eine gleich junge übertragen werde, der Empfänger aber abnormal lange im Larvenzustande verharre. Für eine eindeutige Erklärung dieses Befundes wäre wohl eine histologische Untersuchung des Falles notwendig. Bei Beachtung der übrigen Befunde Weigls, sowie jener von Uhlenhuth und mir glaube ich doch, daß auch dieser Fall keinen unbedingten Widerspruch mit den Auffassungen Uhlenhuths enthält. Denn der Faktor, welcher vom Gesamtorganismus dem Einzelorgan mitgeteilt werden muß, ist, wie auch Uhlenhuth besonders in seinen neuesten, später noch zu besprechenden Arbeiten hervorhebt, keineswegs die einzige für das $\mathrm{Zu}$ standekommen der Metamorphose notwendige Bedingung. Es wäre denkbar, daß in dem von Weigl beschriebenen Ausnahmsfalle die Beeinflussung der Einzelorgane vom Gesamtorganismus her zur normalen Zeit erfolgte, daß aber abnormerweise den jOrganen des Wirtstieres irgendein anderer "Realisationsfaktor" ermangelte. Daher konnte die zur richtigen Zeit erfolgte Beeinflussung vom Gesamtorganismus her am Wirtskörper selbst keine Matamorphose bewirken, wohl aber 
am Transplantat, in welchem im richtigen Zeitpunkt jener andere "Realisationsfaktor" in normaler Weise vorhanden war. Weigl selbst aber entnimmt diesem Ausnahmsfalle eine Bekräftigung seiner Auffassung, daB nicht nur die die Metamorphose des Transplantats determinierenden, sondern auch die sie realisierenden Faktoren bereits im Transplantat selbst gegeben sind, daß also die Metamorphose der Haut auf vollkommener Selbstdifferenzierung beruhe. Diese allgemeine Deutung der Resultate Weigls wird aber schon durch die bereits besprochenen Ergebnisse Weigls bei Verwendung gleich alter Tiere unwahrscheinlich gemacht. Noch deutlicher aber wird die Abhängigkeit der metamorphotischen Entwicklung des Transplantats vom Gesamtorganismus des Wirtstieres in folgendem überaus wichtigem Befunde Weigls: Wird die Haut von Axolotln auf Salamanderlarven verpflanzt, dann metamorphosiert sie kurze Zeit nach der Metamorphose des Empfängers in der für Axolotl charakteristischen Weise. Da normalerweise Axolotl des verwendeten Alters überhaupt nicht, ältere aber auch nur durch besondere äußere Einwirkungen zur Metamorphose veranlaßt werden können, beweist dieses Ergebnis einwandfrei, daß die Metamorphose der transplantierten Haut durch Einwirkung von seiten des metamorphosierenden Empfängers ausgelöst wurde. Ferner beweist dieser Versuch ebenso wie die von Weigl durchgeführten Transplantationen von Salamanderlarvenhaut auf Tritonlarven, daß die vom Wirtstier ausgehende Anregung zur Metamorphose eine nicht für die Tierart spezifische, sondern auch über die Grenzen der Art und sogar der Gattung hinaus wirksame ist. Dies ist um so interessanter, als Weigl feststellen konnte, daß Axolotlhaut, auf Salamanderlarven überpflanzt, stärkeres Wachstum aufweist, als die sie umgrenzende Haut des Wirtstieres. Das Transplantat behält also auch auf der artfremden Unterlage die Tendenz eines stärkeren, für den Spender charakteristischen Wachstums bei. Diese Tatsachen zeigen, daß die Erscheinungen der metamorphotischen Entwicklung von denen des Wachstums scharf zu trennen sind. Jene werden vom Wirtstiere her geregelt, diese dagegen setzen sich auch auf fremden Boden in der für das überpflanzte Gebilde charakteristischen Art durch.

Unterdessen hatte sich der Entwicklungsphysiologie ein neuer Fragenkomplex in den Erscheinungen der inneren Sekretion erschlossen. Es war naheliegend, auch die Tatsachen der Synchronie der Entwicklungsschritte auf Wirkungen von Inkreten zurückzuführen. Wenn die Verknöcherung der Epiphysenfugen durch Produkte der Hormondrüsen geregelt wird, dann ist es beispielsweise leicht verständlich, daß in den Versuchen von Rehn und Wakabayaschi (s. o.) dieser Entwicklungsschritt auch bei den eingepflanzten Skeletteilen 
gleichzeitig mit der Verknöcherung der körpereigenen Skeletteile durchgeführt wird. Es wird die Tatsache begreiflich, da $B$ bei Meerschweinchen die auf das Ohr verpflanzte Anlage einer Mamma genau gleichzeitig mit den wirtseigenen Brustdrüsen zur Milchproduktion schreitet, nämlich in jenem Zeitpunkte, in dem das Wirtstier geworfen hatte (Ribbert 1897). In dem gleichen Zusammenhange wird uns folgender Befund verständlich: Foá (1900) verpflanzte jugendliche Ovarien in die Bauchhöhle versehieden alter. Tiere: In jugendlichen, noch nicht geschlechtsreifen Tieren behielten sie ihre ursprüngliche Struktur im wesentlichen bei, in erwachsenen, geschlechtsreifen Tieren hingegen nahmen sie rasch die Struktur eines ausgewachsenen Eierstocks an. Die Entwicklungsgeschwindigkeit des Transplantats erwies sich also auch hier als abhängig von dem Entwicklungszustande des Empfängers. Hierher gehört auch die von Meyns (1912) festgestellte Tatsache, daß das Tempo der Spermatogenese reifer Froschhoden bei Transplantation des Hodens vom Geschlechtszustande des Empfängers abhängig ist.

Auch jene Entwicklungserscheinungen, deren Analyse durch die Arbeiten von Uhlenhuth, von Weigl und von mir angebahnt werden sollte, sind im letzten Dezennium auf die Frage hin untersucht worden, welche Rolle hier die einzelnen Hormondrüsen spielen könnten. Gudernatsch (1913) zeigte, daß Fütterung mit Thyreoidea die metamorphotische Entwicklung von Kaulquappen beschleunigt und dabei das Wachstum der Tiere hemmt. Dagegen wirke Thymus, als Futter verwendet, hemmend auf die metamorphotische Entwicklung, während sie das Wachstum der Larven fördere. Wachstum und Differenzierung erweisen sich auch hier wieder als verschiedenartige Erscheinungen, die durch verschiedenartige Faktoren geregelt sein müssen. Diese Ergebnisse sind seither durch mehrfache Wiederholungen und Modifikationen der Versuche bestätigt und auch durch Beobachtungen über die Folgen der Exstirpation von Hormondrüsen ausgebaut wor. den (L. Adler 1914). Alle diesbezüglichen Untersuchungen drängen zu der Annahme, daß die Drüsen mit innerer Sekretion tatsächlich in dem Verlaufe der metamorphotischen Entwicklungserscheinungen eine regelnde, vielleicht sogar beherrschende Rolle spielen.

In einer Reihe weiterer Arbeiten gelangt nun Uhlenhuth zu einer Vereinigung der durch Transplantationsversuche ermittelten Ergebnisse mit jenen Erkenntnissen, welche sich aus den Forschungen über die endokrinen Drüsen ergeben haben. Vor allem überprüfte er (1917) die Resultate Weigls über die Metamorphose transplantierter Hautstüeke und gelangte $\mathrm{zu}$ der Uberzeugung, daß auch die Metamorphose der Haut nicht, wie Weigl behauptete, durch Selbstdifferenzierung erfolge, sondern ebenso wie die der Augen und der 
Kiemen vom Gesamtorganismus geregelt werde. Wenigstens einer der zur Metamorphose dieses Organs notwendigen Faktoren muß außerhalb der Haut - normalerweise im übrigen Organismus - enthalten sein und von ihm aus seine Wirksamkeit der Haut mitteilen. Ferner bestätigt Uhlenhuth die Feststellung Weigls, daß dieser Faktor nicht artspezifisch ist, sondern auch bei heteroplastischer Transplantation wirksam sei. Dies ergab-sich aus Verpflanzung von Haut und Auge von Amblystoma punctatum auf Individuen der Art Amblystoma tigrinum. Endlich vergleicht Uhlenhuth hier die Wirksamkeit der von Gudernatsch verfütterten Thyreoidea mit der Wirksamkeit des dem Transplantate vom Wirtstier übermittelten, zur Metamorphose anregenden Reizes. In beiden Füllen wirke ein außerhalb des Organs liegender Faktor und in beiden Fällen sei dieser Faktor nicht nur für eine Tierart spezifisch. Ferner soll in beiden Fällen nur eine einmalige Einwirkung zur Auslösung der Metamorphose notwendig sein, während der weitere Verlauf der metamorphotischen Erscheinungen auch ohne andauerndes Einwirken des Faktors vor sich gehe. Endlich scheine in beiden Fällen die Beeinflussung sich an sehr jungen Larvenorganen langsamer durchzusetzen als an älteren. In dieser Publikation spricht Uhlenhuth noch die Ansicht aus, daß für die Auslösung der metamorphotischen Erscheinungen der Augen, der Kiemen und der Haut ein gemeinsamer Faktor verantwortlich zu machen sein dürfte.

In einer weiteren Arbeit (1919a) geht Uhlenhuth von Befunclen Swingles aus, welcher bewiesen habe, daß auch Verfütterung von anorganischem Jod eine beschleunigte Metamorphose von Anurenlarven erzwinge, und daß3 Larven, denen die Schilddrüse entnommen worden war und die daher bei normaler Fütterung nie metamorphosiert hätten, bei Verfütterung von Jodkristallen bald metamorphosierten. Uhlenhuth folgert, daß normalerweise mit dem Futter geringe Mengen Jod aufgenommen werden, welche in der Thyreoidea gespeichert werden. Im geeigneten Zeitpunkte werden von der Thyreoidea die angesammelten Jodmengen in den Körper ausgeschwemmt und lösen hier die Metamorphose aus. Fehlt den Tieren die Thyreoidea, dann mangelt ihnen die Fähigkeit, aus der Nahrung das Jod allmählich zu speichern, und sie können daher nur dann metamorphosieren, wenn man ihnen durch Darreichung konzentrierter Jodmengen den Ausfall ersetze. Fütterung von Thymus hemme die Metamorphose dadurch, daß in diesem Organe die zur allmählichen Speicherung notwendigen Jodmengen fehlen. Es sei nun noch ein anderer Faktor notwendig, welcher in der normalen Entwicklung die Larven im richtigen Augenblick veranlasse, das Jod aus der Thyreoidea in den übrigen Körper auszuschwemmen und dadurch die Metamorphose auszulösen. Uhlen- 
huth gelangt zu der Anschauung, daß dieser zweite Faktor eine Substanz sei, deren Erzeugung mit dem Fortschreiten des Wachstums parallel gehe. Haben die Larven eine entsprechende Größe erreicht, dann sei diese Substanz unter normalen Umständen in genügender Menge ausgebildet, um eine Ausschüttung des Thyreoideasekretes zu veranlassen. Dafür spreche die Beobachtung, daß in verschiedenen Serien von normal gefütterten Versuchstieren die Metamorphose immer dann eintrete, wenn ein bestimmter relativer Wachstumseffekt erreicht sei, das heilit, wenn die Tiere eine Gröbe erreicht haben, die zu der durchschnittlichen Größe der Tiere der betreffenden Versuchsgruppe beim Ausschlüpfen in einem bestimmten Verhältnis steht. Durch den bei Thymusfütterung erzielten Jodmangel werde in diesem Zeitpunkte in der Thyreoidea nicht das normale, sondern ein giftig wirkendes Inkret durch den auslösenden Faktor zur Ausschwemmung in den Körper veranlaßt. Die Folge davon ist nun nicht normale Metamorphose, sondern ein von Uhlenhuth in diesem Zeitpunkte festgestelltes plötzliches Sistieren des Wachstums bei den mit Thymus gefütterten Larven, welche anfangs ein stärkeres Wachstum gezeigt hatten als normal gefütterte. Larven, deren Metamorphose durch Exstirpation der Thyreoidea oder durch angeborenen Mangel des Organs, wie er bei Typhlomolge vorkomme, verhindert sei, zeigen diese Unterbrechung des Wachstums nieht. Denn der sonst die Sekretion auslösende Faktor trifft hier überhaupt keine, also auch keine Gift produzierende Thyreoidea. Der Temperaturkoeffizient für die Bildung der die Sekretion bewirkenden Substanz sei ein größerer als der für das Wachstum; damit könne man es erklären, daß die Larven bis zur Bildung der die Metamorphose auslösenden Menge des Inkretes bei niedriger Temperatur eine bedeutendere Größe erreichen können als normalerweise.

In einer letzten Arbeit ondlich geht Uhlenhuth (1919b) von den bis in die erste Hälfte des 18. Jahrhunderts zurückreichenden Befunden an neotenischen Amphibienlarven aus. Man hatte versucht, die selbständig von der Entwicklung der übrigen Organe fortschreitende Entwicklung der Fortpflanzungsorgane als Stütze für die von Weismann angenommene Gegensätzlichkeit zwischen Keimplasma und Soma aufzufassen. Uhlenhuth ist nun bemüht zu zeigen, daß in dieser fallweisen Selbständigkeit der Keimdrüsen gegenüber den übrigen Entwicklungsvorgängen keine im Entwicklungsgeschehen einzig dastehende Erscheinung vorliege, sondern daß auch sonst in der Entwicklung mehrere verschiedene Prozesse nebeneinander hergehen, welche unter Umständen in ihrem Verlauf voneinander gesondert werden können. Er kommt damit einer Analyse der im Beginne meiner Ausführungen aufgeworfenen Fragen am nächsten und gelangt be- 
züglich der Amphibienmetamorphose zu einer Auffassung, die mir, wie bereits erwähnt, schon bei der Betrachtung meiner Resultate über Kiementransplantation sehr ansprechend erschien. Obwohl die ein. zelnen Entwicklungsvorgänge an den Organen nicht selbständig verlaufen, sondern vom Gesamtorganismus her geregelt werden, sind doch nicht alle untereinander untrennbar verknüpft. Das scheint eine Folge des Umstandes zu sein, daß für die Regelung der Entwicklungsvorgänge durch den Gesamtorganismus eben nicht ein, sondern mehrere verschiedene Faktoren verantwortlich zu machen sind. Im einzelnen findet Uhlenhuth die Erscheinungen der ersten Häutung und der Kiemenrückbildung zeitlich untrennbar miteinander verknüpft und faßt sie als durch einen gemeinsamen Faktor ausgelöst auf. Als dieser Faktor soll das Jod wirken. Diese durch Jod beeinflußbaren Vorgänge bilden das Wesen der "Metamorphose ". Unabhängig von diesen Vorgängen, unbeeinflußbar durch Jod und nicht zur eigentlichen Metamorphose gehörig sei die Ausbildung der definitiven Hautfärbung, die Entwicklung der Beine, die Ausbildung der Sexualorgane sowie endlich die Entwicklung der Zunge und der Gaumenzähne. Zunge und Gaumenzähne können in ihrer- Entwicklung gehemmt werden, wenn auch die übrige (metamorphotische) Entwicklung der Tiere fortschreitet. Es seien so in der Amphibienentwicklung mindestens sechs voneinander unabhängige Gruppen von Vorgängen zu unterscheiden, deren gegenseitiges zeitliches Verhältnis abgeändert. werden kann. So kann eine Temperaturänderung eine Verschiebung in der Reihenfolge dor einzelnen Prozesse herbeiführen, was durch verschiedene Temperaturkoeffizienten der die einzelnen Vorgänge regelnden Falstoren erklärlich wäre.

Auf eine abnorme Loslösung der einzelnen Komponenten aus dem Komplex der metamorphotischen Erscheinungen deuten auch zwei Befunde von Kahn (1916) hin: Bei Tieren, welche mit frischer Thyreoidea gefüttert werden, umfassen die künstlich beschleunigten Vorgänge auch die Rückbildung des Rudersaumes am Schwanze der Froschlarven; bei Verwendung von Präparaten, die durch Alkoholextraktion und Ausschütteln mit Äther gereinigt wurden, werde dagegen nur die Rückbildung der Kiemen und das Durchbrechen der Beine, nicht aber die Rückbildung des Rudersaumes beschleunigt. Ferner werde bei der durch Thyreoideafütterung beschleunigten Metamorphose ein auffallendes Vorauseilen des linken Vorderbeines gegenüber dem rechten erzielt, während sonst höchstens viel geringere zeitliche Differenzen im Auftreten der beiden Vorderextremitäten zu beobachten seien, wobei dann meist die rechte vor der linken Extremität durchbrechen soll. Wir sehen also auch in diesen zwei Beobachtungen Kahns, daß unter dem Finfuß der Thyreoideafütterung 
nicht nur die Entwicklungserscheinungen an den einzelnen Organen in ihrem zeitlichen Ablaufe verändert, sondern daß auch die unter normalen Umständen vorhandenen Regelungen des gegenseitigen zeitlichen Verhältnisses zwischen einzelnen Entwicklungsvorgängen aufgehoben werden und die gleichzeitig zu beobachtenden Entwicklungsstufen an den einzelnen Organen gegen die Norm verschoben erscheinen.

Daß auch durch abnorme funktionelle Beanspruchung eine Loslösung der normalerweise durch Synchronie verketteten Entwicklungsvorgänge in verschiedenen Teilen des Körpers eines Lebewesens erfolgen kann, beweisen ältere Untersuchungen von Held (1896), Dieser öffnete neugeborenen oder weniger als 3 Tagen alten Kaninchen auf der einen Seite künstlich die Lidspalte, welche sich bei Kaninchen normalerweise erst später öffnet. Der durch die frühere Lichteinwirkung gereizte Opticus zeigte dann bei einer nach mehreren Tagen durchgeführten Untersuchung eine weiter fortgeschrittene Markreifung als der Opticus der anderen Seite. Der Entwicklungsvorgang der Markreifung, der sonst in beiden Körperseiten ganz gleichartig fortschreitet, ist hier durch früheres Einsetzen des funktionellen Reizes auf der einen Seite beschleunigt, der normalerweise bestehende zeitliche Parallelismus der Entwicklungsvorgänge auf den beiden Körperseiten durch abnorme Verteilung der funktionellen Beanspruchung also gelöst worden.

Wir können den bisher besprochenen Befunden entnehmen, daß bei den. Wirbeltieren die Entwicklungsvorgänge an den einzelnen Organen nicht ganz selbständig verlaufen, sondern daB sie - abgesehen von der spezifischen Art der Differenzierung, welche wir hier außer acht lassen - in ihrem zeitlichen Verlaufe vom Gesamtorganismus her geregelt werden. Dabei scheint es sich nicht um eine einheitliche Regelung sämt. licher Entwicklungsprozesse von einem Zentrum aus zu handeln. Vielmehr spielen sich verschiedene Gruppen von Vorgängen nebeneinander ab und werden wahrscheinlich durch verschiedenartige Einflüsse in ungleicher Art geregelt. Auch kommt wahrscheinlich für jede einzelne Gruppe von Entwicklungsvorgängen nicht nur ein einzelner regulierender Faktor in Betracht, sondern es dürfte wohl immer das Zusammenwirken mehrerer Faktoren den normalen Ablauf des Entwicklungsgeschehens am Einzelorgan regeln. Innerhalb einer derartigen Gruppe von Entwicklungsprozessen wird der zeitliche Parallelverlauf durch gemeinsam einwirkende Faktoren festgehalten. Dagegen besteht zwischen den verschiedenen Gruppen kein zwangsmäBiger Zusammenhang. Die zeitlichen Beziehungen der verschiedenen Gruppen zueinander scheinen vielmehr nur durch 
die für alle Individuen einer Art annähernd gleichen Ablaufszeiten der einzelnen Vorgänge bedingt zu sein. Denkbar wäre es ferner, da $\beta$ mehrere Erscheinungsgruppen, von denen jede einzelne durch Gemeinsamkeit vieler Faktoren zusammengehalten wird, miteinander zu einer größeren Gruppe von Vorgängen zusammengefaßt sind, deren Zusammengehörigkeit nur mehr auf der gleichartigen Beinflussung durch einen oder wenige Faktoren beruht. Endlich könnte durch den einen Faktor eine Gruppe von Vorgängen $\mathbf{a}, \mathbf{b}, \mathbf{c}$ durch einen anderen dagegen eine Gruppe c, d, e gemeinsam beeinflußt werden, so daß die experimentell nachweisbaren Grenzen der Gruppen je nach der Anordnung des Experimentes verschieden und ein einzelner Vorgang (c!) bald der einen, bald der anderen Gruppe zugehörig gefunden werden könnte. - Durch experimentell erzielte Änderung der einwirkenden Faktoren können die Entwicklungsgeschwindigkeiten geändert und die normalerweise bestehenden zeitlichen Zusammenhänge zwischen verschiedenen Entwicklungsvorgängen gelöst werden. Als wichtige Faktoren scheinen vor allem in vielen Fallen versehiedene Hormone zu wirken, außerdem in manchen Fällen die spezifische funktionelle Beanspruchung. Es bleibt nun die Frage offen, ob auch eine Entwicklungsregelung in jenen Fällen besteht, in denen diese beiden Prinzipien nicht als wirksam angesehen werden können und wodurch in solchen Fällen eine Regelung erfolgen könnte.

Es zeigt sich beispielsweise, daß in den Wirkungsgebieten der inneren Sekretion zwischen den einzelnen Tiergruppen betrëchtliche Unterschiede bestehen. So wurden im Gegensatze zu der bei Wirbeltieren festgestellten Abhängigkeit der sekundären Geschlechtscharaktere von den Keimdrüsen bei den Schmetterlingen die sekundüren Geschlechtscharaktere von den Gonaden unbeeinflußbar gefunden (Meisenheimer 1907 und 1908). Dementsprechend fand Kopec (1911) auch die Entwicklungsgeschwindigkeit transplantierter Gonaden bei Schmetterlingen unbeeinflußbar durch den Wirtsorganismus im Gegensatz zu den oben beschriebenen Befunden von Foà und von Meyns an Wirbeltieren.

Wir werden uns fragen müssen, $o b$ und in welcher Weise bei niederen Tieren, ferner aber auch bei Pflanzen und vor allem auch bei frühen Entwicklungszuständen höherer Tiere, bei denen wohl noch weder an eine funktionelle Beanspruchung, noch an die Wirksamkeit von eigenen Hormondrüsen gedacht werden kann, eine Regelung der zeitlichen Verhältnisse verschiedener nebeneinander hergehender Prozesse zustande komme. Schon Fischel (1912) betonte, daß den späteren Wirkungen der inneren Sekretion analoge Beziehungen schon vor.der Ausbildung des Blutkreislaufes angenommen werden müssen, und daß die in Betracht kommenden Stoffe 
durch Diffusion in die Zellen des Keimes gelangen. Bei der Besprechung dieser Fragen wird daher unsere Aufmerksamkeit noch vielmehr als bisher auf die zellulären Vorgänge selbst gelenkt. Denn in den frühesten Entwicklungszuständen, vor Ausbildung des Nervensystems und der Blutgefäße können etwa bestehende Beziehungen zwischen einzelnen Teilen eines Keimes nur als Beziehungen von Zelle zu Zelle aufgefaßt werden. Auch sind in diesen frühen Stadien alle Entwicklungsvorgänge selbst rein zelluläre Prozesse. Ähnlich tritt aber auch die Bedeutung der einzelnen zellulären Elemente bei späteren Stadien der niederen Tiere und der Pflanzen mehr in den Vordergrund als bei den späteren Stadien höherer Tiere, bei denen zwischen die zellulären Vorgänge in den einzelnen Organen eine Vermittlung durch die spezifischen Funktionen des Nerven- und vor allem des Blutgefäßsystems eingeschaltet ist.

Aber nicht nur die frühembryonalen Prozesse bei höheren Tieren sowie die Entwicklungsvorgänge bei Pflanzen und niederen Tieren lenken unsere Aufmerksamkeit auf die Fragen nach der zeitlichen Regelung der zellulären Vorgänge, sondern auch gerade die späteren Entwicklungsschritte bei höher organisierten Tieren lassen, von einem anderen Gesichtspunkte aus betrachtet, diese Probleme wichtig erscheinen. Denn wenn wir für diese Entwicklungsschritte auch zum Teil in der funktionellen Beanspruchung, besonders aber in Hormonwirkungen wichtige Faktoren für die Regelung ihres Ablaufes kennen gelernt haben, so blieb damit doch die Frage unbeantwortet, in welcher Weise diese Faktoren an den einzelnen Organen selbst ihre Wirksamkeit entfalten. Und hier werden wir wohl auch für diese Fülle bis an das Zellenleben selbst herangehen und zu ermitteln trachten müssen, in welcher Weise die Regelung des grob morphologisch zu beobachtenden Entwicklungsvorganges aus den Reaktionen der zellulären Elemente zustande kommt. Wir müssen also auf der einen Seite bei eventuellen Entwicklungsregelungen in jenen Geschehnissen, bei denen wir nicht mit Hormondrüsen u. dgl. rechnen dürfen, unsere Aufmerksamkeit besonders auch den zellulären Prozessen zuwenden; wir dürfen aber auf der anderen Seite gerade von Erfahrungen über die Regelung zellulären Entwicklungsgeschehens Aufschlu $\beta$ erwarten auch über die Wirkungsart der Entwicklungsregelungen in jenen Fällen, in denen, wie bei der späteren Entwicklung höherer Tiere, das zelluläre Geschehen am Einzelorgan der Wirksamkeit übergeordneter Faktoren unterstellt ist.

Daß auch bei Pflanzen eine Regelung nebeneinander einhergehender Entwicklungsschritte vorliege, wird uns auch hier schon durch alltägliche Beobachtungen nahe gelegt. Man denke etwa an die Gesetzmäßigkeiten in der Entwicklung und im Aufblühen der einzelnen 
Blüten größerer Blütenstände. Diese Entwicklungsregelungen lassen sich wohl noch durch die gleichartigen Ernährungsbedingungen in einfacher Weise erklären. Aber auch in feineren Einzelheiten scheint ein gesetzmüßig gebundener Parallelverlauf bestimmter Entwicklungsvorgänge innerhalb eines Individuums nachweisbar zu sein. Herr Prof. Dr. Kolmer hatte die Freundlichkeit, mich auf dic Tatsache aufmerksam zu machen, daß man bei Schnitten durch die Blütenknospen von Allium, Lilium u. a. sämtliche Pollenmutterzellen einer Anthere in den gleichen Zellteilungsphasen findet und daß auch zwischen den Pollenmutterzellen verschiedener Antheren in den meisten Fällen noch eine weitgehende, wenn auch nicht ebenso vollkommene Übereinstimmung des Entwicklungszustandes besteht. Ich habe mich dann wegen dieser und eventuell ähnlicher Tatsachen aus dem Pflanzenreiche an Herrn Dr. G. Klein, Assistent am pflanzenphysiologischen Institute der Wiener Universität gewendet, der mir mitteilte, daß eine gewisse Übereinstimmung der Zellteilungsvorgänge in den verschiedenen Antheren einer Blütenknospe und besonders die weitgehende Übereinstimmung der Phasen innerhalb einer Anthere, eine auch ihm bekannte Tatsache sei; nähere Literaturangaben über diese Verhältnisse konnte ich aber nicht finden. Herrn Dr. Klein, der mich auch sonst bei der Durchsicht der botanischen Literatur unterstützte, sei auch hier mein bester Dank ausgesprochen. Aus den in der Literatur verstreuten Angaben über hierher gehörige Befunde seien beispielsweise die folgenden hervorgehoben: Mottier (1897) weist darauf hin, da $\beta$ bei der Teilung der Pollenmutterzellen von Lilium die beiden Tochterkerne gleichzeitig zu einer neuerlichen Teilung schreiten. An den beigegebenen Abbildungen läßt sich eine deutliche Synchronie der Teilungsschritte in den beiden Tochterzellen erkennen. Iuel (1897) beschreibt abnorm vorlaufende Teilungen von Pollenmutterzellen. Es kann bei der ersten Teilung durch Liegenbleiben eines Chromosoms neben zwei annähernd normalen Tochterzellkernen noch ein dritter kleiner Zellkern gebildet werden. Dieser abnorm kleine Kern schreitet dann gleichzeitig mit den beiden großen Kernen zu einer neuerlichen Teilung. Auch wenn der kleine Kern nur aus der einen Hälfte eines schon gespaltenen Chromosoms entstanden ist, bildet er doch synchron mit den beiden anderen Kernen noch eine Teilungsspindel aus, die in diesem Falle jedoch wahrscheinlich nicht zu einer Kernteilung, sondern nur zu der Wiederausbildung eines kleinen Kernes führt. Gerade diese Tatsache, daß auch mit einem Material, das sich im weiteren Verlaufe als unzureichend für die Durchführung der Teilung erweist, eine synchrone Kernteilung wenigstens angebahnt wird, spricht meiner Ansicht nach zugunsten der Auffassung, daß hier eine Regelung des Entwicklungsgeschehens in den einzelnen Komponenten das 
synchrone Fortschreiten bedingt. Dabei könnte es sich entweder um eine Unterordnung der Entwicklung der einzelnen Teile unter einen von außen einwirkenden Faktor oder um eine gegenseitige ausgleichende Beeinflussung zwischen den einzelnen zellulären Elementen handeln. Besonders einige später zu besprechende Befunde aus dem Gebiete des Tierreiches sprechen für letztere Deutung.

Eine ähnliche Regelung des zeitlichen Verlaufes zellulärer Vorgänge im Pflanzenkörper scheint mir aus folgendem Befunde von Palm (zitiert nach einem Referate in: Zeitschr. f. Botanik 1916) hervorzugehen: Bei Tanacetum vulgare folgen den beiden ersten Kernteilungen der Embryosackmutterzellen in der Regel keine Zellteilungen nach. Die beiden obersten Kerne erfahren eine Volumzunahme und teilen sich, während die beiden unteren Kerne noch ungeteilt bleiben. Dann findet eine simultane Teilung sümtlicher Kerne statt und erst dieser Teilung folgt gewöhnlich die Bildung von Zellwänden nach. Hier erfolgt also an mehreren Kernen eines genetisch zusammengehörigen Komplexes ein synchroner Entwicklungsschritt, obwohl diese Kerne eine verschiedene Anzahl von Teilungen hinter sich haben, also verschicdenen Kerngenerationen angehören. Wir werden sehen, daß ein ähnlicher Befund auf zoologischem Gebiete von Gurwitseh (1911) zu einer Analyse der die Zellteilungen regelnden Faktoren verwendet wurde. Fin anderes Beispiel für gesetzmäßige Synchronie von Kernteilungen in pflanzlichen Lebewesen liegt in folgenden Feststellungen von Kniep (1917): Bei gewissen zweikernigen Zellarten von Pilzen verläuft die Teilung immer gleichzeitig an den beiden Kernen einer Zelle, während in dem Auftreten von Kernteilungen zwischen benachbarten Zellen koine Gesetzmäßigkeiten zu bestehen scheinen. Endlich sei eine neue Arbeit von Dahlgren (1920) erwähnt. Dieser Autor findet, daß bei Lactuca die Entwiicklung der fünf Blüten eines Köpfchens meistens ziemlich synchron verläuft. In Köpfchen von $2,5 \mathrm{~mm}$ Lünge findet er in allen Blüten den Kern der Embryosackzelle im Spiremstadium, in 3,5-4 mm langen Köpfchen in der Regel in allen Blüten Tetraden, in einem $5 \mathrm{~mm}$ langen Köpfchen findet er durchwegs vierkernige Embryosäcke. Ferner teilt er mit, daß im allgemeinen bei den Kompositen die Eizelle und der sekundüre Embryosackkern ziemlich gleichzeitig geteilt werden; bei Ageratum stellt er fest, daß die Kernteilungen sich anfangs gleichzeitig an allen Endospermzellen vollziehen dürften, so wie man auch bei Lactuca oft alle Kerne in dem jungen Endosperm gleichzeitig in Teilung finde. Wir sehen auch hier wieder, wie sich im pflanzlichen Entwicklungsgeschehen die Synchronie oft bis in die zellulären Vorgänge verfolgen läßt.

Auf dem Gebiete tierischen Entwicklungsgeschehens dürfte als 
erster Gurwitsch (1909) der zeitlichen Regelung zellulärer Vorgänge eingehende Beachtung gewidmet haben. Seine Untersuchungen über die Entwicklung zentrifugierter Froscheier führten ihn zu der Frage nach den die Zellteilung zeitlich und räumlich bestimmenden Faktoren. Er gelangt zu der Anschauung, daß für das Zustandekommen einer Zellteilung das Zusammentreffen von zwei unabhängig voneinander variierenden Faktoren notwendig sei. Das würde die Fälle von scheinbar zufälligem, regellosem Auftreten einzelner Zellteilungen in größeren Zellkomplexen erklären, wie sie im allgemeinen bei den späteren Entwicklungsvorgängen vorzuliegen scheinen. In einer späteren Arbeit untersucht Gurwitsch (1910) die Frage, ob das Auftreten der Zellteilungen wirklich derart zufallsmäßig verlaufe, nur durch Festsetzung bestimmter Chancen "normiert" sei oder ob die Zellteilungen einer strengeren Gesetzmäßigkeit folgend durch bestimmte Faktoren "determiniert" seien. Gurwitsch beweist auf statistischem Wege, daß die bilaterale Symmetrie der Seeigelgastrula durch eine gesetzmüßige Determinierung der Zellteilungen erhalten werde. Es ist die Übereinstimmung in der Zahl der rechts und links von der Symmetrieebene anzutreffenden Mitosen eine genauere, als es nach den Gesetzen der Wahrscheinlichkeitsrechnung der Fall sein dürfte, wenn das Auftreten der Zellteilungen dem Zufall überlassen, nur durch die für alle Zellen des Komplexes gleichen Chancen geregelt wäre. Dagegen seien auch zahlreiche Objekte zu finden, bei denen keine Determination des Auftretens der Zellteilungen vorliegt, sondern die Variabilität in der Verteilung der Mitosen innerhalb eines homogenen Zellkomplexes genau den Gesetzen der Wahrscheinlichkeitsrechnung entspricht. Als derartige Objekte ergaben sich auskeimende Zwiebelwurzeln, ferner Cornea und Linse junger Hühnerembryonen. Gurwitsch zieht daraus den Schluß, daß regelmäßige embryonale Formbildung unter Umständen auch ohne zeitliche Determination der Zellteilungen möglich ist. Wohl aber sind dann die Zellteilungen normiert durch bestimmte Chancensetzung, eventuell durch Begünstigung des Prozesses in bestimmten Bezirken und Hemmung in anderen. Das entspreche der positiven und negativen Beeinflußbarkeit der Zellteilungen durch innere und äußere Einwirkungen verschiedenster Art.

In manchen Fällen legt nach Gurwitsch die auffallende Regelmäßigkeit im Verlauf der Zellteilungen von vornherein die Vermutung einer zeitlichen Determination nahe; so bei den ersten Furchungsteilungen regelmäßiger Furchungstypen, bei den meist synchron verlaufenden Kernteilungen in mehrkernigen Zellen und Syncytien, bei den Scheitelzellen in den Vegetationspunkten kryptogamer Pflanzen und endlich bei den spermatogonialen Zellteilungen. Einen derartigen 
Fall, die Spermatogenese im Crodelenhoden, untersuchte Gurwitsch in einer dritten Arbeit (1911). Durch wiederholte Teilungen je einer von Follikelzellen umgebenen Ursamenzelle entstehen größere Nester von Spermatogonien, welche durch eine von den Follikelzellen gebildete bindegewebige Kapsel streng voneinander geschieden bleiben. Innerhalb dieser Kapsel verlaufen dann auch die Reifeteilungen und die spermatogenetischen Prozesse, bis jede Kapsel endlich ein dichtes Büschel fertiger Spermien enthält. . Die Zellen je eines Nestes sind sowohl in bezug auf ihre gemeinsame Abstammung von je einer Zelle als auch in bezug auf ihre prospektive Potenz als untereinander identisch anzusehen. Sie zeigen diese Identität auch in einer besonders genauen Synchronie ihres Entwicklungsganges, ja sogar auch in gewissen degenerativen Vorgängen, welche bisweilen derartige Nester ergreifen. Dabei ist der Eintritt dieses degenerativen Prozesses nicht an ein bestimmtes Stadium der Spermiogenese gebunden. Gurwitsch stellte sich nun die Frage, ob auch der Zellteilungsvorgang in den identischen Zellen eines Nestes ebenso synchron verlaufe und ob die Gesamtzahl der spermatogonialen Teilungen und damit der Generationen, welche der Spermatidenbildung vorausgehen, für alle Zellen eines Nestes identisch und konstant sei. Er fand, daß die Mitosen nie sporadisch, sondern stets epidemisch auftreten. Doch werden ab und zu Nester angetroffen, in denen neben einer Mehrzahl von Teilungsstadien einzelne ruhende Zellen liegen. Der Synchronismus der mitotischen Stadien ist dabei nur selten ein annähernd volikom. mener; die zeitliche Verknüpfung der identischen Zellen eines Nestes ist in bezug auf die einzelnen Phasen der spermatogonialen Teilungen viel lockerer als in bezug auf die eventuellen Degenerationsvorgänge oder auf die Endphasen der Spermiogenese. Eine geradezu ideale Synchronie der Spermiogenese innerhalb eines Nestes beginnt bei den Reifeteilungen. Erste und zweite Reifeteilung verlaufen stets für alle Zellen eines Nestes gleichzeitig, wenn auch nicht in den einzelnen Phasen streng synchron.

Wenn ein Zellnest nur Zellen gleicher Generation enthält, dann muß die Gesamtzahl der Zellen eine Potenz von 2 sein. Tatsächlich findet aber Gurwitsch bei sorgfältigster Zählung nur in einer Minderheit von Nestern die Zahl der Zellen $=2^{n}$ und schließt daraus, daß die schließlich doch gleichzeitig verlaufenden Reifeteilungen sich an Zellen verschiedener Generationen abspielen. Es sei dann an einer oder mehreren Zellen eine oder mehrere Teilungen ausgefallen, entsprechend den vereinzelt gefundenen ruhenden Zellen neben den Teilungsepidemien. Da einzelne sporadische Teilungen in ruhenden Nestern nie zu finden seien, schließt $\mathrm{Gur}$ witsch, daß die ausgefallenen Teilungen nicht eingebracht werden. Nester mit heterotypi- 
schen Teilungen enthielten maximal 120 Zellen, was $2^{7}$ nahe kommt, Nester mit reifen Spermien zwischen 480 und 512 , also nahe an $2^{9}$. Die erste Reifeteilung betrifft daher in der Regel Zellen der siebenten Generation, daneben aber stets einige Zellen früherer Generationen. Nester mit gerader Zahl von Mitosen, die aber nicht gleich $2^{\mathrm{n}}$ ist, sollen nach Gurwitsch beweisen, daß Zellen, die sich an einer be: stimmten Teilungsepidemie nicht beteiligt hatten, sich nachträglich doch noch teilen konnten, aber nur wieder in einer Epidemie, gleichzeitig mit den anderen Zellen des Nestes. Dieser SchluB scheint mir allerdings nicht zwingend, da die gerade Anzahl auch durch eine zufällig gerade Zahl von in der Teilung zurückgebliebenen Zellen bedingt sein könnte. Hat die Mehrzahl der Zellen eines Nestes die siebente Generation erreicht, dann machen alle Zellen des Nestes die Reifeteilung mit ihren histogenetischen Folgen durch, auch jene einzelnen, welche noch einer früheren Generation angehören. Gurwitsch lehnt trotzdem die Annahme einer von außen induzierten Zeitbestimmung für Reifeteilung und Spermiohistogenese als unwahrscheinlich ab und vertritt folgende Auffassung: In der Nachkommenschaft jeder Ursamenzelle laufen streng synchron Prozesse ab, deren Abschluß in der Spermiogenese, deren notwendiges Zwischenstadium in den Reifeteilungen zu erblicken sei. Der Ablauf dieser Prozesse ist von den dazwischen fallenden spermatogonialen Teilungen völlig unabhängig. Andererseits scheint aber doch das Maximum dieser Teilungen fixiert zu sein. Diesen Umstand sowie das epidemieartige Auftreten der Teilungen und die Unmöglichkeit, eine ausgefallene Teilung wieder einzubringen, erklärt Gurwitsch damit, daß dem Inhalt jedes Nestes während des Entwicklungszyklus sechsmal die Möglichkeit zur Zellteilung geboten wird und zwar in bestimmten, durch innere Vorgänge fixierten Zeitabständen. Es hönnen aber einzelne Zellen eine oder mehrere Gelegenheiten unverwertet vorbeigehen lassen, ohne dadurch aus der normalen Entwicklungsbahn auszuscheiden. Die identischen Zellen haben also in bezug auf den Teilungsakt eine Gleichheit der Möglichkeiten, nicht aber der Verwirklichung; diese erfordert das Fingreifen eines zweiten Faktors. Die Wahrscheinlichkeit für das Eintreffen einer Mitose nimmt hier also nicht - wie man es im allgemeinen glaubt - in Abhängigkeit von der zuletzt stattgefundenen Mitose kontinuierlich, zu, sondern sie steigt und sinkt für alle Zellen eines Nestes immer synchron und periodisch ohne Rücksicht darauf, ob sie in der letzten Periode an der einzelnen Zelle verwirklicht wurde oder nicht. Das Zusammenwirken des periodischen Möglichkeitsfaktors mit dem Verwirklichungsfaktor entspricht der ursprünglichen Annahme Gurwitschs, daß für das Zustandekommen einer Zellteilung zwei voneinander unabhängige Ursachen notwendig seien. - Es blieb noch 
die Tatsache zu deuten, daß innerhalb eines Nestes keine strenge Synchronie der Teilungsphasen, sondern ein Voraneilen der dem Zystenlumen näher liegenden Zellen zu beobachten sei. Gurwitsch nimmt an, daß dies durch ein Fortschreiten des Verwirklichungsfaktors durch den Zellkomplex hindurch und durch sukzessives Zusammentreffen mit dem streng synchronen Möglichkeitsfaktor zu erklären sei; er verweist dabei wieder darauf, daß ja auch das Ausbleiben einzelner Teilungen für die geringere Identität der Zellen in bezug auf den Verwirklichnngsfaktor als in bezug auf den Möglichkeitsfaktor spreche. Ein gewissermaßen wellenförmiges Fortschreiten des Teilungsvorganges durch den Zellkomplex in gewisser Richtung würde auch mit einer botanischen Beobachtung übereinstimmen: Die strenge Synchronie der mitotischen Bilder an den Pollenmutterzellen soll besonders an Querschnitten durch Antheren hervortreten, während in der Längsrichtung der Anthere eine leichte (allmähliche?) Verschiebung der mitotischen Stadien von der Basis gegen die Spitze zu vorzuliegen scheine.

Das Fehlen einer genauen Synchronie in den Teilungsvorgängen bei Zellen, die als untereinander "identisch" bezeichnet werden können, legte die Frage nahe, wodurch in anderen Fällen, in denen eine genaue Synchronie der einzelnen mitotischen Phasen zwischen zwei Zellen besteht, die hierzu notwendige Regelung erfolge. Diese Frage suchte eine Schülerin Gurwitschs, Sorokina (1913) an der Hand der ersten Furchungsstadien von Seeigeleiern zu lösen. Normale Eier von Paracentrotus lividus zeigen beim zweiten Furchungsschritt ausnahmslos eine strenge Synchronie der Mitosen in beiden Blastomeren. Sorokina trennte nun die beiden Blastomeren durch Schütteln voneinander. Führte dieses zu einer völligen Trennung der Blastomeren, dann war die Synchronie des folgenden Teilungsschrittes wohl aufgehoben, doch folgten die Teilungen in den beiden Zellen einander ziemlich schnell. Behielten dagegen die beiden Zellen trotz Schüttelns und Entfernung der Eimembran ihren Zusammenhang miteinander, dann erfolgte entweder eine streng synchrone Teilung oder - offenbar an geschädigten Zellen! - eine bedeutende Verzögerung, eventuell Aufhebung der Teilung an der einen Blastomere. Da bei den verschiedenartigen Ergebnissen dieser Versuche damit zu rechnen war, daß der mechanische Eingriff die beiden Blastomeren in ungleicher Weise schïdigte, wandte Sorokina in einer zweiten Versuchsreihe die Behandlung der Eier mit Ca-freiem Seewasser nach einer Methode von Herbst an. Es genügt dann ein viel sanfteres Schütteln der noch ungefurchten Eier, um eine Entfernung der Eimembran und dadurch bei der erst später sich vollziehenden Furchung eine völlige Loslösung der beiden Blastomeren ohne jede Schädigung zu erzielen. Die zweite Furchungsteilung verläuft an den so getrennten Zellen gleich schnell 
mit unbeeinflußten Kontrolleiern. Trotzdem teilt sich die Mehrzahl der Blastomeren dieser Versuchsreihe deutlich anachron. Dies darf bei Berücksichtigung der Versuchsanordnung wohl nur auf die Sonderung der Blastomeren zurüokgeführt werden. Trotzdem hält Sorokina es nicht für bewiesen, daß die normal verbundenen Blastomeren einander in der betreffenden Hinsicht beeinflussen. Es lasse sich nur behaupten, daß durch die Trennung der Blastomeren ihr Teilungsmechanismus beeinflußt, werde und zwar ohne Schädigung, nur im Sinne einer Verstellung. Die voneinander gelösten Blastomeren zeigen in der nicht mehr genauen, wohl aber noch annähernd vorhandenen Übereinstimmung ihres Teilungsrhythmus große Übereinstimmung mit dem Verhalten der spermatogonialen Zellteilungen, während die normal verbundenen Blastomeren an die genaue Synchronie der Kernteilungen in Syncytien erinnem. Sorokina hält es für naheliegend, den genauen Synchironismus der Blastomerenteilungen, der sonst bei den Teilungen identischer Zellen, beispielsweise der Spermatogonien, kein Homologon hat, auf den besonders innigen, bei anderen Zellarten fehlenden Zusammenhang zwischen den Blastomeren zurückzuführen. Ich möchte dabei die Vermutung aussprechen, daß diese Sicherung der synchronen Entwicklung der beiden Blastomeren unter normalen Umständen einem durch den Kontakt ermöglichten Stoffaustausch zuzuschreiben ist. Nach Aufhebung dieses Kontaktes dagegen dürften minimale Verschiedenheiten der beiden Zellen, die auch sonst wahrscheinlich vorhanden, aber durch gegenseitige Beeinflussung der beiden Zellen unwirksam gemacht sind, eine verschieden schnelle Entwicklung bedingen.

Außer den eben besprochenen Befunden von Gurwitsch und Sorokina sind mir in der zoologischen Literatur keinerlei Arbeiten bekannt geworden, welche eine Untersuchung des Zellteilungsrhythmus, der Regelung der Zellteilungsvorgänge innerhalb des Individuums zum Ziel gehabt hätten. Hier schien mir daher noch ein weites Feld für wertvolle Forschungsarbeit brach zu liegen. Nur gelegentlich fand ich, ähnlich wie in der botanischen Literatur, in anderen Publikationen vereinzelte Angaben, welche über hierhergehörige Tatsachen andeutungsweise berichten. Eine derartige Beobachtung mag hier zitiert werden, weil sie den mir gestellten Problemen am nächsten kommt und sich auch auf ein ähnliches Objekt bezieht, wie meine eigenen Untersuchungen. Häcker (1918) fand bei einer Untersuchung über Zeichnung und Hautwachstum beim Axolotl, daß auffallenderweise in der Epidermis bei einzelnen Individuen überwiegend Asterstadien und Ubergangsfiguren zwischen Aster und Spirem zu finden sind, bei anderen Exemplaren dagegen die Aster zurücktreten und neben den Ubergangsformen Knäuel, besonders aber Diaster und Dispireme hüufiger 
sind. Er schließt daraus auf eine im allgemeinen bestehende Synchronie der Teilungen, so dab bald das länger dauernde Asterstadium, bald die Endstadien der Teilung sowie die unmittelbar daran sich anschließenden Prophasen des nächstfolgenden Teilungsschrittes angetroffen werden. Noch bevor das diese Angaben enthaltende Buch Häckers in meine. Hände gelangt war, hatte ich mir im Herbst 1918 eine diesem Befunde sehr nahe stehende Fragestellung als Arbeitsprogramm gewählt. Ich wollte untersuchen, wie weit bei den späteren Entwicklungsvorgängen höherer Tiere die Zellteilungsvorgänge innerhalb verschiedener Teile des Individuums eine einheitliche Regelung erfahren.

Um dem Problem der Zellteilungsregelung bei späteren Entwicklungsstadien höherer Tiere näher zu treten, wollte ich vor allem an einem Objekte, dessen Zellteilungsfiguren möglichst klar und leicht zu beobachten sind, feststellen, wie weit die Zellteilungstätigkeit in verschiedenen Zellkomplexen eines Individuums parallel verläuft. Als erste, grundlegende Frage war dabei zu untersuchen, wie weit die Zellteilungstätigkeit zwischen zwei möglichst gleichartigen Zellkomplexen eines Individuums in jedem Zeitpunkte übereinstimmt, dann erst, wie sich in bezug auf die Zellteilungen verschiedenartige Zellkomplexe eines Individuums zueinander verhalten. Im Zusammenhange mit diesen Fragen ließe sich dann auch die Rolle, welche äußere und innere Faktoren wie Nahrung, Stoffwechsel, Licht, Temperatur, Gifte einerseits, funktionelle Beanspruchung und Hormone andererseits, bei der Regelung des Zellteilungsrhythmus spielen, systematisch analysieren. Nur bezüglich der erstgenannten Frage, nach dem Verhältnis der Zellteilungstätigkeit zwischen gleichartigen Zellkomplexen sowie bezüglich des Zusammenhanges zwischen Fütterungsbedingungen und Lebhaftigkeit des Zellteilungsprozesses sind meine Untersuchungen bereits zu eindeutigen Resultaten gediehen, welche hier mitgeteilt werden sollen. Bezüglich einiger anderer von den genannten Fragen habe ich teils Untersuchungen begonnen, teils hoffe ich entsprechende Untersuchungen in der kommenden Zeit ausführen zu können.

Als lgünstigstes Objekt für die Untersuchung eines Zellteilungsproblems verwendete auch ich wieder die stets für derartige Zwecke bevorzugten Epithelien von Urodelenlarven, speziell von Salamandra maculosa. Die Bedingung möglichster Gleichartigkeit und guter Abgrenzbarkeit zweier Zellkomplexe fand ich in vollkommener Weise in den beiderseitigen Corneaepithelien erfüllt. Als andersartige Zellkomplexe, in welchen die Mitosen ebenso leicht zu untersuchen sind, kämen beispielsweise die Kiemenplättchen oder der Mundhöhlenboden 
in Betracht, als noch mehr abweichende Gewebe das mesodermale Peritonealepithel oder das entodermale Lungenepithel.

Die Untersuchung des zuerst gestellten Problems wurde mit einer Überprüfung der Beziehungen zwischen Fütterungsbedingungen und Auftreten der Mitosen verbunden. Wir finden in Häckers Zellenund Befruchtungslehre (1899) die Angabe, daß bei jungen Salamanderlarven am sichersten auf eine größere Menge von Kernteilungsfiguren zu rechnen ist, wenn man die Larven, nachdem sie ein paar Tage gehungert haben, bis zur Übersättigung mit Tubifex oder mit Chironomus-Larven füttert und dann etwa am vierten Tage nach Beginn der Fütterung konserviert. Diese und ähnliche Angaben werden vielfach verwendet, um für mikroskopische. Kurse oder für wissenschaftliche Arbeiten ein für die Untersuchung der Karyokinese günstiges Material zu gewinnen. Doch lauten die Angaben über die damit erzielten Erfolge widersprechend. Schon aus diesem praktischen Grunde, mehr aber noch des allgemeinen theoretischen Interesses halber, das der Zusammenhang zwischen Ernährung einerseits, Einsetzen und Ablauf der Mitosen andererseits beanspruchen darf, hielt ich eine genauere systematische Untersuchung dieser Verhältnisse für wertvoll.

Tabelle I. Versuchsanordnung in der Serie Syn. I.

\begin{tabular}{|c|c|c|c|}
\hline $\begin{array}{c}\text { Datum } \\
1918\end{array}$ & Gruppe I & Gruppe II & Gruppe III \\
\hline 30. XI. & Uterusentnahme $\mathbf{F}$ & Uterusentnahme $\mathbf{F}$ & Uterusentnahme $\mathbf{F}$ \\
\hline 1. XII. & $\mathrm{E}$ & $\mathbf{E}$ & $\mathbf{F}$ \\
\hline 2. 3 & F 2 & F & $\mathbf{F}$ \\
\hline 3. & $\mathbf{F}$ & $\mathbf{F}$ & $\mathbf{F}$ \\
\hline $4 * \gg$ & F 3 & $\mathbf{F}$ & $\mathbf{F}$ \\
\hline 5. & - & - & $\mathbf{E}$ \\
\hline $6 . \$$ & -4 & - & F 5 \\
\hline 7. & - & - & $\mathbf{F}$ \\
\hline 8. $\gg$ & -6 & $\mathrm{~F}$ & $\mathbf{F}$ \\
\hline 9. & - & $\mathrm{F}$ & $\mathrm{F}$ \\
\hline 10. $\%$ & -7 & F 8 & F. 9 \\
\hline 11. & F 10 & F 11 & $\mathbf{F}$ \\
\hline 12. " & F 12 & F 13 & $\mathbf{F}$ \\
\hline 13. \# & F 14 & F 15 & $F$ \\
\hline 14. " & F 16 & F 17 & F 18 \\
\hline 15. 》 & F 19 & $\mathbf{F}$ & $\mathbf{F}$ \\
\hline 16. " & $\mathbf{F} 20$ & $\mathrm{~F}$ & $\mathbf{F}$ \\
\hline 17. & $F 21$ & $\mathrm{H}^{2}$ & $\mathbf{F}$ \\
\hline 18. & $\mathrm{~F} 22$ & $\mathrm{~F} 23$ & F 24 \\
\hline
\end{tabular}


Das Material für die hier zu besprechenden Beobachtungen ent* stammt zwei Versuchsserien, die in meinen Protokollen als Syn. I und Syn. IV geführt sind. Für Syn. I wurden am 30. November 1918 aus dem Uterus eines trächtigen Weibchens die Larven entnommen; es fanden sich 35 Tiere, von denen eines mißbildet und eines bei der Entnahme verletzt worden war. Die übrigen wurden in drei Gruppen geteilt. Jede Gruppe wurde in einer runden weißen Porzellanschale, in der etwa $5 \mathrm{~cm}$ hoch Wasser eingefüllt war, untergebracht. Es wurde den Tieren nach der Uterusentnahme probeweise Tubifex vorgesetzt und da sie bald danach schnappten, in allen drei Gruppen eine erste Fütterung durchgeführt. In der ersten Gruppe wurde dann fünf Tage hindurch, bis zum 4. XII. täglich einmal stark mit Tubifex gefüttert, vom 5. bis zum 10. wurde die Fütterung unterlassen, vom 11. an wieder täglich gefüttert. Die zweite Gruppe wurde ähnlich behandelt, nur wurde hier die Hungerperiode auf drei Tage (5. XII. - 7. XII.) beschränkt. Die dritte Gruppe wurde als Vergleichsmaterial ohne Unterbrechung täglich gefüttert. Aus jeder der drei Gruppen wurden an verschiedenen Tagen Tiere konserviert, worüber im einzelnen die Tabelle I genauen Aufschluß erteilt. Es wurden für diese Versuchsserie 24 Tiere verwendet, während die restlichen 9 anderen $Z$ wecken dienten ${ }^{1}$. Als Fixierungsmittel wurde meist eine Mischung von 7 Teilen $3 \%$ iger Kaliumbichromatlösung, 2 Teilen Formol, 1 Teil Eisessig verwendet, in einigen Fällen Zenkersche Flüssigkeit, in einigen anderen Sublimat-Pikrinsäure nach C. Rabl. Nach entsprechender Weiterbehandlung wurden den Larven die für Zellteilungsuntersuchungen im Flächenpräparat günstigsten Organe, vor allem Cornea, Kiemenplättchen und Mundhöhlenboden auspräpariert. Diese Teile wurden dann mit Delafieldschem Hämatoxylin oder Hämalaun, nachher mit Eosin gefürbt und in Kanadabalsam eingeschlossen.

Für die Serie Syn. IV wurde am 7. X. 1920 wieder einem trächtigen Weibchen von Salamandra maculosa der Uterusinhalt entnommen. Von den vorgefundenen 46 Larven war eine mißbildet; zwei offenbar in der Entwicklung zurückgebliebene gingen bald zugrunde. Die übrigen Tiere wurden in zwei Gruppen geteilt. In beiden wurde am 10. X. zum erstenmal gefüttert, wieder mit Tubifex. Die Fütterung wurde dann in der einen Gruppe täglich einmal ohne Unterbrechung wiederholt. Auch in der zweiten Gruppe wurde täglich einmal gefüttert, om 13. bis zum 16. aber eine Hungerperiode eingeschaltet. Tabelle II 'gibt Auskunft über die Verteilung der zur Untersuchung

1) Bei einem der 24 verwendeten Tiere (Nr. 21) ging die eine Cornea bei der Präparation verloren, so daß es nicht für alle hier angeführten Tabellen verwertet werden konnte. 
konservierten 41 Tiere. (Zwei Tiere blieben unverwendet.) Zur Konservierung diente wieder teils die Zenkersche, teils die Rablsche Flüssigkeit, meist aber die von Kolmer empfohlene Mischung: 4 Teile konzentriert́e wäßrige Kaliumbichromatlösung, 4 Teile $10 \%$ iges wäßriges Formol, 1 Teil Eisessig. Die Weiterbehandlung war die gleiche wie in der Serie Syn. I, als Kernfarbstoff wurde mehrfach auch das Ehrlichsche Hämatoxylin verwendet. Alle in beiden Serien verwendeten Fixierungen und Fürbungen ergaben für meine Zwecke brauchbare Resultate.

\begin{tabular}{|c|c|c|c|c|}
\hline $\begin{array}{c}\text { Datum } \\
1920\end{array}$ & Gruppe 1 & & Gruppe II & \\
\hline 7. $\mathrm{X}$. & Uterusentnahme - & 1 & Uterusentnahme & F 40,41 \\
\hline 8. " & - & 2 & & - \\
\hline 9. & - & 3 & & $\longrightarrow$ \\
\hline 10." " & $\mathrm{E}$ & 4 & & - \\
\hline 11. " & $\mathbf{I}$ & 5 & & $\mathbf{F}$ \\
\hline 12. 》 & $\mathrm{F}$ & 6 & & F \\
\hline 13. » & $\mathbf{H}$ & 7 & & $\mathbf{F}$ \\
\hline 14. $\gg$ & I & 9 & & -8 \\
\hline 15. 》 & $\mathbf{E}$ & 11,12 & & -10 \\
\hline 16. 》 & $\mathrm{H}$ & 14,15 & & -13 \\
\hline 17. $»$ & $\mathrm{~F}$ & 17,18 & & -16 \\
\hline 18. » & $\mathrm{H}$ & 20,21 & & F 19 \\
\hline 19. 》 & $\mathrm{F}$ & 23,24 & & T 22 \\
\hline $20 . "$ & $\mathrm{E}$ & 26,27 & & F 25 \\
\hline 21. * & $\mathrm{F}$ & 30 & & F $\quad 29, \mathbf{2 9}$ \\
\hline $22 . *$ & $\mathrm{I}$ & 33 & & F 31,32 \\
\hline $23 . "$ & $\mathrm{E}$ & 36 & & F $\quad 34,35$ \\
\hline 24. & 1 & 39 & & F 37,38 \\
\hline
\end{tabular}

Bezeichnungen wie in Tabolle $I$.

Die Untersuchung des in dieser Mitteilung allein berücksichtigten Corneaepithels wurde in folgender Weise durchgeführt: Es wurde zunächst bei schwacher (60 facher) Vergrößerung mit dem Zeichenapparat eine Umrißskizze der Cornea entworfen. Als Grenze diente die innerste Schichte Leydigscher Zellen, welche den Beginn der normalen Epidermisstruktur anzeigen. In dieser Skizze wurden - ebenfalls noch mit dem Zeichenapparat - alle bei der verwendeten schwachen Vergrößerung deutlich erkennbaren Einzelheiten, wie auffällige Pigmentzellen am Rande, einzelne weiter nach innen vorspringende Leydigsche Zellen, Risse oder Falten am Objekt usw. genau eingezeichnet. Dadurch wurde es möglich, bei dem nun vor- 
genommenen Übergang zur stärkeren Vergrößerung jede Stelle des Präparats wieder mit der richtigen Stelle in der Skizze zu identifizieren. Es wurden nun die Grenzen der bei etwa 300 facher Vergrößerung sichtbaren Gesichtsfelder als Kreise mit Hilfe eines Zirkels eingetragen, der fü̈r die betreffende Vergrößerung ein für alle mal eingestellt worden war. In diese Kreise wurden dann die gefundenen Mitosen eingezeichnet. Die eingezeichneten Resultate wurden endlich mit Hilfe einer noch stärkeren (etwa 600 fachen) Vergrößerung überprüft und eventuell korrigiert oder ergänzt. Jede einzelne Mitose wurde durch einen Buchstaben dargestellt, wodurch die verschiedenen Stadien des karyokinetischen Vorganges gekennzeichnet wurden. Als "a" bezeichnete ich die Vorbereitung zur Mitose von dem Zeitpunkte an, in dem sich der Zellkern durch die Anordnung seines Chromatins deutlich von einem ruhenden Kerne unterscheidet und das dichte Spiremstadium; als »b" den lockeren Knäuel, solange die Chromosomen noch nicht völlig voneinander gesondert sind. Das Asterstadium wurde als "c«, die Metakinese - solange noch wenigstens ein Paar von Tochterchromosomen eine Berührung zeigte - als "d ", das Diasterstadium als "e " bezeichnet; "f" diente als Bezeichnung für das Dispiremstadium, "g " für die Endphase der Teilung, in der die betreffenden Tochterkerne sich von ruhenden Kernen noch durch auffallende Färbbarkeit und charakteristische Form- und Lageverhältnisse auszeichneten. Die gefundenen Zahlen sind in den Tabellen III und IV zusammengestellt.

Tabelle III. Syn. I.

\begin{tabular}{|c|c|c|c|c|c|c|c|c|c|c|c|c|c|c|c|c|c|}
\hline \multirow[b]{2}{*}{ Tier Nr. } & \multicolumn{9}{|c|}{ Absolute Zahlen } & \multicolumn{8}{|c|}{ VerhältniszahIen } \\
\hline & $a$ & $\mathrm{~b}$ & $\mathrm{c}$ & d & e & f & $\mathrm{g}$ & $\begin{array}{c}\text { Sum- } \\
\text { me I. }\end{array}$ & $\begin{array}{l}\text { Sum- } \\
\text { me II }\end{array}$ & $\mathrm{a}$ & $\mathrm{b}$ & c & $\mathrm{d}$ & e & f & $g$ & 2 \\
\hline \multirow{2}{*}{$\mathrm{I}_{\beta}^{\alpha}$} & 0 & 0 & 0 & 0 & 1 & 0 & 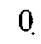 & 1 & \multirow{2}{*}{11} & 0 & 0 & 0 & 0 & 100 & 0 & 0 & \\
\hline & 2 & 1 & 5 & 0 & 1 & 0 & 1 & 10 & & 20 & 10 & 50 & 0 & 10 & 0 & 10 & 91 \\
\hline \multirow{2}{*}{ II ${ }_{\beta}^{\alpha}$} & 0 & 0 & 5 & 1 & 2 & 1 & 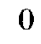 & 9 & \multirow{2}{*}{14} & 0 & 0 & 56 & 11 & 22 & 11 & 0 & 64 \\
\hline & 0 & 0 & 2 & 0 & 0 & 0 & 3 & 5 & & 0 & 0 & 40 & 0 & 0 & 0 & 60 & 36 \\
\hline \multirow{2}{*}{ III $\%$} & 1 & 1 & 3 & 1 & 2 & 2 & 3 & 13 & \multirow{2}{*}{23} & 8 & 8 & 23 & 8 & 16 & $\mid 16$ & $|23|$ & 56 \\
\hline & 0 & 0 & 3 & 1 & 2 & 2 & 2 & 10 & & 0 & 0 & 30 & 10 & 20 & 20 & 20 & 44 \\
\hline \multirow{2}{*}{ IV $\frac{a}{\beta}$} & 7 & 1 & 1 & 2 & 2 & $\pi$ & 1 & 15 & \multirow{2}{*}{36} & 47 & 7 & 7 & 13 & 13 & 7 & 7 & 42 \\
\hline & 10 & 2 & 6 & 0 & 2 & 1 & 0 & 21 & & 48 & 10 & 29 & 0 & 10 & 5 & 0 & 58 \\
\hline \multirow{2}{*}{$V_{\beta}^{c}$} & 1 & 1 & 3 & 1 & 0 & 0 & 0 & 6 & \multirow{2}{*}{10} & 17 & 17 & 50 & 17 & 0 & 0 & 0 & 60 \\
\hline & 0 & 0 & 2 & 1 & 0 & 0 & 1 & 4 & & 0 & 0 & 50 & 25 & 0 & 0 & 25 & 40 \\
\hline \multirow{2}{*}{$\mathrm{VI}_{\beta}^{\alpha}$} & 17 & 1 & 11 & 3 & 2 & 4 & 8 & 46 & \multirow{2}{*}{74} & 37 & 2 & 24 & 7 & 4 & 9 & 18 & 62 \\
\hline & 9 & 3 & 5 & 1 & 2 & 3 & 5 & 28 & & 33 & 11 & 18 & 4 & 7 & 11 & 18 & $\because 8$ \\
\hline \multirow{2}{*}{ VII ${ }_{\beta}^{a}$} & 11 & 2 & 5 & 2 & 4 & 7 & 13 & 44 & \multirow{2}{*}{90} & 25 & 5 & 11 & 5 & 9 & 16 & 29 & 49 \\
\hline & 9 & 31 & 15 & 6 & 9 & 1 & 3 & 46 & & 20 & 7 & $|33|$ & 13 & 20 & 2 & $7 !$ & 51 \\
\hline
\end{tabular}




\begin{tabular}{|c|c|c|c|c|c|c|c|c|c|c|c|c|c|c|c|c|c|}
\hline \multirow{2}{*}{ Tier Nr. } & \multicolumn{9}{|c|}{ Absolute ,Zahlen } & \multicolumn{8}{|c|}{ Verlıältniszahlen } \\
\hline & a & & $c$ & & e & f & $\mathrm{g}$ & & & a & b & c & $d$ & e & $f$ & $g$ & \\
\hline \multirow{2}{*}{ VIII $^{\alpha}$} & 1 & & 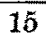 & & 5 & 4 & & & \multirow{2}{*}{92} & & 2 & 36 & 10 & 2 & 10 & 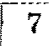 & \\
\hline & & 3 & $n$ & & 4 & 6 & $\therefore$ & & & & 6 & 26 & 6 & 8 & 12 & 10 & \\
\hline \multirow{2}{*}{$\mathrm{IX}_{\beta}^{\alpha}$} & & & & & 7 & $\sigma$ & 2 & & & & 7 & 21 & 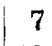 & 24 & 10 & 7 & 48 \\
\hline & & 1 & 10 & & 6 & 5 & 2 & & & & 3 & 32 & 10 & 9 & 16 & 6 & . \\
\hline \multirow{2}{*}{$\mathrm{X}_{\beta}^{\alpha}$} & & & & & & & & & \multirow{2}{*}{43} & 2 & 12 & 24 & & & 8 & $\mid 12$ & $\tilde{0} 8$ \\
\hline & 0 & 1 & 5 & & 1 & 3 & 2 & & & 33 & 6 & 28 & 0 & 6 & 17 & 11 & 4 \\
\hline \multirow{2}{*}{$\mathrm{XI}{ }_{\beta}^{\alpha}$} & 4 & 1 & 1 & 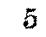 & 5 & 7 & 13 & 4 & \multirow{2}{*}{107} & 9 & 2 & 24 & 11 & 11 & 15 & 28 & 4 \\
\hline & 9 & 2 & 7 & 3 & 8 & 8 & 14 & 6 & & $1 \tilde{0}$ & 3 & 28 & 5 & 3 & 13 & 23 & 5 \\
\hline \multirow{2}{*}{$\mathrm{XII}_{\beta}^{\alpha}$} & 6 & 4 & 1 & & 7 & 3 & 7 & & \multirow[b]{2}{*}{4} & 16 & 11 & 26 & 3 & 18 & 8 & 18 & 5. \\
\hline & 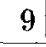 & 1 & 1 & & 3 & 1 & 10 & & & $2 b$ & 3 & 31 & 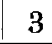 & & 3 & 28 & 4 \\
\hline \multirow{2}{*}{ XIII ${ }_{\beta}^{a}$} & 9 & 6 & 10 & 2 & 7 & 4 & 5 & & \multirow[b]{2}{*}{ nu } & 21 & 14 & 23 & 5 & 16 & 9 & 2 & $55^{2}$ \\
\hline & & 3 & 11 & 0 & 4 & 3 & 7 & & & 20 & 9 & 31 & 0 & 2 & 31 & 20 & 4 \\
\hline \multirow{2}{*}{$\begin{array}{r}\text { XIV } \\
\beta \\
\end{array}$} & 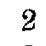 & 1 & 7 & & & & 9 & & \multirow{2}{*}{34} & 8 & 4 & 29 & 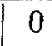 & & 4 & 8 & 44 \\
\hline & 8 & U & 11 & 0 & 6 & 2 & 3 & 50 & & 27 & 0 & 37 & 0 & u & 7 & 10 & 5 \\
\hline \multirow{2}{*}{$\begin{aligned} & X{ }^{*} \\
& \beta\end{aligned}$} & 1 & & & 5 & 8 & 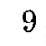 & 3 & & \multirow[t]{2}{*}{137} & 3 & 8 & 23 & 8 & 12 & 14 & 5 & 47 \\
\hline & 3 & 3 & $I$ & 5 & 9 & 8 & 4 & & & 34 & 7 & 23 & 7 & 12 & 11 & 5 & b: \\
\hline \multirow{2}{*}{$\mathrm{XVI} \underset{\beta}{\beta}$} & 5 & 0 & & 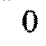 & 3 & 0 & 0 & 1 & \multirow[t]{2}{*}{4} & 42 & 0 & 33 & 0 & 25 & 0 & 0 & 30 \\
\hline & 1 & & 5 & 1 & 0 & 3 & 3 & & & 50 & 7 & 18 & 4 & 0 & 11 & 11 & 70 \\
\hline \multirow{2}{*}{$\mathrm{XVII}_{\beta}{ }_{\beta}$} & 2 & 3 & 16 & 3 & 14 & 15 & 13 & 9 & 66 & 3 & 3 & 18 & 3 & 15 & 16 & 14 & 55 \\
\hline & 2 & 5 & 1 & 4 & 11 & 10 & 9 & & & 28 & 7 & 20 & 5 & 15 & 13 & 12 & 40 \\
\hline & 42 & 12 & 28 & 5 & 19 & 13 & 7 & 121 & 35 & 35 & 10 & 19 & 4 & 16 & $11 \mid$ & 6 & 51 \\
\hline & 35 & & 23 & 0 & $1 \tilde{0}$ & 16 & 6 & & & & 8 & 20 & 9 & 4 & 16 & 5 & 4 \\
\hline 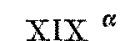 & 7 & 0 & 8 & 0 & 4 & 2 & 10 & & 89 & 23 & 0 & 6 & 0 & & 6 & 32 & 3 \\
\hline & 1 & & & & -1 & 4 & 1 & & & 31 & 4 & 1 & 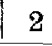 & 10 & 0 & 28 & 0 \\
\hline & 1 & 5 & & 1 & 5 & 9 & 1 & 54 & & & 9 & 31 & 2 & 9 & 17 & & 46 \\
\hline & 1 & & & 3 & $x$ & 6 & 3 & & & 21 & 5 & o. & 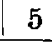 & 22 & 10 & 0 & D \\
\hline 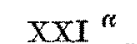 & 27 & 6 & 27 & $\check{b}$ & 14 & 7 & 2 & 8 & & 13 & 7 & 31 & 6 & 16 & 8 & 2 & - \\
\hline & - & - & - & - & - & - & - & $=$ & & -1 & $1-$ & $1-$ & - & - & $1-$ & 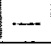 & \\
\hline II & 13 & 10 & 17 & 4 & 8 & 4 & 2 & 5 & & 22 & 17 & 29 & 7 & 1 & 7 & 3 & 4 \\
\hline & 2 & 8 & 2 & 0 & 12 & 10 & 3 & & & 28 & 10 & 3 & 0 & 5 & 12 & 4 & อั \\
\hline te & 26 & 3 & 4 & 1 & 20 & 19 & 9 & 132 & & 20 & 10 & 33 & 1 & 15 & 14 & 7 & 58 \\
\hline & 2 & & 37 & 2 & 11 & $2 x$ & E. & 0 & & 22 & 6 & 39 & 2 & 12 & 15 & 3 & 48 \\
\hline V & 0 & 2 & 13 & 8 & $\tilde{n}$ & 3 & 3 & 3 & 61 & 15 & 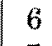 & 3 & 6 & 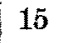 & 9 & 9 & $\tilde{\sigma}$ \\
\hline & 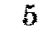 & & & & & 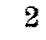 & & 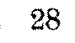 & 01 & 10 & 7 & 29 & & 32 & $r$ & 4 & 46 \\
\hline
\end{tabular}

Zahlen der in den einzelnen Corneapithelien gefundenen Mitosen, geordnet nach den einzelnen karyokinetischen Phasen. Bei jedem Tiere beziehen sioh die in der Querkolonne $\alpha$ stehenden Zahlen auf die Cornea des einen die in der Querkolonne $\beta$ stehenden Zahlen auf diejenige des anderen Auges. Summe I gibt die Gesamtzahlen in je einem Corneaepithel,

1) Die eine Cornea des Tieres Nr. XXI ging bei der Präparation verloren. 
Summe II die Gesamtzahl in beiden Corneaepithelien eines Tieres an. Die Verhältniszahlen wurden berechnet nach der Formel $\frac{n \cdot 100}{S}$, wobei $n$ die Zahl der Mitosen des betreffenden Stadiums, $S$ die Summe I bedeutet. Die Zahlen der Kolonne $\Sigma$ zeigen das Verhältnis der Gesamtzahl der einzelnen Comeae zu der Gesamt-

zahl der beiden Corneae eines Tieres und wurden nach der Formel $\frac{\text { Summe I } \cdot 100}{\text { Summe II }}$ berechnet.

Tabelle IV. Serie Syn. IV.

\begin{tabular}{|c|c|c|c|c|c|c|c|c|c|c|c|c|c|c|c|c|c|c|}
\hline \multirow{2}{*}{ Tier Nr. } & \multicolumn{10}{|c|}{ Absolute Zablen } & \multicolumn{8}{|c|}{ Verhältniszahlen } \\
\hline & & $\mathbf{a}$ & b & $\mathrm{c}$ & $\mathrm{d}$ & e & f & $\mathrm{g}$ & $\begin{array}{l}\mathrm{m}- \\
\mathrm{eI}\end{array}$ & $\begin{array}{l}\text { Sum- } \\
\text { me II }\end{array}$ & $\mathrm{a}$ & b & c & $\mathrm{d}$ & e & $f$ & g & $\Sigma$ \\
\hline & & 3 & 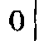 & 0 & 1 & 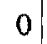 & 1 & & \pm & \multirow{2}{*}{10} & $7 \overline{0}$ & 0 & 0 & 0 & 0 & 25 & 0 & 40 \\
\hline & & 3 & 0 & 1 & $1)$ & 0 & 0 & 1 & 6 & & 50 & 0 & 17 & 17 & 0 & 0 & 17 & 60 \\
\hline \multirow{2}{*}{ II } & & 4 & 3 & 1 & 3 & 2 & 3 & 1 & 16 & \multirow{2}{*}{30} & 25 & 19 & 6 & 19 & 12 & 19 & 0 & 53 \\
\hline & & 9 & 2 & 1 & 0 & 0 & 1 & $-\infty$ & 14 & & 64 & 14 & 7 & 0 & 0 & 7 & 7 & 47 \\
\hline \multirow{2}{*}{ III } & & 4 & 1 & $\tilde{b}$ & 91 & 1 & 6 & 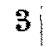 & 22 & \multirow[t]{2}{*}{40} & \multirow{2}{*}{\multicolumn{2}{|c|}{\begin{tabular}{r|r|}
18 & 5 \\
11 & 17 \\
\end{tabular}}} & 23 & 9 & $\dot{b}$ & 27 & 14 & 55 \\
\hline & & 2 & 3 & $5 !$ & $1)$ & 2 & 4 & & 18 & & & & 28 & 6 & 11 & 22 & 61 & 45 \\
\hline \multirow{2}{*}{ IV } & & 5 & 2 & 7 & 1 & 1 & 1 & 0 & 17 & \multirow{2}{*}{41} & \multirow{2}{*}{\multicolumn{2}{|c|}{$\begin{array}{l}29,12 \\
17: 4\end{array}$}} & 41 & 6 & 6 & $6)$ & 0 & 41 \\
\hline & & 4 & 1) & $7^{1}$ & 3 & 5 & 4 & 1 & 24 & & & & 29 & 13 & 21 & 17 & 0 & 59 \\
\hline \multirow{2}{*}{$\mathrm{V}$} & & 1 & 3 & 4 & 0 & .1 & 0 & $\bar{x}$ & 10 & \multirow{2}{*}{18} & 10 & 30 & 40 & 0 & 10 & 0 & 10 & 56 \\
\hline & & 3 & 11 & 1 & 0 & 0 & 2 & 1 & 8 & & $37\}$ & 12 & 12 & 0 & 0 & $25 \mid$ & 12 & 44 \\
\hline \multirow{2}{*}{ VI } & & 0 & 0 & 0 & 0 & 0 & 1 & 1 & 2 & \multirow{2}{*}{6} & 0 & 0 & 0 & 0 & 0 & 50 & 50 & 33 \\
\hline & & 0 & 0 & 1 & 0 & 0 & 0 & 3 & 4 & & 0 & 0 & 25 & 0 & 0 & 0 & 75 & 67 \\
\hline \multirow{2}{*}{ VII } & & 2 & 2 & 4 & 1 & 1 & 0 & 0 & 10 & \multirow{2}{*}{18} & 20 & 20 & 40 & 10 & 10 & 0 & 0 & 56 \\
\hline & & 1 & 3 & 4 & 0 & 0 & 0 & 0 & 8 & & 13 & 37 & 50 & 0 & 0 & 0 & 0 & 44 \\
\hline \multirow{2}{*}{ VIII } & & 3 & 0 & 3 & 2 & 0 & 0 & 3 & 11 & \multirow{2}{*}{18} & 27 & 0 & 27 & 18 & 0 & 0 & 27 & 61 \\
\hline & & 3 & 1 & 1 & 0 & 0 & 0 & 2 & 7 & & 43 & 14 & 14 & 0 & 0 & 0 & 29 & 39 \\
\hline \multirow{2}{*}{ IX $\begin{array}{l}r \\
1\end{array}$} & & 0 & 0 & 0 & 0 & 0 & 0 & 1 & 1 & \multirow{2}{*}{4} & 0 & 0 & 0 & 0 & 0 & 0 & 100 & 25 \\
\hline & & 0 & 0 & 1 & 0 & 0 & 0 & 2 & 3 & & 0 & 0 & 33 & 0 & 01 & 01 & 67 & 75 \\
\hline & & 9 & 1 & 3 & 0 & 3 & 4 & 0 & 20 & 40 & 45 & $\tilde{\sigma}$ & 15 & 0 & 16 & 20 & 0 & 50 \\
\hline & & 5 & 3 & 3 & 2 & 2 & 4 & 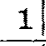 & 20 & & 25 & 15 & 15 & 10 & 10 & 20 & 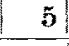 & 50 \\
\hline T & & 3 & 4 & 8 & 1 & $3)$ & 5 & 0 & 24 & 50 & 13 & 17 & 33 & 4 & 12 & 2 & 0 & 48 \\
\hline $\mathrm{NI}$ & & 9 & 3 & $\delta$ & 1 & 3 & 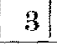 & 2 & 26 & & $35 \mid$ & 12 & 19 & 4 & 12 & 1 & $\stackrel{0}{-}$ & 52 \\
\hline$X$ & & 14 & 2 & 8 & 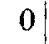 & 5 & 11 & 0 & 40 & & 35 & 5 & 20 & 0 & 13 & 2 & 0 & 52 \\
\hline All & & 9 & 3 & 14 & 1 & 4 & 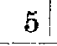 & 1 & & & 24 & 8 & 100 & 3 & 11 & 14 & 3 & 48 \\
\hline & & 3 & 0 & 7 & 0 & 4 & 0 & 1 & 1 & 3 & 20 & 0 & 47 & 0 & 27 & & & 39 \\
\hline $\mathrm{AlH}$ & & 6 & 3 & 9 & 1 & 1 & 2 & 1 & 25 & & 26 & 13 & 39 & 4 & 4 & & \pm & 61 \\
\hline & & 21 & 12 & 6 & 3 & 6 & 6 & 2 & 56 & & 38 & 21 & 11 & 5 & 11 & 11 & & 59 \\
\hline AIV & & 1 & 6 & 12 & 21 & 3 & 4 & -1 & 39 & 95 & 28 & 15 & 31 & 5 & 7 & 10 & 0 & 41 \\
\hline XV & & 10 & 7 & 9 & 4 & 4 & 4 & 1 & 39 & 78 & 26 & 18 & 23 & 10 & 10 & 10 & 3 & 50 \\
\hline & & 10 & 3 & 7 & 4 & 10 & 5 & 0 & & 10 & 26 & 8 & 18 & 10 & 26 & 13 & 0 & 50 \\
\hline & 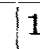 & 14 & 6 & 8 & 1 & 9 & 2 & 0 & 40 & 91 & 35 & 15 & 20 & 3 & 22 & $\bar{b}$ & 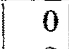 & 44 \\
\hline & & 16 & $6 !$ & 81 & 6 & 7 & 5 & 1 & 51 & & $|35|$ & 12 & $16 \%$ & 12 & 14 & 10 & 2 & 00 \\
\hline
\end{tabular}




\begin{tabular}{|c|c|c|c|c|c|c|c|c|c|c|c|c|c|c|c|c|c|c|}
\hline \multirow{2}{*}{\multicolumn{2}{|c|}{ Tier Nr. }} & \multicolumn{9}{|c|}{ Absolute Zahlen } & \multicolumn{8}{|c|}{ Verhältniszahlen } \\
\hline & & $a$ & & c & d & e & $f$ & $\mathrm{~g}$ & & & a & $\mathrm{b}$ & $\mathrm{c}$ & $d$ & e & $f$ & $\mathrm{~g}$ & 3 \\
\hline XVII & 1 & 5 & & $\begin{array}{r}7 \\
10\end{array}$ & $\begin{array}{l}0 \\
0\end{array}$ & $\begin{array}{l}2 \\
9\end{array}$ & & & $\begin{array}{l}30 \\
31\end{array}$ & 61 & {$\left[\begin{array}{l}20 \\
16\end{array}\right.$} & $\mid \begin{array}{r}10 \\
3\end{array}$ & $\begin{array}{l}23 \\
32\end{array}$ & $\begin{array}{l}0 \\
0\end{array}$ & $\left|\begin{array}{r}7 \\
29\end{array}\right|$ & $\left|\begin{array}{l}27 \\
13\end{array}\right|$ & $\begin{array}{r}13 \\
6\end{array}$ & 4 \\
\hline XVIII & $\begin{array}{l}\mathbf{r} \\
\mathbf{1}\end{array}$ & $\begin{array}{r}14 \\
8 \\
\end{array}$ & 1 & 12 & $\begin{array}{l}\mathbf{3} \\
\mathbf{1}\end{array}$ & $\begin{array}{l}10 \\
10 \\
\end{array}$ & 10 & & $\begin{array}{l}71 \\
37\end{array}$ & 108 & 2 & $\begin{array}{l}7 \\
3\end{array}$ & 39 & $\begin{array}{l}4 \\
3\end{array}$ & $\left|\begin{array}{l}14 \\
27\end{array}\right|$ & \begin{tabular}{|l|}
14 \\
11
\end{tabular} & $\left.\begin{array}{l}1 \\
3\end{array}\right]$ & 66 \\
\hline XIX & $\begin{array}{l}\mathbf{r} \\
1\end{array}$ & $\begin{array}{l}14 \\
15\end{array}$ & 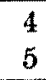 & 14 & $\begin{array}{l}1 \\
1\end{array}$ & \begin{tabular}{|r}
12 \\
4
\end{tabular} & 1 & & $\begin{array}{l}57 \\
49\end{array}$ & 106 & $\tilde{6}$ & $\left|\begin{array}{r}7 \\
10\end{array}\right|$ & $\left|\begin{array}{l}26 \\
29\end{array}\right|$ & $\begin{array}{l}2 \\
2\end{array}$ & $\begin{array}{r}21 \\
8\end{array}$ & $\left|\begin{array}{l}14 \\
14\end{array}\right|$ & $\begin{array}{l}5 \\
6\end{array}$ & $\tilde{0}$ \\
\hline $\mathrm{xx}$ & $\begin{array}{l}\mathbf{r} \\
\mathbf{l}\end{array}$ & $\begin{array}{l}16 \\
18 \\
\end{array}$ & $\begin{array}{r}5 \\
10 \\
\end{array}$ & $\begin{array}{l}27 \\
29 \\
\end{array}$ & $\begin{array}{l}5 \\
5 \\
\end{array}$ & $\begin{array}{l}10 \\
14 \\
\end{array}$ & 1. & 1 & $\begin{array}{l}75 \\
88 \\
\end{array}$ & 163 & $\begin{array}{l}21 \\
20 \\
\end{array}$ & $\begin{array}{r}7 \\
11 \\
\end{array}$ & $\left|\begin{array}{l}36 \\
33\end{array}\right|$ & $\begin{array}{l}7 \\
6 \\
\end{array}$ & $\left|\begin{array}{l}13 \\
16\end{array}\right|$ & $\left|\begin{array}{l}15 \\
11\end{array}\right|$ & $\begin{array}{l}1 \\
2\end{array}$ & \\
\hline $\mathrm{XXI}$ & $\begin{array}{l}\mathbf{r} \\
1\end{array}$ & $\begin{array}{l}24 \\
16\end{array}$ & $\begin{array}{r}13 \\
9 \\
\end{array}$ & & $\begin{array}{l}4 \\
5\end{array}$ & $\begin{array}{l}15 \\
10\end{array}$ & 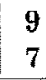 & u & $\begin{array}{l}97 \\
77\end{array}$ & 174 & $\tilde{5}$ & \begin{tabular}{|l|}
13 \\
12 \\
\end{tabular} & & $\begin{array}{l}4 \\
6\end{array}$ & $\left|\begin{array}{l}15 \\
13\end{array}\right|$ & $\begin{array}{l}9 \\
9\end{array}$ & $\begin{array}{l}5 \\
6\end{array}$ & \\
\hline $\mathrm{XXI}$ & $\begin{array}{l}\mathbf{r} \\
\mathbf{1}\end{array}$ & $\begin{array}{l}24 \\
11 \\
\end{array}$ & $\begin{array}{r}12 \\
9 \\
\end{array}$ & & $\begin{array}{l}2 \\
1 \\
\end{array}$ & $\begin{array}{l}13 \\
14 \\
\end{array}$ & 8 & 1 & $\begin{array}{l}94 \\
66 \\
\end{array}$ & 160 & $\begin{array}{l}26 \\
17 \\
\end{array}$ & $\begin{array}{r}13 \\
14 \\
\end{array}$ & & $\begin{array}{l}2 \\
2 \\
\end{array}$ & $\left|\begin{array}{l}14 \\
21\end{array}\right|$ & $\begin{array}{l}11 \\
11 \\
\end{array}$ & $\begin{array}{l}2 \\
2\end{array}$ & \\
\hline $\mathrm{X}$ & $\begin{array}{l}x \\
1\end{array}$ & $\begin{array}{l}29 \\
16 \\
\end{array}$ & $\begin{array}{l}12 \\
12 \\
\end{array}$ & & $\begin{array}{l}8 \\
3 \\
\end{array}$ & $\begin{array}{l}20 \\
25 \\
\end{array}$ & \begin{tabular}{|l}
22 \\
31 \\
\end{tabular} & $\begin{array}{l}3 \\
6 \\
\end{array}$ & $\begin{array}{l}133 \\
120 \\
\end{array}$ & 253 & $\begin{array}{l}22 \\
13 \\
\end{array}$ & \begin{tabular}{|r|}
9 \\
10 \\
\end{tabular} & & $\begin{array}{l}6 \\
3 \\
\end{array}$ & $\left|\begin{array}{l}15 \\
21\end{array}\right|$ & $\left|\begin{array}{l}17 \\
26\end{array}\right|$ & $\begin{array}{l}2 \\
\delta\end{array}$ & \\
\hline $\mathrm{X}$ & $\begin{array}{l}r \\
1\end{array}$ & $\begin{array}{l}23 \\
21 \\
\end{array}$ & & & $\begin{array}{l}3 \\
2 \\
\end{array}$ & $\begin{array}{l}16 \\
28 \\
\end{array}$ & $\begin{array}{l}19 \\
22 \\
\end{array}$ & $\begin{array}{l}3 \\
7 \\
\end{array}$ & & $22 \delta$ & $\begin{array}{l}22 \\
17 \\
\end{array}$ & $\begin{array}{r}13 \\
8 \\
\end{array}$ & $\left\lfloor\begin{array}{l}25 \\
26\end{array} \mid\right.$ & $\begin{array}{l}3 \\
2 \\
\end{array}$ & $\left|\begin{array}{l}16 \\
23\end{array}\right|$ & $\begin{array}{l}18 \\
17\end{array} \mid$ & $\begin{array}{l}3 \\
6 \\
\end{array}$ & \\
\hline $8 \mathrm{~V}$ & $\begin{array}{l}r \\
1\end{array}$ & 9 & & & $\begin{array}{l}0 \\
1 \\
\end{array}$ & $\begin{array}{l}8 \\
4 \\
\end{array}$ & 5 & & $\begin{array}{l}34 \\
40 \\
\end{array}$ & 74 & & $\begin{array}{l}3 \\
5 \\
\end{array}$ & & $\begin{array}{l}0 \\
2 \\
\end{array}$ & $\begin{array}{l}24 \\
10 \\
\end{array}$ & & $\begin{array}{l}9 \\
5\end{array}$ & \\
\hline & $\begin{array}{l}\mathbf{r} \\
\mathbf{l}\end{array}$ & $\begin{array}{l}25 \\
30 \\
\end{array}$ & 8 & & $\begin{array}{l}2 \\
3 \\
\end{array}$ & $\begin{array}{l}11 \\
18 \\
\end{array}$ & 10 & 4 & $\begin{array}{r}95 \\
107 \\
\end{array}$ & 202 & & $\begin{array}{l}8 \\
7 \\
\end{array}$ & & $\begin{array}{l}2 \\
3 \\
\end{array}$ & $\mid \begin{array}{l}12 \\
17\end{array}$ & & $\begin{array}{l}8 \\
4\end{array}$ & \\
\hline & $\begin{array}{l}r \\
1 \\
\end{array}$ & 38 & & & $\begin{array}{l}2 \\
3 \\
\end{array}$ & $\begin{array}{l}11 \\
14\end{array}$ & $I 2$ & $\begin{array}{l}9 \\
8\end{array}$ & $\begin{array}{r}83 \\
113 \\
\end{array}$ & 196 & $\begin{array}{l}29 \\
34 \\
\end{array}$ & $\begin{array}{l}8 \\
5\end{array}$ & & $\begin{array}{l}2 \\
3 \\
\end{array}$ & \begin{tabular}{|l|}
13 \\
12 \\
\end{tabular} & $\begin{array}{l}10 \\
11 \\
\end{array}$ & $\begin{array}{r}11 \\
7\end{array}$ & \\
\hline & $\begin{array}{l}\mathbf{r} \\
\mathbf{I}\end{array}$ & 1 & 8 & & $\begin{array}{l}0 \\
0 \\
\end{array}$ & $\begin{array}{r}11 \\
8\end{array}$ & $\begin{array}{r}7 \\
12 \\
\end{array}$ & $\begin{array}{r}7 \\
15 \\
\end{array}$ & $\begin{array}{l}57 \\
86 \\
\end{array}$ & 13 & $\begin{array}{l}26 \\
21\end{array}$ & $\begin{array}{l}7 \\
9 \\
\end{array}$ & & $\begin{array}{l}0 \\
0\end{array}$ & $\begin{array}{r}19 \\
9\end{array}$ & \begin{tabular}{|l|}
12 \\
14
\end{tabular} \mid & $\begin{array}{l}12 \\
17\end{array}$ & \\
\hline & $\begin{array}{l}\mathrm{r} \\
\mathrm{l}\end{array}$ & 6 & 4 & 0 & 0 & $\begin{array}{l}3 \\
1\end{array}$ & 1 & & $\begin{array}{l}34 \\
24 \\
\end{array}$ & 58 & $\begin{array}{l}38 \\
25\end{array}$ & $\begin{array}{r}12 \\
4 \\
\end{array}$ & & $\begin{array}{l}0 \\
0\end{array}$ & \begin{tabular}{l|}
9 \\
4
\end{tabular} & $\begin{array}{r}3 \\
12\end{array}$ & $\left|\begin{array}{l}21 \\
21\end{array}\right|$ & \\
\hline & $\begin{array}{l}\mathbf{r} \\
\mathbf{l}\end{array}$ & $\begin{array}{l}27 \\
26\end{array}$ & $\begin{array}{l}10 \\
12 \\
\end{array}$ & 13 & $\begin{array}{l}6 \\
3\end{array}$ & $\begin{array}{l}21 \\
25 \\
\end{array}$ & & & $\begin{array}{l}119 \\
139\end{array}$ & 58 & $\begin{array}{l}23 \\
19 \\
\end{array}$ & $\begin{array}{l}8 \\
9\end{array}$ & & $\begin{array}{l}5 \\
2\end{array}$ & $\left|\begin{array}{l}18 \\
18\end{array}\right|$ & \begin{tabular}{l|l|}
11 \\
13
\end{tabular} \mid & 6 & \\
\hline & $\begin{array}{l}\mathrm{r} \\
1\end{array}$ & 7 & 3 & 8 & $\begin{array}{l}1 \\
0\end{array}$ & $\begin{array}{l}6 \\
6\end{array}$ & 7 & & $\begin{array}{l}30 \\
32\end{array}$ & 62 & & $\begin{array}{l}3 \\
9\end{array}$ & & $\begin{array}{l}3 \\
0\end{array}$ & $\left|\begin{array}{l}20 \\
19\end{array}\right|$ & $\mid \begin{array}{r}7 \\
12\end{array}$ & $\left|\begin{array}{r}3 \\
12\end{array}\right|$ & \\
\hline & $\begin{array}{l}\mathbf{r} \\
1\end{array}$ & $\begin{array}{r}4 \\
10\end{array}$ & 7 & $\begin{array}{l}15 \\
10\end{array}$ & $\begin{array}{l}0 \\
1\end{array}$ & \begin{tabular}{|r}
10 \\
5
\end{tabular} & 3 & & $\begin{array}{l}46 \\
38\end{array}$ & 81 & $\begin{array}{r}9 \\
26\end{array}$ & \begin{tabular}{|l|}
13 \\
18
\end{tabular} & & $\begin{array}{l}0 \\
3\end{array}$ & $\left|\begin{array}{l}22 \\
13\end{array}\right|$ & $\begin{array}{r}13 \\
8\end{array}$ & \begin{tabular}{|r|}
11 \\
5
\end{tabular} & 55 \\
\hline & $\begin{array}{l}\mathbf{r} \\
1\end{array}$ & $\begin{array}{l}44 \\
40 \\
\end{array}$ & $\begin{array}{r}12 \\
8 \\
\end{array}$ & $\begin{array}{l}20 \\
28 \\
\end{array}$ & $\begin{array}{l}1 \\
4\end{array}$ & $\begin{array}{l}15 \\
16 \\
\end{array}$ & $\begin{array}{l}4 \\
8\end{array}$ & $\begin{array}{l}8 \\
6 \\
\end{array}$ & $\begin{array}{l}114 \\
110 \\
\end{array}$ & 24 & $\begin{array}{l}39 \\
36 \\
\end{array}$ & $\begin{array}{r}11 \\
7 \\
\end{array}$ & $\left|\begin{array}{l}18 \\
25\end{array}\right|$ & $\begin{array}{l}1 \\
4\end{array}$ & $\left|\begin{array}{l}13 \\
15\end{array}\right|$ & $\begin{array}{r}12 \\
7 \\
\end{array}$ & \begin{tabular}{l|}
7 \\
5
\end{tabular} & \\
\hline & $\begin{array}{l}\mathbf{r} \\
1\end{array}$ & $\begin{array}{l}29 \\
15\end{array}$ & $\begin{array}{r}10 \\
4\end{array}$ & $\begin{array}{l}19 \\
15 \\
\end{array}$ & $\begin{array}{l}2 \\
2\end{array}$ & \begin{tabular}{|r}
15 \\
7 \\
\end{tabular} & 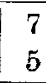 & 5 & $\begin{array}{l}87 \\
50\end{array}$ & 37 & $\begin{array}{l}33 \\
30\end{array}$ & $\begin{array}{r}11 \\
8\end{array}$ & $\begin{array}{l}22 \\
30\end{array}$ & $\begin{array}{l}2 \\
4\end{array}$ & $\left|\begin{array}{l}17 \\
14\end{array}\right|$ & $\mid \begin{array}{r}8 \\
10\end{array}$ & $\begin{array}{l}6 \\
4\end{array}$ & $\begin{array}{l}64 \\
36\end{array}$ \\
\hline $\mathrm{XXXV}$ & $\begin{array}{l}\mathbf{r} \\
\mathrm{l}\end{array}$ & $\begin{array}{l}49 \\
30\end{array}$ & $\begin{array}{l}10 \\
15\end{array}$ & $\begin{array}{l}24 \\
38 \\
\end{array}$ & $\begin{array}{l}3 \\
3\end{array}$ & $\begin{array}{r}7 \\
15 \\
\end{array}$ & 0 & $\begin{array}{l}15 \\
13\end{array}$ & $\begin{array}{l}116 \\
119\end{array}$ & 235 & $\begin{array}{l}42 \\
25\end{array}$ & \begin{tabular}{|r|}
9 \\
13 \\
\end{tabular} & \begin{tabular}{l|}
21 \\
32
\end{tabular} & $\begin{array}{l}3 \\
3\end{array}$ & $\mid \begin{array}{r}6 \\
13\end{array}$ & \begin{tabular}{l|}
7 \\
4
\end{tabular} & $12 !$ & $\begin{array}{l}44 \\
5\end{array}$ \\
\hline & $\mathrm{r}$ & $\begin{array}{l}60 \\
61\end{array}$ & $\begin{array}{l}10 \\
13\end{array}$ & $\mid \begin{array}{l}24 \\
50\end{array}$ & $\begin{array}{l}3 \\
3\end{array}$ & $\mid \begin{array}{l}23 \\
24\end{array}$ & $\begin{array}{l}9 \\
9\end{array}$ & $\mid \begin{array}{l}14 \\
21\end{array}$ & $\begin{array}{l}143 \\
191\end{array}$ & 334 & $\begin{array}{l}42 \\
32\end{array}$ & $\begin{array}{l}7 \\
7\end{array}$ & & $\begin{array}{l}2 \\
2\end{array}$ & $\left|\begin{array}{l}16 \\
13\end{array}\right|$ & $\left|\begin{array}{r}6 \\
10\end{array}\right|$ & $\mid \begin{array}{l}10 \\
11\end{array}$ & 4 \\
\hline
\end{tabular}




\begin{tabular}{|c|c|c|c|c|c|c|c|c|c|c|c|c|c|c|c|c|c|}
\hline \multirow[b]{2}{*}{ Tier Nr. } & \multicolumn{9}{|c|}{ Absolute Zahlen } & \multicolumn{8}{|c|}{ Yerhältniszahlen } \\
\hline & $a$ & $\mathrm{~b}$ & c & $d$ & e & f & $\mathrm{g}$ & $\mathrm{Im}-1$ & $\begin{array}{l}\text { Sum- } \\
\text { me II }\end{array}$ & a & b & c & $d$ & e & $\mathbf{f}$ & $\mathrm{g}$ & 2 \\
\hline $\begin{array}{l}\mathbf{r} \\
1\end{array}$ & $\begin{array}{l}58 \\
38\end{array}$ & $\begin{array}{l}4 \\
8\end{array}$ & \begin{tabular}{|l|}
22 \\
33 \\
\end{tabular} & $\begin{array}{l}1 \\
2\end{array}$ & $\begin{array}{r}14 \\
8 \\
\end{array}$ & $\begin{array}{l}21 \\
17\end{array}$ & $\begin{array}{l}24 \\
20\end{array}$ & $\begin{array}{l}144 \\
126 \\
\end{array}$ & 270 & $\begin{array}{l}40 \\
30\end{array}$ & $\begin{array}{l}3 \\
6 \\
\end{array}$ & $\begin{array}{l}15 \\
26\end{array}$ & $\begin{array}{l}\overline{1} \\
2\end{array}$ & $\begin{array}{r}10 \\
6\end{array}$ & $\left|\begin{array}{l}15 \\
14\end{array}\right|$ & $\left|\begin{array}{l}17 \\
16\end{array}\right|$ & $\begin{array}{l}53 \\
47 \\
\end{array}$ \\
\hline $\begin{array}{l}\mathrm{r} \\
1\end{array}$ & $\begin{array}{l}50 \\
51\end{array}$ & $\begin{array}{l}9 \\
9\end{array}$ & $\mid \begin{array}{l}30 \\
23\end{array}$ & $\begin{array}{l}3 \\
4\end{array}$ & $\begin{array}{l}14 \\
12\end{array}$ & $\begin{array}{l}16 \\
15\end{array}$ & $\begin{array}{l}24 \\
28\end{array}$ & $\begin{array}{l}146 \\
142\end{array}$ & 288 & $\begin{array}{l}34 \\
36\end{array}$ & $\begin{array}{l}6 \\
6\end{array}$ & $\mid \begin{array}{l}21 \\
16\end{array}$ & $\begin{array}{l}2 \\
3\end{array}$ & $\begin{array}{r}10 \\
8\end{array}$ & $\left|\begin{array}{l}11 \\
11\end{array}\right|$ & $\left|\begin{array}{l}16 \\
20\end{array}\right|$ & 49 \\
\hline $\begin{array}{r}r \\
1\end{array}$ & $\begin{array}{l}42 \\
37 \\
\end{array}$ & $\begin{array}{l}4 \\
8 \\
\end{array}$ & $\begin{array}{l}22 \\
31\end{array}$ & $\begin{array}{l}0 \\
0\end{array}$ & $\begin{array}{r}19 \\
9 \\
\end{array}$ & $\begin{array}{l}17 \\
20\end{array}$ & $\begin{array}{l}24 \\
14 \\
\end{array}$ & $\begin{array}{l}128 \\
119 \\
\end{array}$ & 247 & $\begin{array}{l}33 \\
31\end{array}$ & $\begin{array}{l}3 \\
7 \\
\end{array}$ & $\begin{array}{l}17 \\
26 \\
\end{array}$ & $\begin{array}{l}0 \\
0\end{array}$ & $\begin{array}{r}15 \\
8 \\
\end{array}$ & $\begin{array}{l}13 \\
17 \\
\end{array}$ & 19 & $\begin{array}{l}52 \\
48 \\
\end{array}$ \\
\hline $\mathrm{XL} \frac{\mathrm{r}}{1}$ & $\begin{array}{l}47 \\
49\end{array}$ & $\begin{array}{l}8 \\
5\end{array}$ & $\begin{array}{l}32 \\
24\end{array}$ & \begin{tabular}{l|l}
0 & \\
1
\end{tabular} & $\begin{array}{l}18 \\
31\end{array}$ & $\begin{array}{l}13 \\
15\end{array}$ & $\begin{array}{l}20 \\
19\end{array}$ & $\begin{array}{l}138 \\
144\end{array}$ & 282 & $\begin{array}{l}34 \\
34\end{array}$ & \begin{tabular}{l|}
6 \\
3
\end{tabular} & $\begin{array}{l}23 \\
17\end{array}$ & $\begin{array}{l}0 \\
1\end{array}$ & $\begin{array}{l}13 \\
21\end{array}$ & \begin{tabular}{r|}
9 \\
10
\end{tabular} & $\begin{array}{c}14 \\
13\end{array}$ & $\begin{array}{l}49 \\
51 .\end{array}$ \\
\hline XUr ${ }_{1}^{\mathbf{r}}$ & $\begin{array}{l}65 \\
61\end{array}$ & $\begin{array}{l}13 \\
19\end{array}$ & $\begin{array}{l}39 \\
46\end{array}$ & $\begin{array}{l}4 \\
0\end{array}$ & $\begin{array}{l}29 \\
23\end{array}$ & $\begin{array}{l}26 \\
27\end{array}$ & $\begin{array}{l}25 \\
29\end{array}$ & 201 & 406 & $\begin{array}{l}32 \\
30\end{array}$ & \begin{tabular}{|l|}
6 \\
9
\end{tabular} & $\begin{array}{l}19 \\
22\end{array}$ & $\begin{array}{l}2 \\
0\end{array}$ & $\begin{array}{l}14 \\
11\end{array}$ & \begin{tabular}{|l|}
13 \\
13
\end{tabular} & $\begin{array}{l}12 \\
14\end{array}$ & $\begin{array}{l}50 \\
50\end{array}$ \\
\hline
\end{tabular}

Erklärung wie bei Tabelle III. In dieser Versuchsserie war bei der Präparation auf die Zugehörigkeit der einzelnen Cornea zur Körperseite geachtet worden, so daß die Querkolonnen bei jedem Tiere als $r=$ rechts und $1=$ links bezeichnet werden konnten.

Schon die erste Versuchsreihe ("Syn. I ) zeigt in klarer Weise den Einfluß der Ernährungsbedingungen auf die Zellteilungstätigkeit. Die graphische Darstellung (Abb. 1) ergibt, daß die gleich nach der Geburt einsetzende Fütterung eine allmähliche Zunahme der Mitosenzahl veranlaßt. Während aber bis zum 10. XII. offenbar diese erste Fütterung noch in allen drei Gruppen in ähnlicher Weise nachwirkt und die Mitosenzahl auf etwa 60-90 steigen läßt, beginnt um diese Zeit die verschiedenartige Fütterung der einzelnen Gruppen sich in Untersehieden der Zellteilungstätigkeit zu äußern. Durch die gleichmäßige Fütterung der Kontrollgruppe wird am 14. XII. bei Tier Nr. 18 die hohe Zahl von 235 Mitosen erreicht; es dürfte hier also eine weitere kontinuierliohe allmähliche Zunahme der Mitosenzahlen vorgelegen sein. Der 3 tägige Hunger in der Gruppe II bedingt ein kurze Zeit dauerndes Zurückgehen der Mitosenzahl: Tier Nr. 11 zeigt am 11. XII. 107 Mitosen, Tier Nr. 13 am 12. XII. dagegen nur 78 Mitosen und erst am 13. XII. finden wir bei Nr. 15137 , am 14. bei Tier Nr. 17166 Mitosen. Die Kurve steigt also gegen die der 3. Gruppe etwas verspätet an und erreicht mit Nr. 23 am 18. XII. die hohe Zahl 226. Noch deutlicher sind die Verhältnisse in der 1. Gruppe. Hier sinkt die Mitosenzahl von der am 10. XII. bei Nr. 7 gefundenen Zahl 90 am 11. XII. bei Tier Nr. 10 auf 43 und bleibt bis zum 15. XII. niedrig: Tier Nr. 12 besitzt am 12. XII. 74 Mitosen, Nr. 14 am 13. XII. 54, Nr. 16 am 14. nur 40 Mitosen und erst am 15. XII. zeigt Nr. 19 mit 83 Mitosen die neuerlich einsetzende regere Teilungstätigkeit als Folge der am 11. 
wieder begonnenen Fütterung. Es folgt ein weiteres Ansteigen der Mitosenzahl: am 16. zeigt Tier Nr. 20 117, am 17. Tier Nr. 21 in der einen Cornea 88 Mitosen (die andere Cornea dieses Tieres ging bei der Präparation verloren), so daß man hier in beiden Corneae zusammen eine Zahl zwischen 160 und 190 annehmen dürfte. Leider waren in dieser Versuchsreihe von den folgenden Tagen nur mehr am 18. XII. noch 3 Tiere konserviert worden, so daß einige Fragen offen blieben. Ich konnte nicht entscheiden, ob das letzte Absinken der Mitosenzahl in der 1. Gruppe von Tier Nr. 21 zu Tier $\mathrm{Nr} .22$ und das beträchtliche $\mathrm{Ab}$. sinken von Tier Nr. 18 zu Nr. 24 in der 3. Gruppe auf einem zufälligen Abweichen der betreffenden Einzeltiere beruhte oder ob die gleichmäßige Weiterfütterung nach dem starken Ansteigen gesetzmäßig wieder zu einer wesent-

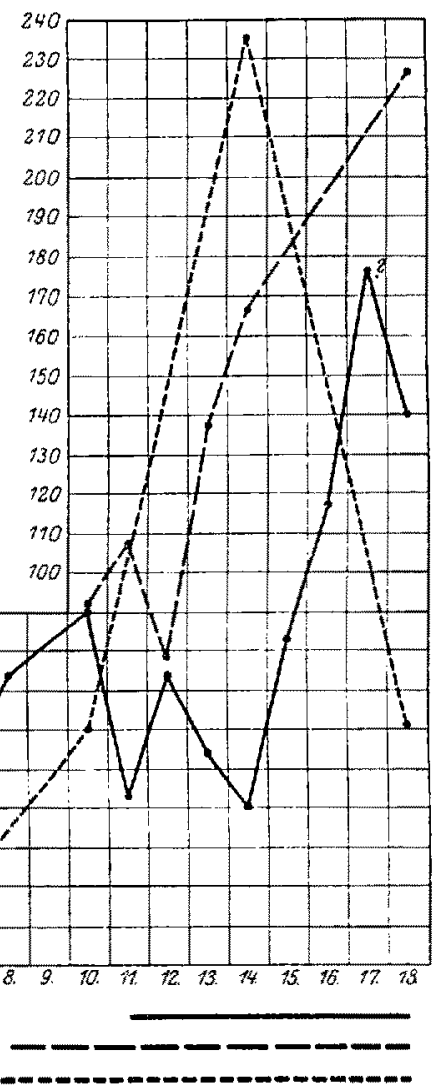

Abb. 1. Serie Syn. I. Abhängigkeit der Mritosenzahl (Summe aus beiden Corneae) von der Futterung.

lichen Abnahme der Mitosenzahl führt. Die Versuchsanordnung war eben von der Voraussetzung ausgegangen, daß die oben angeführten Angaben Häckers richtig seien, daß also das Maximum der Zellteilungen etwa 4 Tage nach der neu begonnenen starken Fütterung erreicht werde. Der Versuch selbst aber hat eine viel langsamere Finwirkung der Ernährung ergeben. Die höchste beobachtete Mitosenzahl war in der 1. Gruppe 14 Tage, in der 2. 10 Tage und in der 3. 6 Tage nach 
der Auffütterung erreicht worden. Je länger die einer starken Auffütterung vorausgehende Hungerperiode bei extrauteriner Lebensweise davert, um so schneller scheint ein Maximum der Zellteilungen erreicht $z u$ werden. Es wäre daher auch denkbar, daß man bei noch stärkerer Hungereinwirkung die Schnelligkeit der Anregung der Zellteilungstätigkeit bis zu jenem Ausmaße steigern könnte, das nach Häcker anzunehmen war. In meinen Versuchen dagegen wurde am 4.-5. Tage nach dem Wiedereinsetzen der Fütterung erst der eben merkbare Beginn eines Ansteigens der Mitosenzahl beobachtet. Die Hungerwirkung äußerte sich in einem Sinken der Mitosenzahl am 7.-8. Tage nach der letzten Fütterung.

Um die Richtigkeit der so gewonnenen Resultate zu erhärten und um einige noch - ungeklärte Fragen beantworten zu können, war im Herbst 1920 die neue Versuchsreihe Syn. IV aufgestellt worden. Die oben (S. 550) bereits besprochene Versuchsanordnung ermöglichte hier eine Untersuchung der Frage nach der Häufigkeit der Mitosen in den ersten Tagen nach der Utérusentnahme ohne Beeinflussung durch Fütterung. Ferner wurden in dieser Serie von dem Tage an, an welchem die beiden Gruppen in bezug auf Fütterung verschieden behandelt wurden, täglich aus jeder Gruppe ein Tier, an den Tagen, an denen ich besonders zahlreiche Mitosen erwartete, täglich zwei Tiere konserviert. Ich habe daher hier einer Irreführung durch zufällige individuelle Verschiedenheiten mit völliger Sicherheit vorgebeugt. Tatsächlich zeigen auch die in Abbildung 2 in graphischer Darstellung wiedergegebenen Resultate (s. auch Tabelle IV) durchaus eindeutige Verhältnisse. Interessant ist die Tatsache, daß es nach der Uterus. entnahme zu einer leichten Zunahme der Mitosenzahl kam, trotz der in dieser Versuchsreihe eingeführten Hungerperiode in den ersten Tagen des extrauterinen Lebens. Ein Vergleich mit den Ergebnissen der I. Versuchsreihe legt sogar den Gedanken nahe, daß diese Hungerperiode nicht nur nicht hemmend, sondern anfänglich sogar geradezu fördernd auf die Zellteilungstätigkeit wirkte. Im AnschluB an den durch das freie Wasserleben gesetzten, durch den Hunger eventuell verstärkten Reiz steigt die Mitosenzahl in den beiden Corneaepithelien von 10 im Laufe der ersten 3-4 Tage auf 40 und 41. Die Zahl von etwa 10 Mitosen ( 11 bei Tier Nr. 1 der I. Versuchsreihe, 10 bei Nr. 1 dieser II. Versuchsreihe) könnte einem in diesem Stadium des uterinen Lebens anzutreffenden äußerst langsamen Zellvermehrungsproze $B$ entsprechen. Der Reiz des extrauterinen Lebens bewirkt eine beschleunigte Verwertung der vorhandenen Zellteilungsmöglichkeiten. Daß diese anfängliche Steigerung der Mitosenzahl durch die 4 Hungertage schnell sistierte, ist leicht damit zu erklären, daß die für die Teilungstätigkeit not- 
wendige Reserve von Assimilaten nach diesem Zeitraume aufgebraucht war. Am 5. Tage des extrauterinen Hungerlebens sinkt die Mitosenzahl von 41 auf 18 , einen Tag darauf finden sich nur 6, am nächsten Tage wieder 18 Mitosen, und zwar zufallig sowohl bei einem Tiere der ersten Gruppe, die nun kontinuierlich weitergefüttert wird, als auch bei einem Tiere der zweiten Gruppe, die an diesem Tage zum ersten Male wieder keine Nahrung erhält, genau die gleiche Zahl. Am nächsten Tage finden wir bei einem Tiere der weiter gefütterten Gruppe wieder nur 4 Mitosen; dagegen ist bei einem Tiere aus der seit dem vorigen Tage neuerlich hungernden Gruppe die Zahl der Mitosen schon wieder auf 40 angestiegen. Dafür wäre vielleicht folgende Erklärung denkbar: In beiden Gruppen hat die am 10.X. begonnene Fütterung wieder eine gewisse Zellteilungsfähigkeit her-

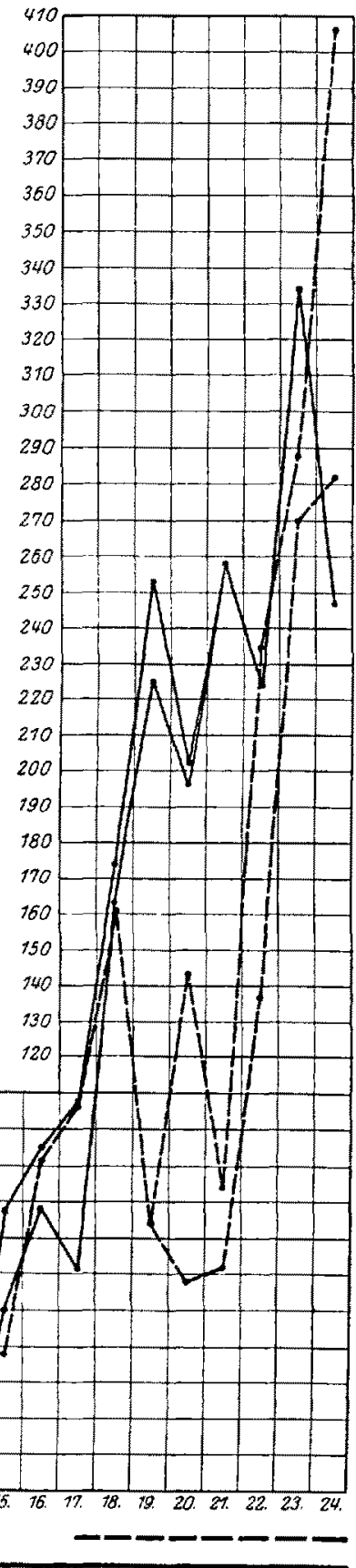

Abb. 2. Serie Syn, IV. Abhängigkeit der Mitosenzahl (Summe nus beiden Corneae) von der fiutterung. 
vorgebracht. Bei dem Tiere aus der weiter gefütterten Serie wurde diese Teilungsfähigkeit am 14. X., also am 4. Tage nach der ersten Fütterung noch nicht beansprucht, während in der anderen Gruppe vielleicht gerade der am 13. X. neuerlich einsetzende Hunger bei dem Tier Nr. 10 schon am nächsten Tage die durch die vorangegangene 3 tägige Fütterung erworbene Teilungsfähigkeit offenbar werden läßt. Am folgenden Tage bricht dann die durch die Fütterung bewirkte Teilungsbereitschaft auch in der weiter gefütterten Gruppe durch und wir sehen nun als Folge der am 10. $\mathrm{X}$. begonnenen Fütterung ein regelmäBiges Ansteigen in beiden Gruppen bis zum 18, X. An diesem Tage zeigte das Tier Nr. 20 aus der ersten, gleichmäßig weiter gefütterten Gruppe 163 Mitosen, das derselben Gruppe entnommene Vergleichstier Nr. 2I 174 Mitosen, das Tier Nr. 22 aus der 2. Gruppe, in der vom 13. X. bis zum 16. X. nicht gefüttert worden war, $160 \mathrm{Mi}$ tosen. Am nächsten Tage aber zeigt sich bereits eine Verschiedenheit. Bei den ohne Unterbrechung gefütterten Tieren steigt die Zellteilungstätigkeit noch weiter an; Nr. 23 zeigt 253 Mitosen, Nr. 24: 225. Dagegen hat in der anderen Gruppe die eingeschobene 4 tägige Hungerperiode jetzt, 6 Tage nach dem ersten Hungertage, eine Abnahme der Mitosen bewirkt: wir finden bei Tier Nr. 25 nur 74 Mitosen. Der gleiche Unterschied bleibt auch an den 2 folgenden Tagen bestehen. Am 20.X. zeigt ein Vertreter der ersten Gruppe 202, ein anderer 196 Mitosen. Dagegen zeigt aus der 2. Gruppe ein Tier 143, ein anderes sogar nur 58 Mitosen. Am 21. X. finden wir bei einem Tiere der ersten Gruppe 258 Mitosen, bei einem Tiere aus der 2. Gruppe 84, bei einem anderen nur 62 Mitosen. Noch einen Tag später beginnt in der 2. Gruppe ein jähes Ansteigen der Zellteilungen als Folge der 5 Tage vorher, am 17. X., wieder begonnenen Fütterung. Ein Tier der 2. Gruppe zeigt 137 Mitosen, ein anderes sogar schon 235! Mit dieser Zahl ist mit einem Sprunge das Niveau der ersten Gruppe erreicht, deren Vertreter an diesem Tage 224 Mitosen besitzt. Am nächsten Tage finden wir schon die Mitosenzahlen beider Vertreter der 2. Gruppe ungefähr in der gleichen Größenordnung, wie die der ersten Gruppe. Ein Tier aus der ersten Gruppe zeigt 334 Mitosen, ein Tier aus der 2. Gruppe 270, ein anderes 288. Am folgenden Tage, dem letzten dieser Versuchsreihe, zeigt der Vertreter der ersten Gruppe 248 Mitosen, der eine Vertreter der 2. Gruppe 282, der andere nicht weniger als 406 Mitosen! Dies war auch die höchste Zahl von Mitosen, die ich bei. meinen Versuchen bei einer Larve in den beiderseitigen Corneaepithelien feststellen konnte.

Außer einer Klärung der bereits beschriebenen Verhältnisse gleich nach der Uterusentnahme brachte diese zweite Versuchsreihe (Syn. IV) die Bestätigung der in der ersten Versuchsreihe gefundenen Tatsache, 
daß das Maximum der die Zellteilungen befördernden Wirkung einer starken Auffütterung bei dem verwendeten Larvenstadium frühestens 6-7 Tage nach Beginn der Fütterung zu erwarten ist. Ferner wurde es wahrscheinlich, daß Hunger anfänglich bei vorhandener Teilungsfähigkeit ein sehr schnelles, aber nur kurze Zeit hindurch andauerndes Steigen der Mitosenzahl bewirkt. Es kommt gewissermaßen zu einer schnelleren, mehr zusammengedrängten Ausnutzung der sonst in einem längeren Zeitraum gleichmäßig sich äußernden Teilungsbereitschaft. 4-6 Tage nach dem Einsetzen des Hungers ist aber durch die verminderte Assimilationsmöglichkeit die Teilungsfähigkeit soweit erschöpft oder doch herabgesetzt, daß die Mitosenzahl zu sinken beginnt. Die teilungs -

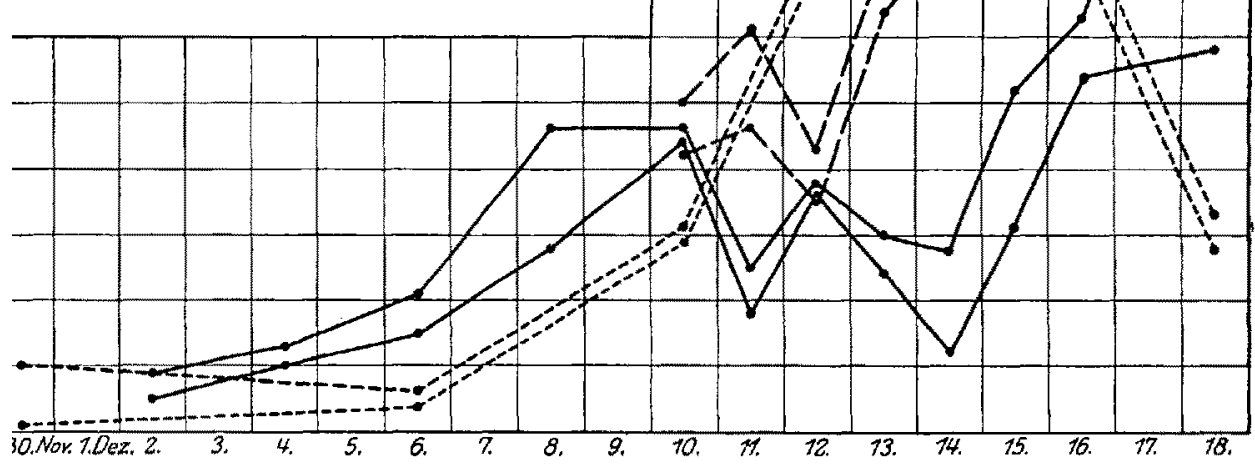

1.Gruope

2. Grupge

3. Grupge

Abb. 3. Serie Syn, I. Vergleich der absoluten Mengen von Kernteilungsfiguren in den beiderseitigen Cornenepithelien.

fördernde Wirkung der Auffütterung nach einer Hungerperiode hält bei den untersuchten Larven wenigstens $5-7$ Tage an. Bei Beachtung der Erfahrungen der zweiten Versuchsserie wird unsere Aufmerksamkeit dann auch auf eine Einzelheit aus den Ergebnissen der ersten Serie gelenkt. Die Vertreter der I. und II. Gruppe weisen dort in der Zeit vom 4. bis zum 10. XII. eine etwas höhere Mitosenzahl auf, als die Vertreter der III. Gruppe. Vielleicht hat auch hier die Hungerperiode der durch die anfängliche Fütterung bedingten 
Teilungsfähigkeit $z u$ einem früheren und auf kürzere Zeit zusammengedrängten Durchbruch verholfen.

Ich komme nun zu der Besprechung der Hauptfrage der vorliegenden Arbeit. $\mathrm{Um}$ die $\mathrm{Be}-$ ziehungen $\mathrm{zwischen}$ den Zellteilungsrhythmen in den beiderseitigen Corneaepithelien je eines Tieres klar zu stellen, mußten zunächst die Gesamtzablen der Mitosen in der rechten und in der linken Cornea eines Tieres miteinander verglichen werden. Dies ermöglichen in übersichtlicher Weise die Kurven Abb. 3 and Abb. 4. Diese entsprechen der Darstellung in $A b b .1$ und $A b b .2$ derart, daB an Stelle je einer Linie dieser $\mathrm{Ab}$ bildungen hier immer ein Paar von Linien zu sehen ist. Die eine Linie eines Paares verbindet die absoluten Mitosenzahlen jener Cornea-

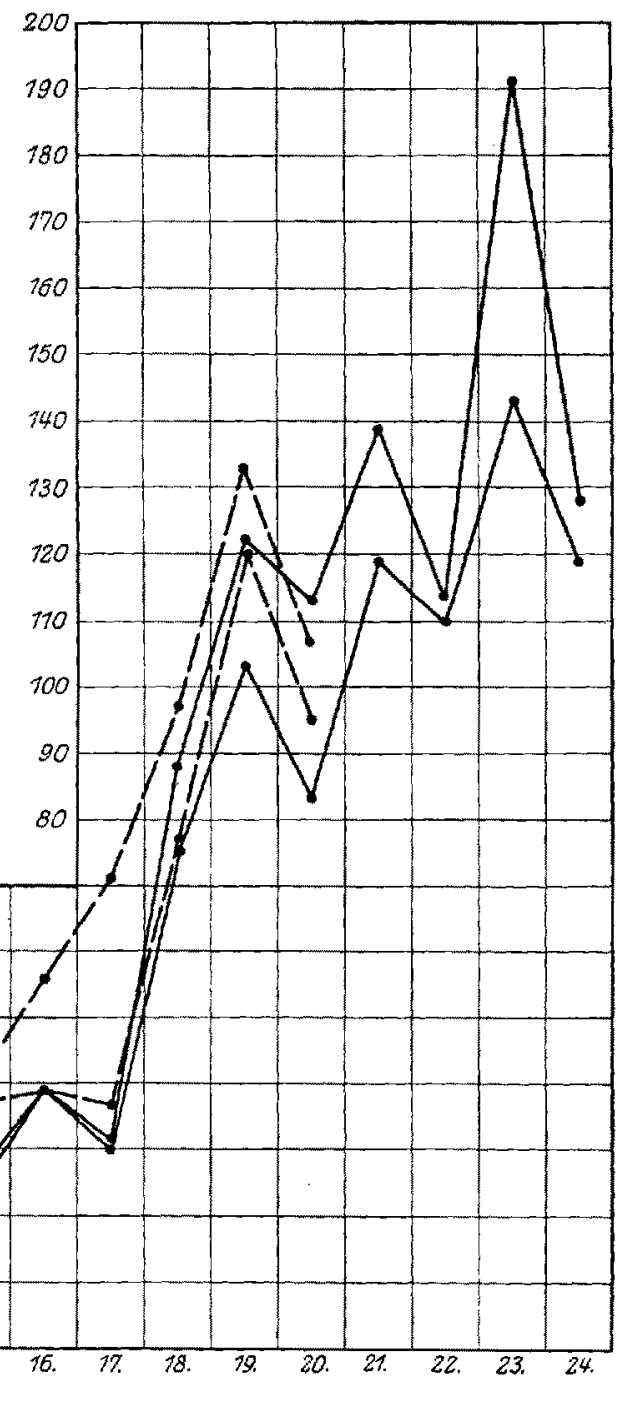

Futter:

Abb. 4a. Serie Syn. IV, 1. Gruppe. Vergleich der absoluten Mengen von Kerntellungstguren in den betderseitigen Comenepithelien.

epithelien der einzelnen Tiere, in welchen die größere Zahl von Mitosen, die andere jener, in welcher die kleinere Zahl von Mitosen gefunden wurde, ohne Rücksicht darauf, welches die rechte und welches die linke Cornea war. Wir sehen, wie sich die in Abb. 1 und Abb. 2 
sichtbaren Schwankungen der Mitosenzahlen aus den in weitgehendem Maße parallel verlaufenden Verschiebungen der nach den Körperseiten getrennten Mitosenzahlen zusammensetzen. In den meisten Fällen ist die Zahl der Mitosen in den beiden Corneaepithelien je eines Tieres eine sehr ähnliche. Bedenken wir die großen Differenzen in den absoluten Mitosenzahlen zwischen verschiedenen Tieren und bedenken wir ferner, daß die in Mitose befindlichen Zellen stets nur einen kleinen Teil der Gesamtheit aller Corneaepithelzellen ausmachen, dann erscheint die weitgehende Utbereinstimmung der beiderseitigen Corneaepithelien in bezug auf die absoluten Mitosenzahlen recht beachtenswert. Es wird durch sie bewiesen, daß die durch die Ernährungsbedingungen geregelte Zell teilungs. tätigkeit in gleichwertigen Zellkomplexen der beiden Körperseiten im

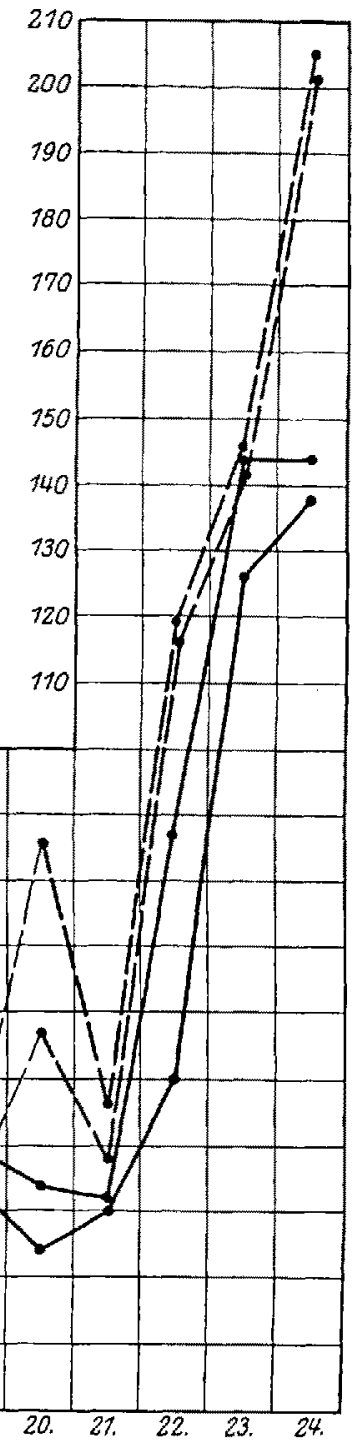

Futter:

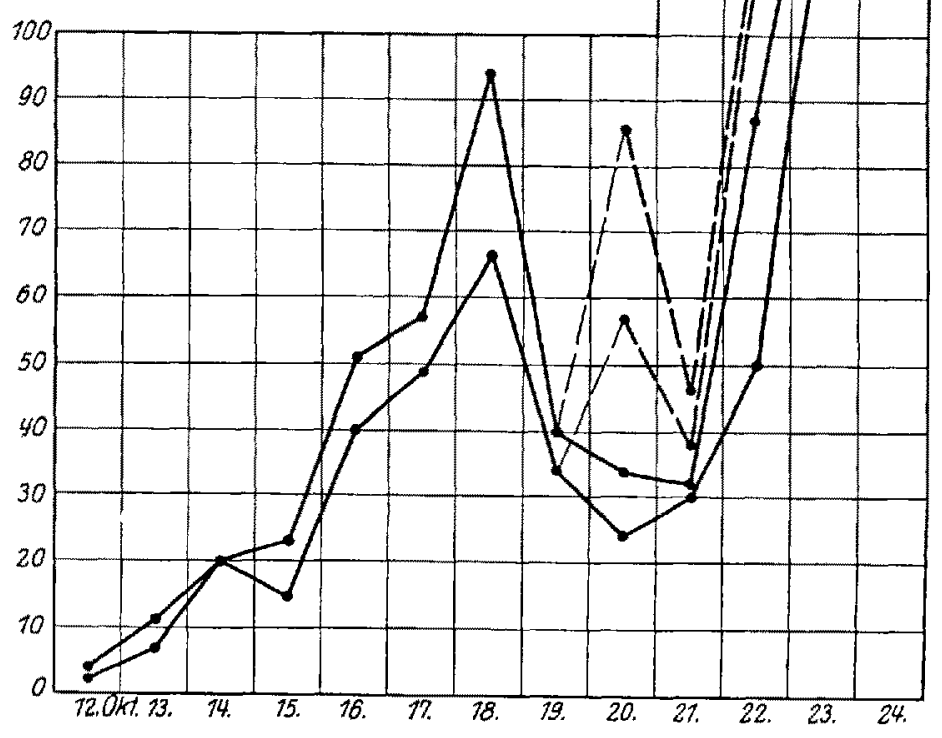

Abb. 40 . Serie Syn. IV, 2. Gruppe, wie Abb. $4 a$.

allgemeinen genau parallel geht. Es erhob sich nun die Frage, ob diese Übereinstimmung des Zellteilungsrhythmus sich auch noch auf die einzelnen Phasen der Zellteilung erstreckt. Zur Be- 
Tabelle V.

Vergleioh des prozentualen Anteils der mitotischen Endphasen $e+f+g$ an der Gesamtsumme derMitosen in den beiden Corneaepithelien jo eines Tieres. Serie Syn. I.

\begin{tabular}{|c|c|c|}
\hline Tier Nr. & Comea $\alpha$ & Cornea $\beta$ \\
\hline 1 & 100 & 20 \\
\hline 2 & 33 & 60 \\
\hline 3 & $5 \check{~}$ & 60 \\
\hline 4 & 27 & 15 \\
\hline 5 & 0 & 25 \\
\hline 6 & 31 & 36 \\
\hline 7 & 54 & 29 \\
\hline 8 & 29 & 30 \\
\hline 9 & 41 & 42 \\
\hline 10 & 28 & 34 \\
\hline 11 & 54 & 49 \\
\hline 12 & 44 & 39 \\
\hline 13 & 37 & 40 \\
\hline 14 & 58 & 37 \\
\hline 15 & 31 & 28 \\
\hline 16 & 25 & 22 \\
\hline 17 & 45 & 40 \\
\hline 18 & 33 & 34 \\
\hline 19 & 51 & 46 \\
\hline 20 & 28 & 37 \\
\hline 21 & 26 & - \\
\hline 22 & 24 & 31 \\
\hline 23 & 36 & 30 \\
\hline 24 & 33 & 43 \\
\hline
\end{tabular}

Tabelle VI.

Vergleich des prozentualen Anteils der mitotischen Endphasen $e+f+g$ an der Gesamtsumme der Mitosen in dem rechten und linken Corneaepithel je eines Tieres. Serie Syn. IV.

\begin{tabular}{|c|c|c|}
\hline Tier Nr. & Rechte Cornea & Linke Cornea \\
\hline 1 & 25 & 17 \\
\hline 2 & 31 & 14 \\
\hline 3 & 46 & 39 \\
\hline 4 & 12 & 38 \\
\hline 5 & 20 & 37 \\
\hline 6 & 100 & 75 \\
\hline 7 & 10 & 0 \\
\hline 8 & 27 & 29 \\
\hline 9 & 100 & 67 \\
\hline 10 & 35 & 35 \\
\hline 11 & 33 & 32 \\
\hline 12 & 40 & 28 \\
\hline 13 & 34 & 17 \\
\hline 14 & 26 & 20 \\
\hline 15 & 23 & 39 \\
\hline 16 & 27 & 26 \\
\hline 17 & 47 & 48 \\
\hline 18 & 29 & 41 \\
\hline 19 & 23 & 14 \\
\hline 20 & 29 & 29 \\
\hline 21 & 29 & 28 \\
\hline 22 & 27 & 34 \\
\hline 23 & 34 & 52 \\
\hline 24 & 37 & 46 \\
\hline 25 & 48 & 38 \\
\hline 26 & 32 & 35 \\
\hline 27 & 34 & 30 \\
\hline 28 & 43 & 40 \\
\hline 29 & 33 & 37 \\
\hline 30 & 36 & 37 \\
\hline 31 & 30 & 43 \\
\hline 32 & 46 & 26 \\
\hline 38 & 32 & 27 \\
\hline 34 & 31 & 28 \\
\hline 35 & 25 & 28 \\
\hline 36 & 32 & 34 \\
\hline 37 & 42 & 36 \\
\hline 38 & 37 & 39 \\
\hline 39 & 47 & 37 \\
\hline 40 & 36 & 44 \\
\hline 41 & 39 & 38 \\
\hline
\end{tabular}


antwortung dieser Frage wollen wir beispielsweise untersuchen, welcher prozentuale Anteil an der Gesamtzahl der Mitosen auf die karyokinetischen Endstadien entfällt. Als Endstadien fasse ich dabei die Phasen vom Diaster an zusammen, nach meiner Bezeichnungsweise also die Stadien e, $\mathrm{f}$ und $\mathrm{g}$. Wir finden (Tabelle 5 und 6), daß dieser Anteil sehr ungleich ist, er schwankt zwischen $0 \%$ und $100 \%$. Unter den 129 Corneaepithelien, welche in den Serien Syn. I und Syn. IV zur Untersuchung gelangten, betrug der Anteil der mitotischen Endphasen an der Gesamtzahl der Mitosen in 12 Fällen weniger als $20 \%$,
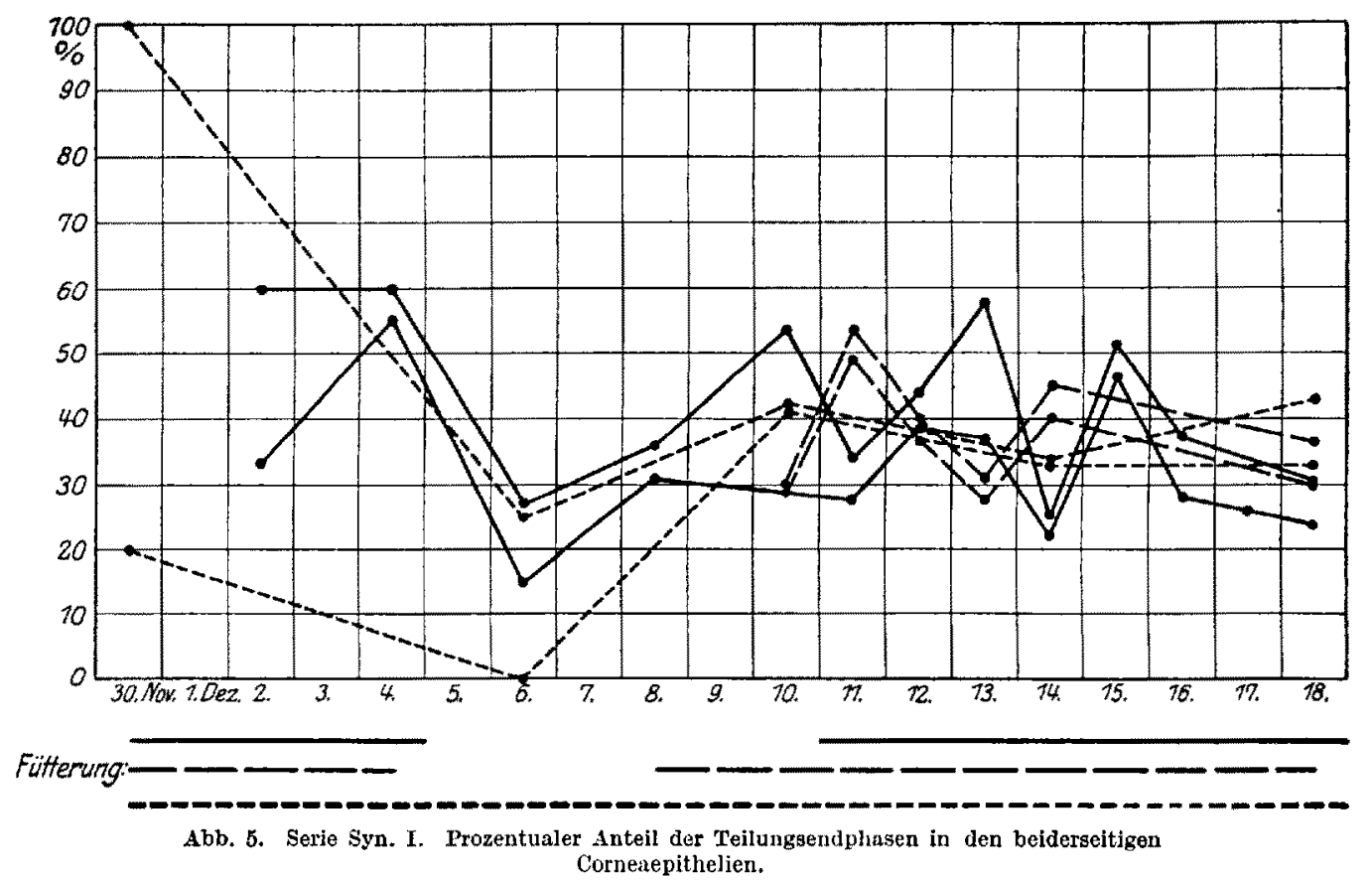

in 35 Fällen $21-30 \%$, in 49 Fällen $31-40 \%$, in 20 Fällen 41 bis $50 \%$ und in 13 Fällen über $50 \%$. Fin gesetzmäßiger Zusammenhang dieser Verschiedenheiten mit den Ernährungsbedingungen konnte nicht allgemein festgestellt werden, soll aber keineswegs geleugnet werden. Vielmehr wird diese Frage in einer neuen bereits begonnenen Versuchsreihe untersucht werden, indem hier zu bestimmten, in verschiedenen Gruppen aber verschiedenen Tageszeiten gefüttert und ebenso nach entsprechender Zeit zu bestimmten Tagesstunden das Untersuchungsmaterial konserviert wird. - Trotz dieser Ungleichheit und scheinbaren Unregelmäßigkeit in dem prozentualen Anteil der Endphasen zeigt sich aber auch in dieser Beziehung wiederum 
eine weitgehende Übereinstimmung zwischen den beiderseitigen Corneaepithelien je eines Tieres. Unter den 64 Paaren von Corneaepithelien betrugen bei 46 Tieren, also in mehr als $2 / 3$ der Fälle, die Differenzen zwischen den prozentualen Anteilen der Endphasen in den beiderseitigen Corneaepithelien höchstens $10 \%$, in 29 Fällen sogar nur höchstens $5 \%$ ! Noch anschaulicher wird diese Utbereinstimmung in der graphischen Darstellung der Abb. 5 und 6. Wie aus den Abb. 3 und 4 die Ubereinstimmung der absoluten Mitosenzahlen, so ist hier die Utbereinstimmung in dem prozentualen Anteil der Endphasen zwischen den beiderseitigen Corneae jedes einzelnen Tieres direkt abzulesen.

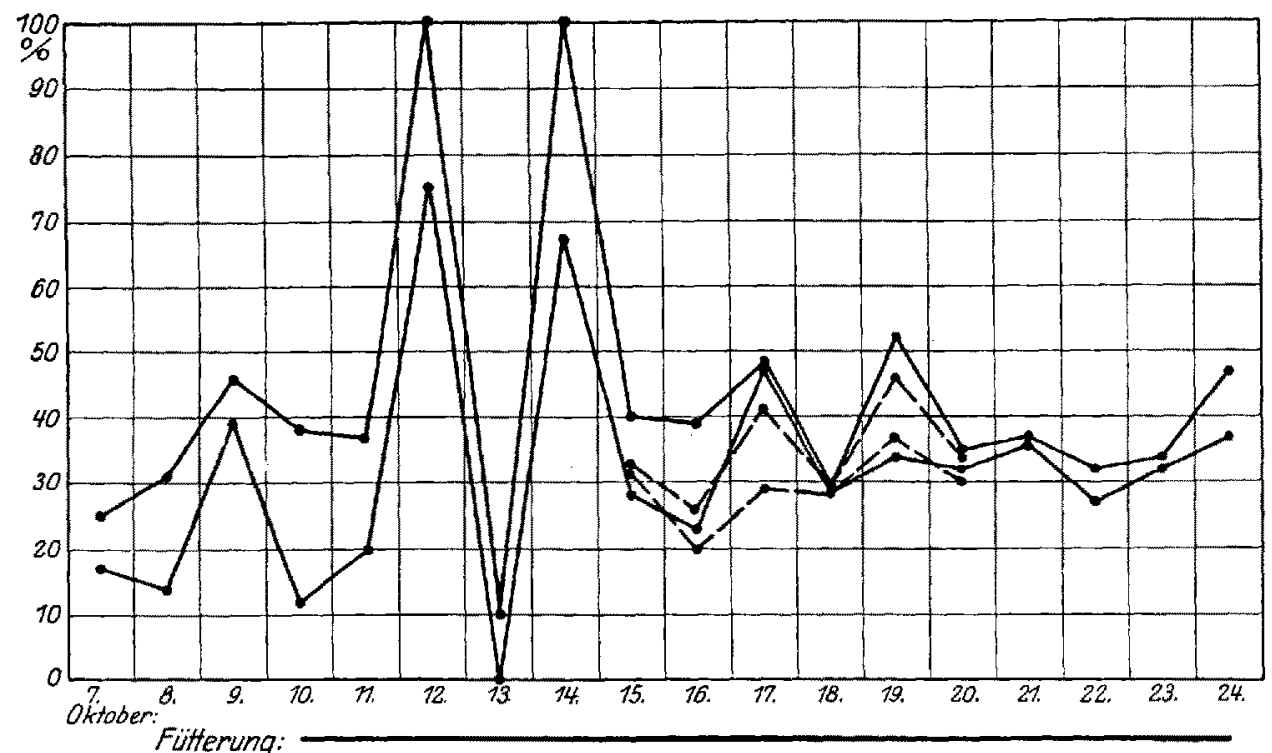

Abb. 6a. Serie Syn. TV, 1. Gruppe, wie Abb. b.

Ich habe mich nicht nur dieser willkürlich gewählten Methode des Vergleiches bedient, sondern außerdem in allen Fällen, die auf jede einzelne mitotische Phase entfallenden Mitosenzahlen zwischen den beiderseitigen Corneae verglichen. Auch hierüber geben die Tabellen 3 und 4 genauen Aufschluß. Da aber auch hier die Tabellenform wenig übersichtlich ist, habe ich für alle untersuchten Tiere $\mathrm{Kurvenpaare}$ gezeichnet, welche die Verteilung der in beiden Corneae gefundenen Mitosen auf die einzelnen mitotischen Stadien veranschaulichen. Eine Wiedergabe all dieser 64 Figuren würde natürlich viel zu viel Raum erfordern und erübrigt sich auch, da ja aus dem in den Tabellen wiedergegebenen Zahlenmaterial die Kurven von jedermann selbst gezeichnet werden können. Nur einige charalkteristische Bei- 
spiele sollen hier abgebildet werden, an deren Hand sich die Verhältnisse leicht übersichtlich besprechen lassen.

Die Form dieser Verteilungskurven ist selbstverständlich wesentlich dadurch beeinflußt, daß die im mikroskopischen Präparat deutlich abgrenzbaren Phasen sehr verschieden lange Dauer beanspruchen. Wäre dies der einzige Faktor, der die Form der Verteilungskurve beherrscht, dann müßten wir in allen Fällen mehr oder weniger übereinstimmende Bilder erhalten. Bei unseren Versuchen war dies nicht der Fall. Wir finden vielmehr Kurven der verschiedensten Typen, eingipflige, zwei- und dreigipflige, steil ansteigende und flach hingezogene. Dies beweist uns, daß die Zellteilungstätigkeit keineswegs auch nur annähernd konstant ist, daß vielmehr ein ziemlich rascher Wechsel zwischen Zeiten besteht, in welchen zahlreiche

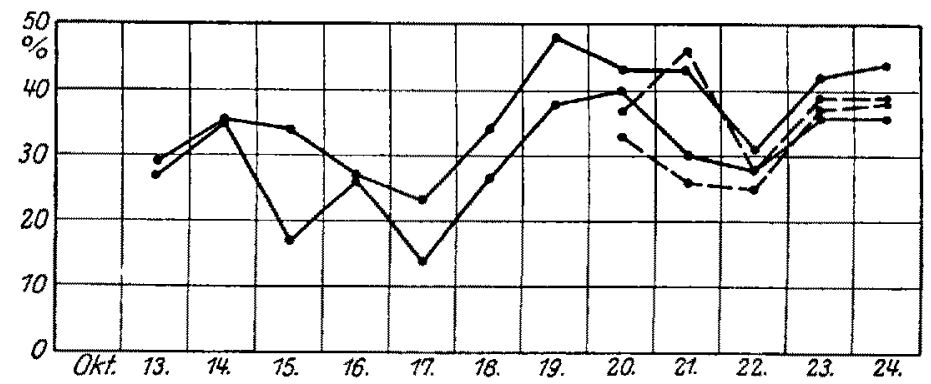

Fütterung:-

Abb. 6 b. Serie Syn. IY, 2. Gruppe, wie Abb. 5.

Zellen zur Teilung schreiten und Zeiten, in denen mehr Ruhe im Zellteilungsbetriebe herrscht. Da ich die verschiedenen Kurventypen in keinen deutlich erkennbaren Zusammenhang mit den schon besprochenen durch die Ernährungsbedingungen beherrschten, offenbar viel langsamer erfolgenden Schwankungen bringen konnte, glaube ich, daß diese weitgehenden Verschiedenheiten der Verteilungskurven Ausdruck eines durch noch unbekannte Faktoren bedingten Zellteilungshythmus, eines schubweisen Anschwellens und Abflauens der mitotischen Tätigkeit sind, ähnlich, wie dies auch Häcker (s. o.) schon angenommen hat.

Es zeigt sich nun, daß in der Mehrzahl der Fälle die Form der Verteilungskurven in den beiderseitigen Corneaepithelien eine deutliche Ubereinstimmung aufweist, daß also die den Zellteilungsrhythmus bestimmenden Faktoren meist die beiden Corneae gleichzeitig treffen und gleichartig beeinflussen. Einige besonders auffällige Beispiele mögen an der Hand der beigegebenen Abbildungen 
besprochen werden. Gewisse Eigentümlichkeiten, die allen oder fast allen Kurven gemeinsam sind, gehen offenbar auf die erwähnte verschieden lange Dauer der einzelnen mitotischen Phasen zurück. So ist in den Stadien $b$ und $d$ stets je ein Minimum zu finden, offenbar deshalb, weil diese Stadien kürzer dauern als die meist die Maxima bildenden, also am längsten dauernden Phasen a und c. Die Zahlen für die einzelnen mitotischen Endstadien $e, f$ und $g$ bewegen sich im allgemeinen zwischen den für a oder c gefundenen Maximalzahlen und den für $b$ und $d$ gefundenen Minimalzahlen der betreffenden Cornea, können in manchen Fällen aber auch Maxima bilden.

Im einzelnen können wir sehr verschiedenartige Typen unter den Kurven unterscheiden. Abb. 7 zeigt uns beispielsweise einen Fall (Syn. IV, 27), bei dem wir in beiden Corneae genau übereinstimmend die höchste Mitosenzahl in a, die zweitgrößte in c, das tiefste Minimum in $d$, ein weniger tiefes Minimum in $b$ finden; für $e, f$ und $g$ finden wir auf beiden Seiten annähernd gleich hohe, zwischen den Maximal- und Minimalwerten liegende Zahlen. Im wesentlichen ähnliche Verhältnisse zeigt Abb. 8 (Syn. IV, 41). Dabei sind aber die absoluten Zahlen hier im allgemeinen höher, nur das eine Minimum in $d$ ist tiefer. Trotz der geänderten Dimensionen finden wir auch hier wieder den parallelen Verlauf der beiden Kurven. Vergleichen wir damit beispielsweise den in Abb.9 wiedergegebenen Fall (Syn. I, 15), so bemerken wir im großen und ganzen das Gleiche. Auch hier die höchste Zahl in a, die zweithöchste in $c$, auch hier steht $e$ und $f$ auf ungefähr gleicher Höhe zwischen Maximal- und Minimalzahlen. Etwas abweichend verhalten sich die anderen Phasen. Die niedrigste Zahl finden wir hier für $g$, etwas höhere Werte für $b$ und $d$, wobei diese beiden Phasen untereinander fast gleiche Zahlen aufweisen. All diese Einzelheiten stimmen wieder für beide Körperseiten genau überein. Ähnliches zeigt Abb. 10 (Syn. IV, 33). Auch eine kleine Abweichung von den vorigen Typen, daß krier nämlich das Minimum in $\mathrm{g}$ zwischen den Werten für $b$ und $d$ liegt, ist beiden Corneaepithelien gemeinsam. Abb. 11 (Syn. I, 10) zeigt in der Verteilung der Maxima und Minima einen ähnlichen Typus, doch verläuft hier für beide Seiten genau übereinstimmend die Kurve sehr flach bei sehr niederen absoluten Werten. Ein etwas veränderter Kurventypus kommt zu stande, wenn das Endstadium g wieder eine größere Erhebung der Kurve bedingt, die allerdings fast niemals das stärkste Maximum der Kurve bildet. Für diesen Fall mag Abb. 12 (Syn. IV, 38) ein Beispiel bringen. Auch hier finden wir in beiden Corneae das stärkste Maximum in a, das tiefste Minimum in d, ein schwächeres Minimum in b, die Werte für $e$ und $f$ zwischen Maximal- und Minimalwerten, näher zu den letzteren. Daneben aber finden wir hier noch zwei Maxima, in $\mathrm{c}$ und in $\mathrm{g}$, 
deren Werte auf beiden Körperseiten untereinander nicht wesentlich differieren. Doch ist auf der einen Seite das Maximum in $c$, auf der anderen Seite dasjenige in $\mathrm{g}$ ein wenig höher. Ganz ähnliche Ver-

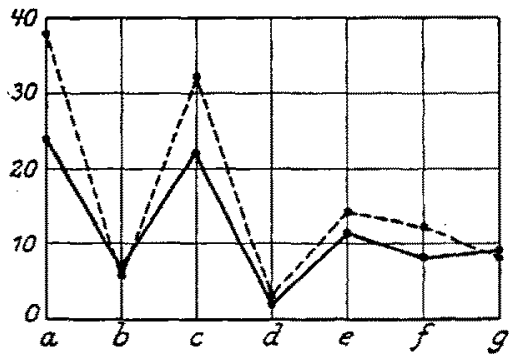

Abb. 7. Syn. IV; 27.

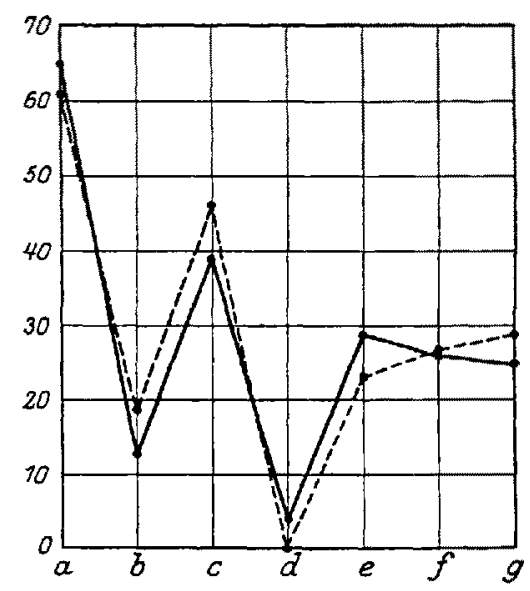

Abb. 8. Syn, IV; 41.

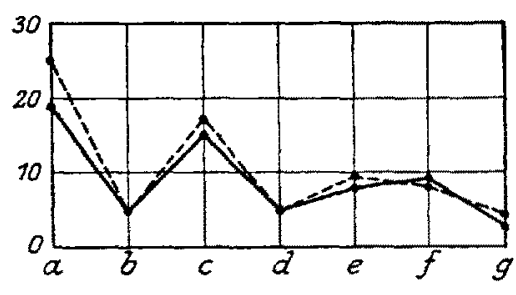

Abb, 9. Syn. I; 15 .

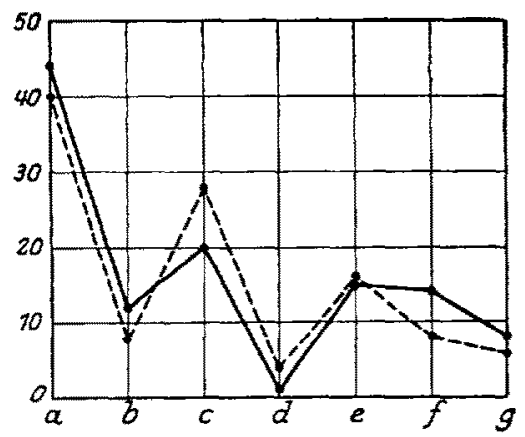

Abb. 10. Syn. IV; 39 .

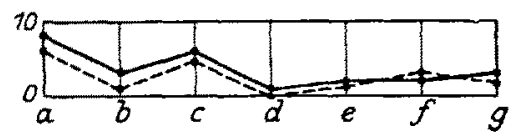

Abb. 11. Syn. I; 10.

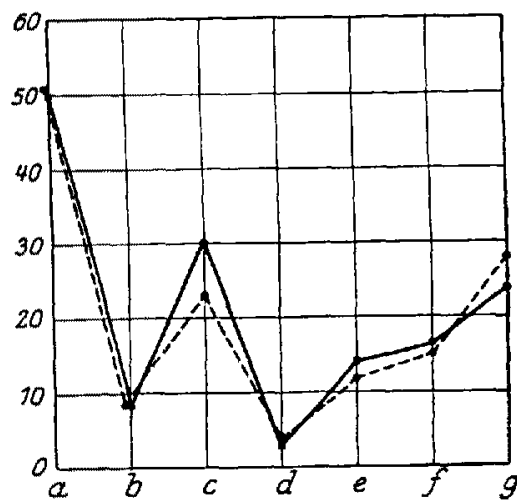

Abb. 12. Syn. IV; 38.

hältnisse zeigt Abb. 13 (Syn. IV, 37), doch beteiligt sich hier - und zwar wieder auf beiden Körperseiten in ganz übereinstimmender Weise - an dem dritten Maximum außer $g$ auch noch $f$ mit einer nur wenig unter dem für $g$ bestimmten Werte liegenden Zahl. Ähnliche Kurven, für die aber eine flach angezogene Form bei sehr niedrigen absoluten Werten charakteristisch ist, zeigen die Corneaepithelien von 
Syn. I, 6 (Abb. 14). Bei guter Ubereinstimmung der gegenseitigen Verhältnisse zwischen den für die einzelnen Phasen geltenden Werten liegen hier aber die absoluten Werte in der einen Cornea im allgemeinen deutlich höher als in der anderen. Wir werden uns mit dieser Erscheinung noch zu beschäftigen haben.

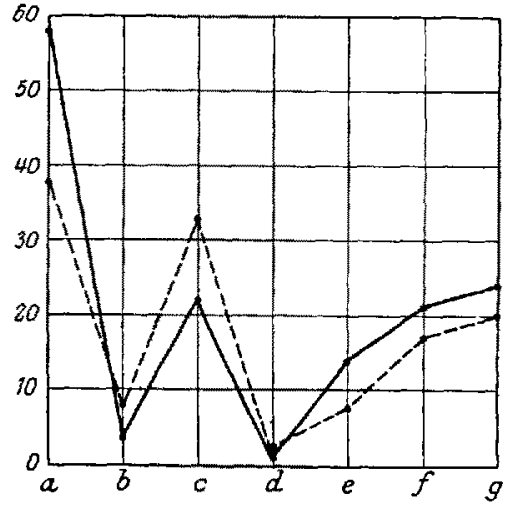

Abb. 13. Syn. IV; 37.

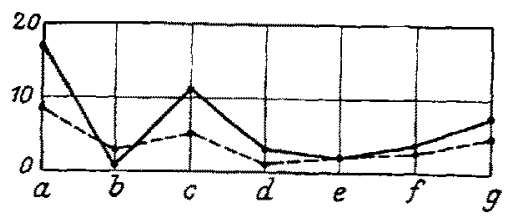

Abb. 14. Syn. I; 6.

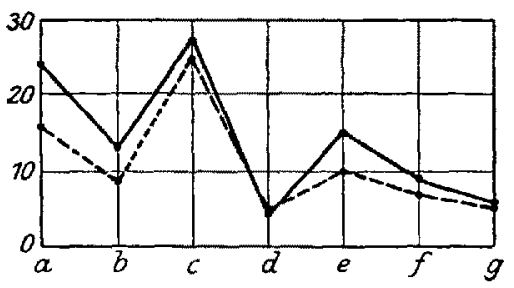

Abb. 15. Syn. IV; 21.

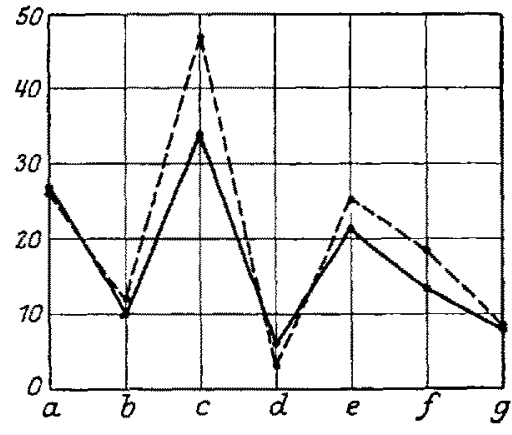

Abb. 16. Syn. IV; 30.

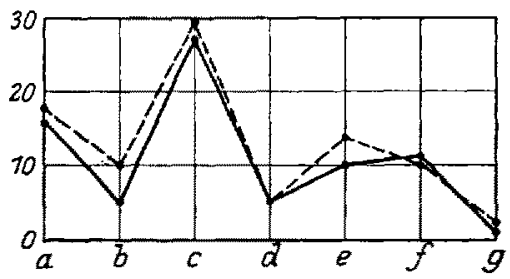

Abb. 17. Syn. IV; 20.

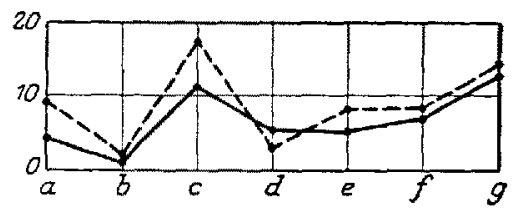

Abb. 18. Syn. I; 11.

Ein anderer Kurventypus kommt ferner zustande, wenn der Wert für e noch über den Wert für a ansteigt und so die Bildung des höchsten Maximums übernimmt. In diesen Fällen war fast immer ein drittes Maximum in e, eventuell unter Mitteilungen von $f$ nachweisbar, während $g$ ein drittes, bisweilen sogar tiefstes Minimum bildete. Für diesen Typus bringen die Abbildungen 15 und 16 (Syn. IV, 21 und Syn. IV, 30) Beispiele auffälligster Ubereinstimmung der beiderseitigen Organe. Einen ähnlichen Fall zeigt Abb. 17 (Syn. IV, 20). Doch ist hier auf der einen Seite der Wert für $f$ noch ein wenig 
höher als der für e, während auf der anderen Seite das dritte Maximum wie bei den früheren Fällen von e, allerdings unter Mitbeteiligung von $f$ gebildet wird. Schließlich zeigt die Abb. 18 (Syn. I, 11) eine schöne Utbereinstimmung der beiden Corneaepithelien in einem Falle, bei dem die zwei höchsten Maxima in $\mathrm{c}$ und $\mathrm{g}$ liegen, das tiefste Minimum in b. Auch hier ist, ähnlich wie in Abb. 14, ein leichtes Uberwiegen der absoluten Zahlen in der einen Cornea zu beachten.

Die hier graphisch wiedergegebenen und besprochenen Fälle sind besonders deutliche Beispiele für gut übereinstimmende Kurvenpaare. Während ich anfangs nur danach suchte, wie weit eine derartige deutliche Ubereinstimmung zwischen den beiderseitigen Corneaepithelien in bezug auf ihre jeweilige Zellteilungstätigkeit nachweisbar sei, wurde meine Aufmerksamkeit bald auch gerade auf jene Fälle gelenkt, in denen die Kurvenpaare eine derartige Ubereinstimmung ihrer Form vermissen ließen. Denn ich gewann den Eindruck, daß auch aus diesen scheinbar unregelmäßigen Verhältnissen ein gewisser Einblick in das Wesen des Zellteilungsrhythmus zu gewinnen sei.

Vor allem erkannte ich, daß auch jene Fälle, in denen die beiderseitigen Verteilungskurven keine vollständige Ubereinstimmung zeigten, sich in verschiedene Gruppen unterteilen ließen, für welche stets eine bestimmtartige Verschiedenheit zwischen den beiderseitigen Teilungszuständen als charakteristisch anzusehen war. Utber die Verteilung dieser im folgenden zu besprechenden Fälle gibt die. Tabelle 7 Aufschluß. Ihre Richtigkeit kann jederzeit an der Hand der in den Grundtabellen mitgeteilten Zahlen überprüft werden. Sie zeigt vor allem, daß von den 64 verwendeten Tieren 19 eine ebenso schöne Übereinstimmung zeigten, wie es die besprochenen Beispiele veran. schaulichen, 6 weitere ebenfalls noch eine brauchbare, wenn auch nicht ebenso gute Übereinstimmung aufwiesen. Es sei bemerkt, daß ich ursprünglich bei der Zusammenstellung dieser Tabelle eine eigene Kolonne für v unregelmäßige Verschiedenheiten zwischen den beiderseitigen Verteilungskurven " bestimmt hatte. Bei der Betrachtung der einzelnen Fälle blieb schließlich aber kein einziger Fall für diese Kolonne übrig, vielmehr ließen sich alle zwanglos in die neun in der Tabelle angeführten Gruppen einreihen.

$\mathrm{Zu}$ einer ersten Gruppe typischer Verschiedenheiten zwischen den Verteilungskurven der beiderseitigen Corneaepithelien leiten zwei bereits besprochene Fälle über. Die Abb. 7 zeigte die Mitosenverteilung bei einem Tiere, bei dem trotz bester Ubereinstimmung der Kurvenform die eine Kurve im ganzen ein wenig über der anderen liegt. In der einen Cornea beträgt die Gesamtzahl der Mitosen 113, in der anderen dagegen 83. Es zeigt sich hier in der einen Cornea eine stärkere mitotische Tätigkeit bei relativ gleichartiger Beteiligung aller 
Tabelle VII.

Úbersicht der untersuchten Tiere, geordnet nach dem gegenseitigen Verhältnis zwischen den mitotischen Verteilungskurven der beiderseitigen Corneaepithelien je eines Tieres.

\begin{tabular}{|c|c|c|c|c|}
\hline \multicolumn{2}{|c|}{ Bezeichnung der Gruppe } & $\begin{array}{c}\text { aus Serie Syn. I } \\
\text { Tier Nr.: }\end{array}$ & $\begin{array}{l}\text { aus Serie Syn. IV } \\
\text { Tier Nr.: }\end{array}$ & $\begin{array}{l}\text { Sumine } \\
\text { der Fälle: }\end{array}$ \\
\hline \multicolumn{2}{|c|}{$\begin{array}{l}\text { Sehr gute Ubereinstimmung } \\
\text { der Verteilungskurven }\end{array}$} & $\begin{array}{l}\left.\left.3^{2}\right), \tilde{b}^{2}\right), 10(\mathrm{Abb} .11) \\
11(\mathrm{Abb} .18), 15(\mathrm{Ab}- \\
\text { bild. } 9), 17,18,22 \\
23\end{array}$ & $\begin{array}{l}72), 20(\mathrm{Abb} .17), 21(\mathrm{Ab}- \\
\text { bild. 15), 26, 30 (Abb. 16), } \\
33(\mathrm{Abb} .10), 37 \text { (Abb. 13), } \\
38(\mathrm{Abb} .12), 39,41(\mathrm{Abb} .8)\end{array}$ & 19 \\
\hline \multicolumn{2}{|c|}{$\begin{array}{l}\text { Brauchbare Ubereinstim- } \\
\text { mung }\end{array}$} & 8,13 & $\left.3,22^{x}\right), 24,40$ & 6 \\
\hline \multicolumn{2}{|c|}{$\begin{array}{l}\text { Bei gehr guter Cberein- } \\
\text { stimmung der Kurven- } \\
\text { form verschieden hohe ab- } \\
\text { solute Werte }\end{array}$} & $\begin{array}{l}6(\mathrm{Abb} .14), 19(\mathrm{Ab}- \\
\text { bild. } 20)\end{array}$ & $\begin{array}{l}\text { 18, } 27 \text { (Abb. } 7 \text { u. 19), } 34 \\
(A b b .21)\end{array}$ & 5 \\
\hline \multicolumn{2}{|c|}{$\begin{array}{l}\text { Bei sonst guter Uberein- } \\
\text { stimmung } 1-2-\text { Minima } \\
\text { verstriohen }\end{array}$} & & 10,16 & 2 \\
\hline \multicolumn{2}{|c|}{$\begin{array}{l}\text { Bei sehr geringer absoluter } \\
\text { Mitosenzahl Ubereinstim- } \\
\text { mung angedeutet }\end{array}$} & & $\left(1,6,9^{1}\right)$ & 3 \\
\hline $\begin{array}{c}\text { Einzelnes Maxi- } \\
\text { mum auf der } \\
\text { einen Körper- } \\
\text { seite stärker } \\
\text { ausgebildet } \\
\end{array}$ & \multirow{3}{*}{$\begin{array}{l}\text { bei sonst } \\
\text { guter } \\
\text { Uberein- } \\
\text { stimmung } \\
\text { der Kur- } \\
\text { venform }\end{array}$} & & $31,36(\mathrm{Abb}, 22)$ & 2 \\
\hline $\begin{array}{l}\text { Einzelnes Maxi- } \\
\text { mum nur auf } \\
\text { einer Seite aus- } \\
\text { gebildet }\end{array}$ & & $\left(1^{1}\right)^{2}$ & $\begin{array}{l}\left.4(\mathrm{Abb} .23), 8^{2}\right)(\mathrm{Abb} .24) \\
19(\mathrm{Abb} .25)\end{array}$ & 4 \\
\hline $\begin{array}{l}\text { Einzelnes Maxi- } \\
\text { mum versoho- } \\
\text { ben }\end{array}$ & & $\begin{array}{l}\left.\left.\left.2^{1}\right)^{2}\right), 4,12,14,16^{1}\right) \\
20,24\end{array}$ & $\begin{array}{l}\left.13^{\mathrm{x}}\right), 15,25 \text { (Abb. } 26 \text { บ. } 27 \text { ), } \\
32\end{array}$ & 11 \\
\hline \multicolumn{2}{|c|}{$\begin{array}{l}\text { Die ganze Verteilungskurve } \\
\text { istgleichsinnig verschoben }\end{array}$} & 7 (Abb. 28 и. 29$), 9$ & $\begin{array}{l}\left.\left.\left.2^{2}\right), 5^{2}\right), 11,12,14^{1}\right), 17, \\
\left.23,28^{3}\right), 29,35\end{array}$ & 12 \\
\hline Summe d & der Fälle: & 23 & 41 & 64 \\
\hline
\end{tabular}

1) Bei deutlich verschiedenen absoluten Werten. - ${ }^{\text {z) }}$ Bei sehr geringen absoluten Werten. 
Stadien darin, daß die Werte für jede einzelne Phase, mit Ausnahme einer unbedeutenden Abweichung im Endstadium 'g, in der einen Cornea höher liegen. Bei einer kurvenmäßigen Darstellung der prozentualen Anteile, welche die für jede einzelne Phase gefundenen Werte an der Gesamtzahl der in einer Cornea gefundenen Mitosen besitzen, wird daher in diesem Falle die Übereinstimmung der Zellteilungszustände in den beiderseitigen Corneaepithelien noch schärfer hervortreten (Abb. 19). Einen ähnlichen Fall gut übereinstimmender Kurvenformen bei Ungleichheit der absoluten Werte in jeder einzelnen mitotischen Phase zeigt auch die Abb. 14. Zwei noch bessere Beispiele, bei welchen die verschiedene Lebhaftigkeit der Zellteilungstätigkeit in den beiden Corneae noch schärfer hervortritt, werden durch die Abb. 20 und 21 veranschaulicht. Abb. 20 stammt von einem Falle (Syn. I, 19), bei dem in der einen Cornea 31 , in der anderen 52 Mitosen gezählt wurden. Dieser beträchtliche Unterschied in der Mitosenzahl ist auch hier nur auf eine im allgemeinen lebhaftere Zellteilungstätigkeit in der einen Cornea zurückzuführen, während die durch den charakteristischen Zellteilungsrhythmus bedingten Einzelheiten der Kurvenform in' beiden Corneaepithelien gut übereinstimmen. Noch deutlicher ist dies in der Abb. 21 zu erkennen, welche von einem Falle (Syn. IV, 34) stammt, bei dem in

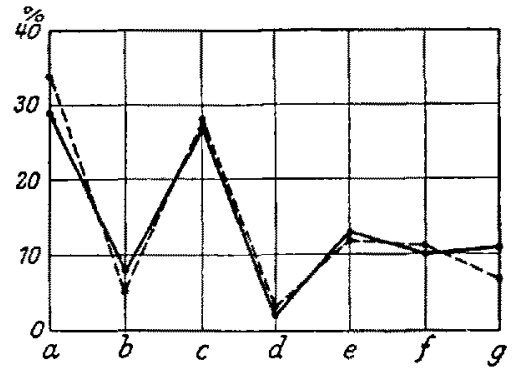

Abb. 19. Syn, IV; 27.

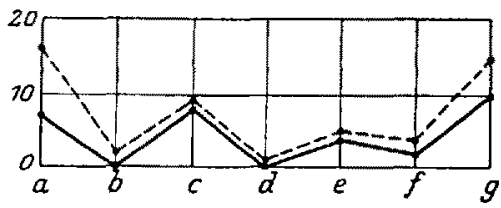

Abb, 20. Syn. I; 19.

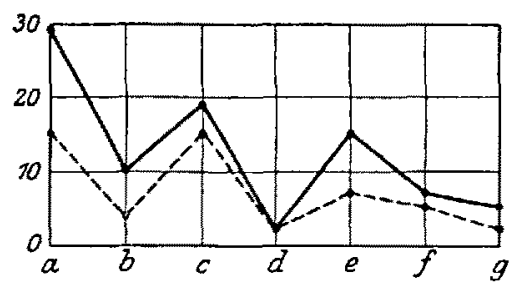

Abb, 21. Syn. IV; 34. der einen Cornea 50, in der anderen 87 Mitosen zu finden waren.

Ganz anders zu deuten sind jene Fälle, bei denen trotz annähernd gleicher Werte für die Gesamtzahl der Mitosen die Form der Verteilungskurven für die beiderseitigen Corneaepithelien charakteristische Unterschiede aufweist, sowie jene, in denen eine Verschiedenheit der Gesamtzahlen der Mitosen besteht, die aber nicht durch proportionierte Ungleichheiten in allen Phasen, sondern durch einzelne Ungleichheiten der Verteilungskurven zustande kommen. Unter diesen Fällen, in denen also die Kurvenformen der beiden Corneae eines 
Tieres typische Unterschiede aufweisen, möchte ich zwei Hauptgruppen unterscheiden. In die eine reihe ich alle jene Fälle ein, bei denen die Kurvenform im allgemeinen noch gut übereinstimmt, ein bestimmtes Maximum aber aufällige Unterschiede zwischen den beiderseitigen Corneae bedingt. Die Unterschiede können darauf zurückgehen, daß dieses eine Maximum wohl in beiden Kurven in derselben Phase vorhanden, aber ungleich stark ausgebildet ist, oder darauf, daß ein in der einen Cornea vorhandenes Maximum in der anderen Cornea überhaupt fehlt oder endlich darauf, daß ein bestimmtes Maximum in der einen Cornea gegen ein vergleichbares

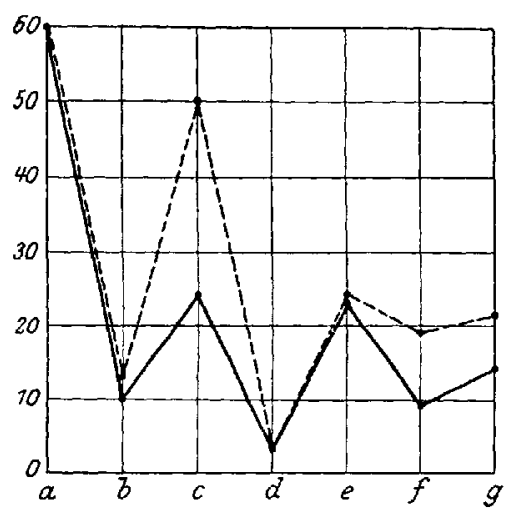

Abb. 22. Syn. IV; 36 .

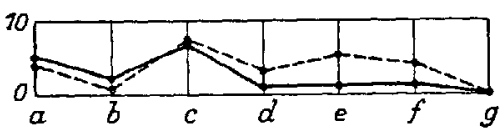

Abb. 23. Syn. IV; 4.

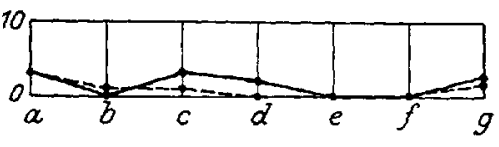

Abb. 24. Syn. IV; 8 .

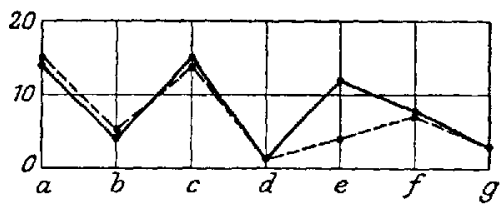

Abb. 25. Syn. IV; 19.

Maximum in der anderen Cornea um ein bis zwei Phasen verschoben erscheint. $\mathrm{Zu}$ der zweiten Hauptgruppe typisch ungleicher Kurvenpaare rechne ich dagegen jene Fälle, in denen die Ungleichheit nicht auf das Verhalten eines èinzelnen Maximum beschränkt ist, sondern die ganze Kurvenform betrifft. Die hier einzureihenden Fälle ließen sich stets als eine gleichsinnige Verschiebung der ganzen Verteilungskurve auffassen.

Ein Beispiel für jene Fälle, in denen der wesentliche Unterschied zwischen den beiden Verteilungskurven nur in dem stärkeren Hervortreten eines bestimmten Maximum in der einen Cornea gelegen ist, möge durch die Abb. 22 erläutert werden (Syn. IV, 36). Wir sehen hier an beiden Kurven das stärkste Maximum in a, ein zweites in c, das tiefste Minimum in d, ferner ein drittes Maximum in e, an welchem in dem einen Falle deutlich, in dem anderen Falle nur eben angedeutet auch noch die Endphasen $f$ und $g$ beteiligt sind. Der Hauptunterschied zwischen den beiden Kurven liegt nun nur darin, daß 
das zweite Maximum in c auf den beiden Körperseiten eine sehr ungleiche Höhe erreicht. Als extreme Steigerung eines derartigen Unterschiedes lassen sich dann jene Fülle auffassen, in denen das eine unterscheidende Maximum in der einen Cornea überhaupt fehlt. Dieser Typus kann auch bei den im übrigen verschiedensten Kurvenformen vorkommen, offenbar aber nur bei geringen absoluten Gesamtzahlen. Beispiele mögen die Abb. 23 und 24 zeigen. Erstere stammat von einem Falle (Syn. IV, 4), bei dem in beiden Corneaepithelien das stärkste Maximum in $\mathrm{c}$ ein zweites in a, das tiefste Minimum in $\mathrm{g}$ liegt. Bei der einen Cornea kommt aber noch ein drittes, flach ausgezogenes Maximum in $d-e-f$ hinzu, das bei der anderen Cornea vollkommen fohlt. In Abb. 24 (Syn. IV, 8) finden wir in beiden Corneae je ein seichtes Maximum in a und $g$, wozu auf der einen Seite noch ein drittes flaches Maximum in $c-d$ hinzukommt. Abb. 25

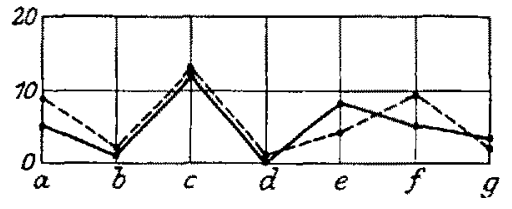

Abb. 26. Syn. 1V; 25.

leitet schon zu jener nächsten Gruppe von nur teilweise ungleichartigen Kurvenpaaren über, in welcher bei sonst guter UUbereinstim-

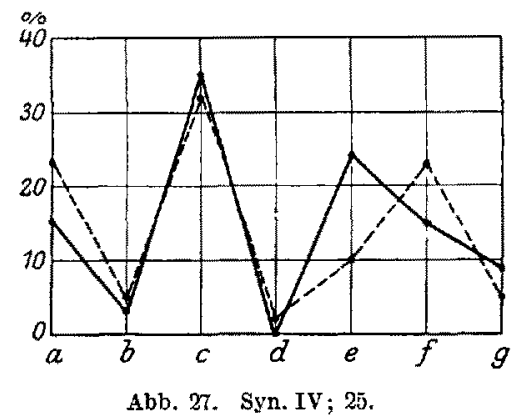
mung der Kurvenform einem einzelnen Maximum der einen Cornea ein in seiner Lage mehr oder weniger verschobenes Maximum in der anderen Cornea entspricht. Wir sehen in dem hier abgebildeten Falle (Syn. IV, 19) in beiden Corneae zwei etwa gleich hohe Maxima in a und $c$, ein tiefstes Minium in $d$, ein zweites in $g$, ein drittes in $b$. Dazu kommt in der einen Cornea ein drittes deutliches Maximum in e unter Mitbeteiligung von $f$, dem auf der anderen Seite nur ein schwach ausgeprägtes Maximum in $f$ entspricht. Als Vertreter jener Gruppe, bei welcher der Unterschied in der Kurvenform mit voller Deutlichkeit nur auf einer Lageverschiebung eines bestimmten, einzelnen Maximum beruht, mag der Fall Syn. IV, 25 (Abb. 26) dienen. Ubereinstimmend für beide Corneae finden wir hier ein stärkstes Maximum in $c$, ein zweites in a, ein tiefstes Minimum in d, ein zweites in $b$, ein drittes in $\mathrm{g}$; dazu kommt ein drittes Maximum, das in der einen Cornea dasjenige von a erreicht, in der anderen Cornea dieses sogar übertrifft; dieses dritte Maximum wird von e und f gebildet, wobei aber auf der einen Seite die ausgesprochene Hauptrolle dem Stadium e, 
auf der anderen Seite dem Stadium $f$ zufällt. Noch auffälliger wird diese Verschiebung von e nach $f$ bei völliger Úbereinstimmung der übrigen Kurvenform, wenn wir wieder an Stelle der absoluten Zahlen den prozentualen Anteil der einzelnen Phasen an der Gesamtzahl der Mitosen in jeder Cornea betrachten, wie dies in Abb. 27 ermöglicht ist.

Im Gegensatze zu den bisher besprochenen Fällen steht nun jene letzte Gruppe in der man die Verschiedenheiten zwischen den beiderseitigen Corneaepithelien am besten als eine Verschiebung der ganzen Verteilungskurve beschreiben kann. Ein Beispiel hierfür zeigt die Abb. 28 (Syn. I, 7). Die Gesamtzahl der Mitosen war hier in der einen Cornea 44, in der anderen 46, also annähernd gleich. Das Hauptmaximum der einen Kurve liegt in c, doch hängt damit sicher auch noch die relativ sehr hohe $\mathrm{Zahl}$ in $\mathrm{d}$, sowie ein zweites Maximum in e zusammen. Die zweite Kurve des Paares besitzt dagegen

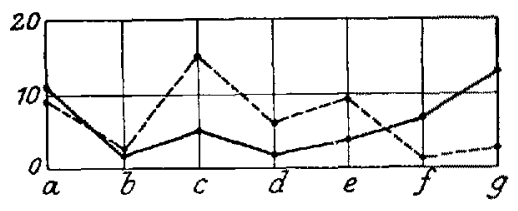

Abb. 28. Syn. I; 7.

in $c$ nur einen verhältnismäßig sehr niederen Wert, dagegen ihr stärkstes Maximum in $\mathrm{g}$, dem wiederum in der ersten Kurve eine

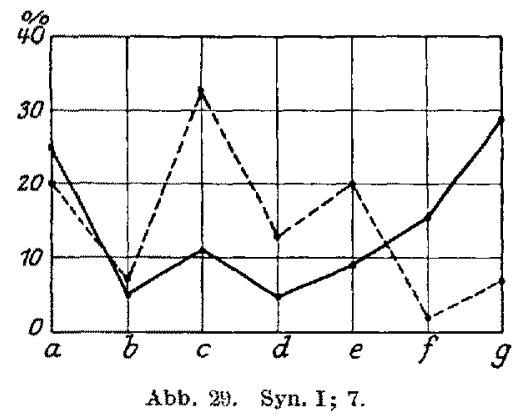
äußerst niedrige Zahl für $g$ gegenübersteht. Mit dem in der zweiten Kurve hervortretenden Maximum in $\mathrm{g}$ lassen sich auch die hohen Werte dieser Kurve in $f$ und in a in Zusammenhang bringen. Auch hier treten die Verhältnisse noch deutlicher bei Heranziehung der prozentualen Verteilung der einzelnen mitotischen Stadien hervor (Abb. 29). Das Bild läßt sich am besten deuten, wenn wir sagen, $\mathrm{da} \beta$ die Teilungswelle, welche in der einen Körperseite das in $\mathrm{c}-\mathrm{d}-\mathrm{e}$ liegende Maximum bedingt hat, in der anderen Körperseite gegen die Endstadien $f-g$ vorgerückt zu sein scheint, wobei ihr hier schon wieder der Beginn einer neuen, in dem Maximum bei a sich ankündigenden Welle folgt.

Es ist selbstverständlich, daß nicht in allen Fällen die Verhältnisse so klar und deutlich zutage treten, wie in den besprochenen. Doch könnte ich für jede der beschriebenen Erscheinungen außer den zur Erläuterung meiner Befunde ausgesuchten Beispielen noch mehrere ebenso einwandfreie Fälle aufzählen. Wie die bereits oben erwähnte Tabelle Nr. VII (S. 572) zeigt, finden sich unter den 64 untersuchten 
Tieren außer den 25 Exemplaren, bei denen die Zellteilungsphasen in den beiden Corneaepithelien gut übereinstimmen, noch fünf Fälle, in denen wohl eine sehr schöne Ưbereinstimmung der Kurvenform vorliegt, dabei aber die für die eine Cornea gültige Kurve als Ganzes höher als die Kurve der anderen Cornea liegt. In zwei weiteren Fällen zeigen die Kurvenpaare zwar noch große Ähnlichkeiten, doch sind ein, beziehungsweise zwei in der 'einen Cornea scharf ausgeprägte Minima in der anderen Cornea des betreffenden Tieres verstrichen. In drei anderen Fällen ist wohl infolge einer sehr geringen Mitosenzahl (in beiden Corneae zusammen höchstens 10 Mitosen!) dio Gesetzmäßigkeit in den gegenseitigen Beziehungen der Zellteilungszustände weniger deutlich ausgeprägt, eine gewisse Ähnlichkeit der Phasenverteilung aber immerhin erkennbar. Bei 17 Tieren besteht wohl eine recht deutliche Ubereinstimmung der Kurvenform im allgemeinen, doch sind durch ein auf beiden Körperseiten verschiedenes Verhalten eines einzelnen Maximums gewisse Unterschiede bedingt. Von diesen 17 Fällen gehören zwei zu jener Gruppe, in der ein Maximum in einer bestimmten Phase wohl auf beiden Körperseiten nachweisbar, aber verschieden stark ausgebildet ist. In vier Fällen ist auf der einen Seite in einer bestimmten Phase ein Maximum vorhanden, das auf der anderen Seite vollkommen fehlt. In elf Fällen endlich findet sich in der einen Cornea ein Maximum in einer Phase, dem in der anderen Cornea ein Maximum in der nächsten oder übernächsten Phase entspricht. Schließlich entfallen 12 Tiere auf jene Kategorie, bei der die Kurven eines Paares keine Úbereinstimmung zeigen und die Verschiedenheiten sich am einfachsten in der Weise beschreiben lassen, daß hier die Hauptmaxima im ganzen in der einen Cornea gegen die Lage, die sie in der anderen Cornea einnehmen, um 1-3 Phasen vorgerückt erscheinen. Dabei müssen wir mit Häcker (s. o.) annehmen, daß sich bei reger Teilungstätigkeit an die Endstadien einer Teilungswelle der Beginn der nächsten Teilungswelle ohne wesentliche Unterbrechung anschließt.

Die Tatsache, daß auch in den nicht übereinstimmenden Kurvenpaaren keine regellosen Verschiedenheiten anzutreffen sind, sondern die Fälle sich immer mehr oder weniger leicht in die beschriebenen, gut charakterisierbaren Gruppen einreihen lassen, weist darauf hin, daß wir auch hierin den Ausdruck gewisser Gesetzmäßigkeiten suchen müssen, wenn wir diese Gesetzmäßigkeiten auch noch nicht im einzelnen kennen. Es macht den Eindruck, als könnte man auch aus diesen Tatsachen biologische Zusammenhänge herauslesen, doch können wir bisher ihre Schrift noch nicht entziffern. Es wird gerade hier mit weiteren, anders angeordneten Versuchen über Zellteilungsrhythmus und Zellteilungsfaktoren anzuknüpfen sein. An- 
sprechend und wenigstens als Arbeitshypothese gut verwertbar scheint mir dabei eine Auffassung zu sein, die den oben besprochenen Ergebnissen von Gurwitsoh (S. 543-545) nahe steht. Es wäre danach anzunehmen, daß für die Regelung der Zellteilungen verschiedenartige Einflüsse maßgebend sind, unter denen wir vor allem einerseits eine gewisse allgemeine Zellteilungsbereitschaft, andererseits auslösende ("innere" und vielleicht teilweise auch "äußere») Faktoren zu unterscheiden hätten. Ich stelle mir nun vor, daß für die momentane Zellteilungsbereitschaft eines Gewebes neben seiner organogenetischen Entwicklungsstufe vor allem der Ernährungszustarid, der Reichtum an verfügbaren Assimilaten verantwortlich sein dürfte. Dieser Einfluß scheint, wie ich oben auseinandersetzte, ein recht schwerfälliger, langsam einsetzender und lange nachwirkender zu sein. Durch ihn wird die GröBenordnung der Gesamtzahl von Mitosen im Gewebe, also auch die absolute Höhenlage der Verteilungskurve bedingt sein. Treffen wir in den beiderseitigen Corneaepithelien wesentlich verschiedene Gesamtzahlen und liegt die Verteilungskurve der einen Cornea deutlich über jener der anderen Cornea bei gut übereinstimmender Kurvenform, s. z. B. Abb. 7, 14, 20, 21, dann möchte ich dies als den Ausdruck einer ungleichen Teilungsbereitschaft auffassen. Die Ursache könnte in andauernden einseitigen Zirkulationsstörungen, vielleicht auch in anderen UnregelmäBigkeiten des lokalen Gewebslebens zu suchen sein. Diese Hypothese wäre vielleicht einer experimentellen Prüfung zugänglich.

Ganz anders sind die Verhältnisse aufzufassen, wenn bei ungefähr gleich starker Lebhaftigkeit des Zellteilungsgeschehens in beiden Corneae die Verteilungskurven eines Corneaepithelpaares ungleiche Formen aufweisen. In diesem Falle möchte ich weniger an die langsam veränderliche Zellteilungsbereitschaft als Ursache des verschiedenartigen Verhaltens der beiden Corneaepithelien denken, sondern vielmehr zur Erklärung kurzfristiger wirkende auslösende Faktoren heranzuziehen trachten. Erscheint die ganze Verteilungskurve der einen Cornea gegen jene der anderen Cornea einsinnig verschoben, s. z. B. Abb. 28 u. 29, dann nehme ich an, daß vielleicht alle an dem Zustandekommen des betreffenden Status beteiligten auslösenden Faktoren die eine Cornea später erreicht oder langsamer beeinflußt haben dürften, als die andere Cornea. Sehe ich dagegen bei sonst guter Utbereinstimmung der Verteilungskurven nur ein bestimmtes Maximum an der Verschiedenheit der Kurvenformen beteiligt, dann stelle ich mir vor, daß ein bestimmter, zeitlich scharf umschriebener Auslösungsfaktor die beiden Corneae in verschiedener Weise betroffen hat. Die Ungleichartigkeit der Einwirkung dieses Faktors kann dann entweder eine quantitative oder eine zeitliche sein. Hat der eine auslösende Faktor seine Ein- 
wirkung auf die beiden Corneae nicht gleichzeitig zur Geltung gebracht, dann finden wir eine Verschiebung des einen Maximum bei sonst guter Utbereinstimmung der Kurvenform, s. z. B. Abb. 26 u. 27. Wirkte der eine Faktor auf der einen Seite stärker, dann sehen wir das eine Maximum auf dieser Seite einen höheren Wert erreichen als auf der anderen, s. z. B. Abb. 22. Gelangte der eine Faktor auf der einen Seite überhaupt nicht zur Auswirkung, dann finden wir bei dem sonst gut übereinstimmenden Kurvenpaar auf der einen Seite ein deutliches Maximum, dem auf der anderen Seite überhaupt kein Maximum entspricht, s. z. B. Abb. 23, 24 u. 25.

Durch diese Erörterungen sind wir von den eingangs berührten allgemeinen Fragen der Entwicklungsregelungen auf dem Wege über die Probleme der Regelung des zellulären Geschehens und des Zellteilungsrhythmus zu den Fragen nach den Bedingungen und nach den auslösenden Faktoren der Zellteilung geführt worden. Die Wichtigkeit dieser Probleme ergibt sich aus ihren engen Beziehungen zu den mannigfachsten naturwissenschaftlichen Gebieten. Es sei hier nur an die Entwicklungsanregung bei der Befruchtung, bei der natürlichen und bei der künstlichen Parthenogenese, sowie an die beherrschende Rolle des Zellteilungsablaufes bei den frühembryonalen formbildenden Prozessen und bei der Regeneration erinnert. Zu wichtigen Gebieten der Pathologie führt das Problem der die Zellteilung bestimmenden Faktoren bei der Frage nach der Entstehung und nach der Ursachen der Neoplasmen, so wie bei den Vorgängen der Wundheilung und Entzündung. Trotz dieser vielseitigen Beziehungen ist in diesen wichtigen Fragen bisher noch kein einheitlicher Gesichtspunkt für die Bearbeitung gewonnen worden.

Von Bedeutung für die Auffassung dieser Verhältnisse war die Theorie von R. Hertwig (1903) über die Kern-Plasmarelation als ein die Zellteilung beherrschendes Prinzip. Hier wurde bekanntlich versucht die periodischen, durch ungleiches Wachstum bedingten Verschiebungen des Massenverhältnisses zwischen Zellkern und Protoplasma für die periodisch auftretenden Teilungen und ebenso besondere Verschiebungen dieses Verhältnisses für die Teilungsunfähigkeit bestimmter Zellarten einerseits und für die Entwicklungsanregung andererseits verantwortlich zu machen.

Angedeutet finden wir diese Probleme ferner in manchen Arbeiten der experimentellen Geschwulstforschung. Wertvoller als die in vielen dieser Arbeiten aufgebauten Theorien über das Wesen "formativer Reize" werden für unsere Betrachtung manche der dort gefundenen Tatsachen sein. Es wird für unsere Gedankengänge von wesentlicher Bedeutung sein, daß es möglich war, durch mechanische und chemi- 
sche Reize, durch Injektionen von Kieselgur, von Farbstoffen, von Eiweißspaltprodukten u. a.m. Bindegewebe und Epithelien zu Wucherungen zu veranlassen. Es wird für uns weiter von Interesse sein, daß die in dieser Richtung chemisch wirksamen Stoffe sämtlich den Charakter der Lipoidlöslichkeit, also die Fühigkeit, die lipoidartige Grenzschichte des Plasmas zu durchdringen, besitzen sollen. In weiterem Sinne werden wir hier an die experimentell analysierbaren Tatsachen des regenerativen und des entzündlich gesteigerten Wachtums im Anschluß an Gewebsschädigungen, an die Arbeitshypertrophie, an die experimentell nachweisbaren Beziehungen von Gewebswachstum und Hyperämie zu denken haben, usf. (Zusammenfassende Angaben über das auf diesen Gebieten Geleistete beispielsweise bei Aschoff, 1919.)

Von großem Interesse sind in diesem Zusammenhange Untersuchungen, welche in neuerer Zeit auf botanischem Gebiete durchgeführt wurden. Haberlandt (1902) stellte zunächst fest, daß künstlich isolierte Zellen von höheren Pflanzen in verschiedenen Nährlösungen wochenlang am Leben bleiben und in der ersten Zeit auch kräftig assimilieren und wachsen können, daß sie jedoch niemals Zellteilungen aufweisen. Dadurch gelangte der Autor zu der Frage, wann isolierte Zellen zur Teilung schreiten und zu der hypothetischen Annahme von Wuchsenzymen in normal wachsenden Pflanzenteilen wie Vegetationsspitzen, Pollenschläuchen, Embryosäcken. In einem Referate über die Arbeit Haberlandts teilte Winkler (1902) mit, daß er isolierte Wurzelparenchymzellen von Vicia faba zur Teilung veranlassen konnte, indem er der Nährlösung Kobaltsulfat zusetzte. Dadurch war die Vermutung bestätigt, daß durch chemische Reize Zellen zur Teilung angeregt werden können und der Schluß nahe gelegt, daß auch in der normal wachsenden Pflanze chemische Reize, die von bestimmten Organen, Geweben oder Zellen ausgehen, eine Rolle spielen. $\mathrm{Zu}$ ähnlichen Gedanken drängten auch die Ergebnisse der Forschungen über Pflanzengallen.

Im Jahre 1913 berichtete dann wieder Haberlandt über die Zellteilungsfähigkeit in kleinen isolierten Zellkomplexen. Er hatte bei Kartoffelknollen gefunden, daB in dünnen Platten aus dem Marke Zellteilungen fast ausnahmslos nur dann eintreten, wenn diese Platten ein Leitbündelfragment enthalten. Es genügte, wenn dieses Fragment aus Leptom, d. h. aus Siebröhren mit Geleitzellen bestand. Auch in der Knollenrinde $\mathrm{kam}$ der die Teilungen begünstigende Einfluß des Leptom deutlich zur Geltung. Klebte er ein bündelloses Gewebsplättchen mit einer dünnen Agarschicht auf ein bündelhaltiges, dann traten in ersterem in der dem bündelhaltigen Plättchen zugekehrten Seite häufig einige Zellteilungen auf. Haberlandt folgerte daraus, daß die Leptombündel einen Reizstoff aussenden, der in Kombination 
mit dem Wundreiz die Zellen des Speichergewebes zur Teilung veranlaßt. Im Jahre 1914 konnte derselbe Forscher mitteilen, daß sich der für die Kartoffelknolle nachgewiesene Einfluß des Leptom auf den Zellteilungsproze $\beta$ auch bei verschiedenen niedrigen Pflanzen geltend macht. Haberlandts Schüler Lamprecht (1918) zeigte dann, daß von tangential gespaltenen Blättern nur die bündelhaltige Lamelle Zellteilungen aufweist. Wurden die beiden Lamellen aufeinander gelegt, dann traten auch in der bündellosen Schicht Zellteilungen auf, und zwar zuerst in unmittelbarer Nähe der GefäBbündel der anderen Lamelle, später aber auch äber die ganze Wundfläche hin. Ähnliche Ergebnisse lieferten Transplantationsversuche. Auch hier wurden die Zellteilungen durch das Leptom auffallend begünstigt. Durch all dies erschien es experimentell erwiesen, dab die bei höheren Pflanzen unter Wundffächen auftretenden Zellteilungen durch einen vom Leptom ausgeschiedenen Reizstoff, einen "Zellteilungsstoff " ausgelöst werden, dessen Einfluß sich mit dem des Wundreizes kombiniert.

Haberlandt fand ferner (1920), daß der durch Konzentrationszunahme der Zellsäfte bei vorübergehender Plasmolyse bewirkte chemische Reiz auch bei höheren Pflanzen wenigstens unvollständige Zellteilungen nach sich ziehen könne, ähnlich wie Isaburo-Nagai (zitiert nach Haberlandt) bei Farnen durch plasmolytisch wirkende Substanzen Zellteilungen erzielen konnte. Haberlandt glaubt, daß eine durch die Plasmolyse bewirkte Steigerung der Konzentration jener Zellteilungsstoffe, deren Existenz durch die früheren Untersuchungen wahrscheinlich gemacht worden war, in diesen Fällen die Zellteilungen auslöse.

Endlich versuchte Haberlandt (1921) das Wesen des "Wundreizes" zu analysieren, der im Verein mit den Zellteilungsstoffen zur Zellvermehrung bei der pflanzlichen Wundheilung führt. Er griff dabei den schon früher ausgesprochenen Gedanken auf, daß in diesen Fällen eine Aúfnahme von Zersetzungsprodukten der bei der Verletzung zerstörten Zellkörper seitens der gesund gebliebenen Zellen eine Rolle spielen könnte. Haberlandt bezeichnet auch derartige hypothetische Stoffe, die in absterbenden oder geschädigten Zellen entstehen, wenn sie nach Utbertritt in andere Zellen oder Gewebe bestimmte physiologische Vorgänge auslösen, als Hormone, und spricht dann in seinem speziellen Falle von "Wundhormonen". Er machte an Querschnitten durch Kohlrabi oder durch Kartoffelknollen je drei Parallelversuche: Ein Schnitt wird kräftig mit Wasser abgespült, ein Schnitt bleibt unbehandelt, ein dritter Schnitt wird abgespült, dann aber mit einem Brei aus zerriebenem Gewebe bedeckt. Unter den abgespülten Wundflïchen treten dann Zellteilungen bedeutend spärlicher oder doch in geringerer Anzahl von Schichten auf, als unter den nicht abgespülten Flächen; wurden aber die Schnitte mit Gewebebrei überzogen, dann 
traten meist ebenso zahlreiche, bisweilen sogar noch zahlreichere Zellteilungen auf als unter nicht abgespülten Flächen. Wurden Kohlrabischnitte mit Kartoffelbrei bedeckt, dann traten die Teilungen nicht zahlreicher auf als unter einer abgespülten Fläche, was für eine gewisse Spezifität der Wundreizstoffe spricht. Auch bei Laubblättern, welche die Fähigkeit haben, Wundkorke zu bilden, konnte Haberlandt eine Abhängigkeit der Zellteilungen von Wundreizstoffen nachweisen. Dabei erwiesen sich auch noch Gewebssäfte innerhalb der gleichen Pflanzenfamilie als teilungsauslösend, während Säfte aus anderen Familien meist gar nicht wirksam oder schädlich waren. Doch herrscht kein weiterer Parallelismus zwischen Wirksamkeit und systematischer Verwandtschaft. Verschiedene organische Verbindungen wie Traubenzucker, Asparagin und Leucin bewirkten keine ähnliche Teilungsauslösung wie Gewebebrei. Die Transplantationen von Lamprecht (siehe oben) hatten ergeben, daß das Zellteilungshormon aus dem Leptom zwar auch nicht artspezifisch, aber doch von systematisch enger begrenzter Wirksamkeit zu sein scheint als das Wundhormon.

Endlich erbrachte Haberlandt in derselben Arbeit den Nachweis, daß bei Pflanzenhaaren, Epidermis- und Spaltöffnungszellen für den Eintritt von Zellteilungen die Nachbarschaft von Zellen, die durch mechanische Schädigungen getötet wurden, nicht unbedingt erforderlich ist. Es genügt lokale Verletzung einzelner Zellen, die nicht bis zum Absterben führt, um in ihnen typische Kern- und Zellteilungen auszulösen. Da diese Teilungen genau so verlaufen, wie jene in der Nachbarschaft getöteter Zellen, und da in jenem Falle auf Grund der Versuche mit Knollen und Blättern die Wirksamkeit von Wundhormonen angenommen werden müsse, so sei daraus der Analogieschluß zu ziehen, daß auch in geschädigten, aber am Leben bleibenden Zellen Wundhormone entstehen, welche Zellteilungen auslösen. Haberlandt hält danach bisher die Existenz von zweierlei Zellteilungshormonen für experimentell erwiesen: vom Leptom aus gebildete Hormone und Wundhormone. Fine dritte Kategorie von Teilungshormonen werde von den physiologisch weiterwachsenden Geweben, den primären und sekundären Meristemen gebildet, was für diese Gewebe eben charakteristisch sei. Auch andere, von anderen Forschern beobachtete Teilungsanregungen führt Haberlandt auf die Wirkung von vermittelnden Wundhormonen zurück, so die Wirkung von giftigen Substanzen, hohen Temperaturen, mechanischen Reizen usf. Diese Erklärungsweise erinnert wieder an die Auffassungen mancher Experimentalpathologen, welche die wachstumfördernde Wirkung gewisser Reize auf primäre Gewebeschädigung und daran angeschlossenes regeneratives oder reparatives Wachstum zurückführen, spezifische von außen einwirkende Wachstumsreize dagegen leugnen. 
Gerade in der neuesten Zeit wurde von botanischer Seite auch der Zellteilungsrhythmus in seiner Abhängigkeit von äußeren und inneren Faktoren untersucht. Karsten (1915 und 1918) ging von der Tatsache aus, daß sowohl bei niederen als auch bei höheren grünen Pflanzen die Kernteilungen zum überwiegenden Teile in der Nacht, und hier oft vorwiegend zu bestimmten Stunden durchgeführt werden. In den Vegetationspunkten mancher Keimlinge werde diese Periodizität auch bei Aufzucht im Dunkeln beibehalten, sei also bis zu einem gewissen Grade erblich festgelegt. Doch könne diese "Tagesperiodeß durch starke Belichtung zu abnormen Zeiten abgeändert werden. Ähnliche Veränderlichkeit der Tagesperiode durch künstlich variierte Belichtungsbedingungen konnte $\mathrm{Karsten}$ bei einzelligen Grünalgen nachweisen. Doch wirke auch hier der normale, erblich festgehaltene Teilungsrhythmus eine Zeitlang nach ${ }^{1}$ ). Die infolge dieses Umstandes auch bei künstlichem lichte noch stattfindenden Teilungen zeigen aber oft abnorme Verhältnisse, so beispielsweise Zellteilung durch Membranbildung ohne Kernteilung. Dadurch werde bewiesen, daß die verschiedenen, in der normalen Zellteilung zusammenwirkenden Vorgänge der Beeinflussung durch künstlich abgeänderte Belichtungsverhältnisse in ungleichem Maße zugänglich sind.

Stellt man aus den Tabellen Karstens Verteilungskurven für die einzelnen mitotischen Stadien bei den stundenweise untersuchten Algenkulturen auf, dann findet man trotz des regelmäßigen Tagesrhythmus seiner Objekte keine für bestimmte Tageszeiten charakteristischen Kurvenformen. Gleichzeitig entnommene Kulturen zeigen vielmehr verschiedenste Verteilungstypen der mitotischen Phasen. Dies bekräftigt mich wieder in der Auffassung, daß die in meinen Versuchen gefundene Ubbereinstimmung der Kurvenform in den beiderseitigen Corneaepithelien durch den für beide Augen übereinstimmenden Ernährungszustand allein nicht genügend erklärt werden kann. Die Teilungen verlaufen offenbar zu schnell, als daß sich der langsame Anstieg und Abfall der Gesamtzahlen von Mitosen in der Häufigkeitsverteilung der einzelnen mitotischen Stadien äußern könnte. - Auch für einen synchronen Verlauf der Zellteilungen innerhalb der Vegetationspunkte höherer Pflanzen ist trotz der nachgewiesenen Tagesperiodizität aus den Tabellen Karstens kein Anhaltspunkt zu gewinnen. Immerhin läßt sich aber aus den von Karsten gefundenen

1) R. Stoppel (Zeitschr. f. Bot. 8. Jahrg. 1916) glaubt, daß es sich hierbei nicht um ein erblich festgehaltenes Beharrungsvermögen, sondern um eine mit Schwan: kungen in der atmosphärischen Elektrizität zusammenhängende Periodizität handeln dürfte. M. G. Stålfelt (Svensk. Bot. Tidskrift, 13. 1919 u. 14. 1920) stellte auch für Erbsenwurzeln eine Periodizität der Zellteilungstätigkeit fest. Durch Einwirkung elelstrischer Ströme konnte er die Zellteilungstätigkeit steigern. 
Werten ein gewisser Zusammenhang der periodischen $\mathrm{Zu}$ - und $\mathrm{Ab}$ nahme der Mitosenzahl mit der Verteilung der Mitosenzahl auf die einzelnen mitotischen Phasen erkennen. So habe ich nach Berechnung der Werte aus der Arbeit von Karsten in graphischer Darstellung den prozentualen Anteil der Anfangsstadien der Karyokinese an der Gesamtsumme der Zellteilungen mit dem prozentualen Anteil der in Teilung begriffenen Zellen an der Gesamtzahl der untersuchten Zellen zu verschiedenen Tageszeiten verglichen. Dabei ergab sich beispielsweise für Closterium, daß das tiefste Minimum der Anfangsstadien 6 Stunden vor dem tiefsten Minimum der Gesamtzahl der Mitosen liegt, also in einer Zeit, in der die Endstadien noch in weiterem Abnehmen begriffen sind. Daher kann die Gesamtzahl in den folgenden 6 . Stunden noch weiter sinken, während die Anfangsstadien schon wieder zunehmen. Das höchste Maximum der Anfangsstadien liegt 10 Stunden vor dem höchsten Maximum der mitotischen Gesamtzahlen, also in einer Zeitperiode, in welcher die Gesamtzahlen der Mitosen durch Zunahme der für die Endstadien geltenden Werte noch weiter steigt. Ähnliches konnte ich aus den von Karsten für Cosmarium mitgeteilten Tabellen entnehmen. In meinen eigenen Untersuchungen hatte ich derartige fast selbstverständlich erscheinende Beziehungen zwischen dem Utberwiegen von Anfangs- oder Endstadien der Mitosen einerseits und $\mathrm{Zu}$ - oder Abnahme der mitotischen Gesamtzahl andererseits auch angedeutet gefunden. $\mathrm{DaB}$ sie hier noch weniger scharf hervortreten, möchte ich damit in Zusammenhang bringen, da $B$ hier die durch die Fütterungen bedingten Schwankungen der mitotischen Gesamtzahlen noch viel langsamer erfolgen als die täglichen periodischen Schwankungen der pflanzlichen Zellteilungstätigkeit.

Karsten faßt als allgemeines Resultat seiner letzten Arbeit die Erkenntnis auf, daß, wenigstens bei den Conjugaten, die vegetativen Zellen sich derart angepaßt haben, daß sie, solange ihnen Tageslicht zu Gebote steht, den Zellmechanismus einseitig auf Assimilation der Kohlensäure und Aufspeicherung chemischer Energie verwenden, die sie in der Nacht zum großen Teile zum Zwecke ihrer Vermehrung wieder ausgeben müssen. Sie sind auf diesen Wechsel ihres Betriebes derart eingestellt, daß das Tageslicht die Zell- oder besser die Kernteilung hemmt, die nächtliche Dunkelheit sie befördert. Damit wäre ein von Sachs formuliertes allgemeines Gesetz betreffs des von den Pflanzen durchgeführten Schutzes der zur Neubildung von Elementen bestimmten Pflanzenteile gegen das Licht in weiterem Rahmen bewiesen.

$\mathrm{Ob}$ bei höheren Tieren eine äbnliche Tagesperiodizität der Zellteilungen vorkommt, wäre durch weitere Untersuchungen klarzustellen. Im Bereiche der Protozoen ist Ähnliches bekannt. Da die Tagesperiodizität der grünen Pflanzen sicher mit der Assimilation im 
Sonnenlichte zusammenhängt, würde ihr als Homologon im Tierreiche die oben besprochene Abhängigkeit der Zellteilungstätigkeit von der Ernährung entsprechen. Es wird aber weiter zu untersuchen sein, ob außerdem die Tageszeit selbst, ob der Belichtungswechsel, ob eine durch längere Zeit hindurch immer zu bestimmten Tageszeiten erfolgende Fütterung den Zellteilungsrhythmus beeinflussen. In bestimmten Fällen scheinen ontogenetische Ent. wicklungsschritte an einen bestimmten Zellteilungsrhythmus geknüpft zu sein. So soll nach Przibram (1912) und Sztern (1914) bei der Gottesanbeterin die Zahl der Zellen stets von einer Häutung bis zur nächsten durch Absolvierung je eines allgemeinen Teilungsschrittes verdoppelt werden. Auf die Regelung der Zellteilungen in frühen Embryonalstadien wurde bereits früher hingewiesen. Bei diesen ersten Entwicklungsvorgängen scheint sich bisweilen eine künftige morphologische Differenzierung zuerst gerade dadurch anzukündigen, da $\widehat{B}$ der bis dahin einheitliche Zellteilungsrhythmus von einem gewissen Stadium an in verschiedenen Zellkomplexen Unterschiede aufzuweisen beginnt. Dies ist beispielsweise besonders auffällig bei späteren Furohungsstadien von Cephalopoden, bei denen zwei Gruppen von Furchungszellen, die sonst keinerlei Verschiedenheiten erkennen lassen, derart in ihren Zellteilungen miteinander abwechseln können, daß immer eine Gruppe Mitosen aufweist, während die andere in Ruhe ist, und umgekehrt (Maas 1903).

Auch von der Seite der physikalisch-chemischen Betrachtung wurde das Problem der Zellteilungsanregung wiederholt in Angriff genommen. Dabei stand meist der Gedanke einer Veränderung des Wassergehaltes durch erhöhte (erleichterte) oder herabgesetzte (erschwerte) Wasserzufuhr im Vordergrund. Dafür, daß physikalischehemische Veränderungen im Innern des Zelleibes an der Beherrschung der Zellteilung beteiligt sind, sprachen auch Ergebnisse bei der experimentell erzielten Gewebswucherung und bei künstlicher Parthenogenese; so beispielsweise die von verschiedenen Forschern festgestellte besondere Wirksamkeit lipoidlöslicher, also bis zu den sonst geschützten Zellkolloiden vordringender Stoffe (siehe besonders Wacker und Schmincke 1911), ferner eine gewisse Parallelität zwischen entwicklungsanregender und permeabilitätsteigernder Wirksamkeit verschiedener Anionen, u. a. m. Im einzelnen möchte ich nur zwei Autoren erwähnen, die gerade in der allerletzten Zeit dieser Seite des Zellteilungsproblems ihre Aufmerksamkeit gewidmet haben: Heilbrunn (1920) hält experimentell nachweisbare Veränderungen der Viskosität des Zellprotoplasmas und gleichzeitige Gelbildungen für eine Vorbedingung des Zellteilungsaktes. Er glaubt dies auch durch Experimente am Seeigelei beweisen zu können; durch verschicdene Ein- 
wirkungen könne die Gelbildung verhindert und dadurch die Mitose unterdrückt werden. Diese Gelbildung sei auf Wasserentzug zurïckzuführen und durch einen solchen nachzuahmen oder zu ersetzen. Speck (1920) faßt im Gegensatz dazu Verquellung und Verflüssigung von Plasmakolloiden als Grundlagen der Zellteilung auf und prüft zur Klärung der Beziehungen zwischen Quellung und Zellteilung den Einfluß verschiedener Ionen auf die Teilung von Paramaecium. Er findet, daß im allgemeinen quellungfördernde Ionen auch die Zellteilungen fördern, entquellend wirkende Salze dagegen die Zellteilungen hemmen. Komplizierend wirke dabei nur der Umstand, daß die verschiedenen Salze in sehr verschiedenem Ausmaße die Fähigkeit bèsitzen, in die Zelle einzudringen. Die Verquellung der Kolloide vor der normalen Zellteilung werde durch das Auftreten einer Base verursacht, die bei der Nukleinsynthese entstehe. Jede Zellteilung leite mehr oder weniger automatisch wieder eine weitere Zellteilung ein. Die von Speck auch als Beweis für einen erhöhten Innendruck der sich teilenden Zellen angeführte Beobachtung, daß bei Nematoden die in Teilung begriffenen Blastomeren gegen die ruhenden Nachbarzellen mit konvexen Konturen vorspringen, glaube ich für die zwischen ruhenden Zellen zur Teilung schreitenden Zellen in Epithelien von Salamanderlarven in manchen Fällen bestätigen zu können.

Die Verschiedenartigkeit der in all diesen Arbeiten ausgesprochenen Anschauungen über das Wesen der Zellteilungsfaktoren, der Mangel eines einheitlichen Gesichtspunktes in der Betrachtung dieser Fragen, erschwert die Verwertung der Resultate für unsere Fragestellung außerordentlich. Ioh halte es durch meine Befunde für erwiesen, daß auch die in späteren Entwicklungsphasen höherer Tiere in den verschiedenen Organen ablaufenden Zellteilungen eine Regelung vom Gesamtorganismus her erfahren. Ich halte es weiter für erwiesen, $d a ß$ diese Regelung nicht durch einen einheit. lichen Faktor erfolgt, sondern daß der Zellteilungsrhythmus im Einzelorgan durch das Zusammenwirken verschiedenartiger Einflüsse beherrscht wird. Unter diesen Einflüssen möchte ich im Sinne von Gurwitsch eine allgemeinere, langsam veränderliche Zellteilungsbereitschaft von schneller wechselnden auslösenden Faktoren unterscheiden. Ich glaube, daß für die Teilungsbereitschaft der vor allem von den vorhergehenden Fütterungsbedingungen abhängige Ernährungszustand des Zellkomplexes von Bedeutung ist. Dieser Faktor könnte für ein wachsendes Gewebe auch als funktionelle Beanspruchung aufgefaßt werden. Als auslösende Faktoren könnten Produkte der Hormondrüsen in Betracht kommen und wir würden hier Anschluß an die Befunde Haberlandts finden. In welcher Weise sich physikalischchemische Zustandsünderungen der Zellen als auslösende Momente 
der Zellteilung in unsere schematisierte Vorstellung vom Wesen der Zellteilungsregelung einfügen ließen, kann ich noch nicht entscheiden.

Von Interesse wären eventuell noch Beobachtungen, die ich an meinen Präparaten über die Verteilung der Mitosen und der mitotischen Stadien innerhalb je einer Cornea machen konnte. Ohne bisher diesen Verhältnissen eingehende Aufmerksamkeit gewidmet zu haben, konnte ich feststellen, daß im allgemeinen die überwiegende Mehrzahl der Mitosen in den Randabschnitten der Cornea zu finden ist, daß also ein vorwiegend appositionelles Wachstum stattfindet. Auch in diesen Randteilen findet sich aber oft keine gleichmäBige Verteilung der Mitosen, sondern wir sehen eher unregelmäBigverteilte, nestartige Ansa mmlungen von Teilungsfiguren. Das würde vielleicht für lokal getrennte, der Blutversorgung folgende Zentren für den Angriff der teilungauslösenden Faktoren sprechen. In einzelnen Fällen erschien mir auch eine ungleichartige Verteilung der verschiedenen Phasen in verschiedenen Teilen der Cornea auffallend. Das würde für 'mehrere, an verschiedenen Stellen ungleichzeitig einwirkende Teilungsauslösungen oder für ein allmähliches Fortschreiten eines Zellteilungsimpulses innerhalb einer Cornea sprechen. Besonders letztere Deutung stünde in gutem Einklange mit den oben erwähnten Befunden von Gurwitsch über das Fortschreiten von Teilungswellen durch die Zellnester des Urodelenhodens und mit dem Umstande, daß auch bei Zellteilungen der Pollenmutterzellen in Angiospermenantheren in der Längsrichtung der Antheren zunehmende Verschiebungen der vorgefundenen Zellteilungsphasen vorkommen, welche durch ein wellenförmiges Fortschreiten eines Teilungsimpulses von der Insertionsstelle der Anthere aus zu erklären wären (siehe oben S. 546).

\section{Zusammenfassung.}

1. Eine Durchsicht der Literatur ergibt, daß für die Frage nach der Regelung der einzelnen Entwicklungsvorgänge innerhalb eines Lebewesens ein einheitlicher Gesichtspunkt bisher nicht gewonnen werden konnte. Die Ergebnisse neuerer experimenteller Arbeiten weisen darauf hin, daß die Entwicklung der einzelnen Organe in bezug auf ihre Ablaufsgeschwindigkeit nicht selbständig, sondern in Abhängigkeit vom Gesamtorganismus verläuft. Beim höher organisierten Lebewesen scheinen verschiedene Gruppen von Prozessen derart nebeneinander herzugehen, daß die Einzelvorgänge innerhalb einer Gruppe durch gemeinsam einwirkende Faktoren in ihrem Verlaufe enger miteinander verknüpft er* scheinen als Vorgänge, welche verschiedenen von diesen Gruppen angehören. Als beherrschende und regelnde Faktoren des Entwicklungsverlaufés konnten Einwirkungen der inneren Sekretion und Einflüsse der funktionellen Beanspruchung experimentell nachgewiesen werden. 
2. Die Entwicklungsvorgänge im Pflanzenreich, bei niederen Tieren und in frühesten Embryonalstadien höherer Tiere zwingen uns, das Problem der Entwicklungsregelungen bis zu den zellulären Prozessen zu verfolgen. Aber auch bei den späteren Entwicklungsvorgängen höherer Tiere müssen wir die Zelle mit ihrem eigenen Entwicklungsgeschehen als Angriffspunkt der regulierenden Faktoren innerhalb des Einzelorganes ansehen, auch wenn hier zwischen die Zellen des Organes einerseits und die Einwirkungen von seiten der Außenwelt und der übrigen Organe des Individuums andererseits spezifische Faktoren der Entwicklungsregelung eingeschaltet sind, welche die Zellkomplexe des Einzelorganes im Wege des Nervensystems oder des Blutgefäßsystems erreichen. Die spärlichen Arbeiten, welche sich bisher mit den grundlegenden Fragen nach der Regelung des zellulären Entwicklungsgeschehens beschäftigt haben, konnten in Einzelfällen das Bestehen einer solchen Regelung deskriptiv oder experimentell beweisen oder doch wahrscheinlich machen, ohne jedoch über das Wesen derartiger Regelungen näheren Aufschluß zu bringen. Es wurde darum eine Reihe von Untersuchungen begonnen, welche die Frage nach der Regelung des zellulären Geschehens speziell in späteren Entwicklungszuständen höherer Tiere klären sollen.

3. Es wurden dabei vor allem systematisch die Angaben überprüft, welche über den Zusammenhang des Zellteilungsreichtums in den Geweben von Urodelenlarven mit den vorausgehenden Ernährungsbedingungen berichten, s. Abb. I u. 2. Eigene Untersuchungen ergaben für das Corneaepithel von Salamanderlarven, die kurze Zeit nach der im Herbste durchgeführten Entnahme aus dem mütterlichen Uterus verwendet wurden, eine Bestätigung der Angabe, daß man durch reichliche Fütterung nach einer kurzen Hungerperiode mit fast absoluter Sicherheit ein starkes Ansteigen der Mitosenzahl erzielen kann. Doch fand ich, daß erst 4-5 Tage nach dem Einsetzen der Fütterung die Zunahme der Mitosenzahl beginnt, während das Maximum dieser Zunahme erst 6-14 Tage nach Beginn der Fütterung erreicht wird. Dabei scheint das Maximum im allgemeinen um so schneller erreicht zu werden, je länger die vorausgegangene Hungerperiode andauerte. Hunger scheint anfangs, solange noch verfügbare Reserven von Assimilaten zur Verfügung stehen, als teilungsfördernder Reiz zu wirken, später bewirkt er selbstverständlich ein Zurückgehen der Mitosenzahl. Diese Wirkung hält dann auch nach dem Einsetzen einer Fütterung noch einige Tage an.

4. Um die Gesetzmäßigkeiten des Zellteilungsrhythmus aufzuklären, wurde zunächst die einfache Fragestellung gewählt, wie weit die Zellteilungstätigkeit zwischen zwei gleichartigen Zellkomplexen eines Tieres, nämlich zwischen den beiderseitigen Corneaepithelien, jeweils übereinstimmt. Dabei zeigte es sich vor allem, daß die absoluten Zahlen 
der Mitosen als Ausdruck der augenblicklichen Lebhaftigkeit der mitotischen Zelltaitigkeit in den beiderseitigen Corneaepithelien im allgemeinen weitgehend übereinstimmen, s. Abb. 3 u. 4. Ferner stimmt im allgemeinen auch die Verteilung der Gesamtzahl der gefundenen Mitosen auf die einzelnen mitotischen Phasen in den beiderseitigen Corneaepithelien gut überein. Dies läßt sich besonders einfach und anschaulich durch Vergleiche zwischen den prozentualen Anteilen, welche die mitotischen Endphasen an der Gesamtzahl der in der rechten und in der linken Cornea gefundenen Mitosen besitzen, nachweisen, s. Abb. 5 u. 6 . Außerdem wurden zum Vergleiche zwischen den mitotischen Vorgängen in den beiderseitigen Corneae Verteilungskurven herangezogen (Abb. $7-29$ ), in denen die Zahlen der in je einer Cornea gefundenen verschiedenen mitotischen Stadien graphisch dargestellt waren. Auch hierbei zeigte sich in einer sehr großen Zahl von Fällen eine auffallende. Übereinstimmung. Es war dadurch bewiesen, daß die Zellteilungen im Gewebe eine gesetzmäßige Regelung erfahren, und zwar durch Faktoren, welche die beiderseitigen Corneaepithelien im allgemeinen gleichzeitig erreichen und gleichsinnig beeinflussen. Daß unter diesen Faktoren solche sein dürften, welche mit dem vorausgehenden Ernährungszustande des Individuums zusammenhängen, wird durch die besprochene Abhängigkeit des Mitosenreichtums von den vorhergehenden Fütterungsbedingungen wahrscheinlich gemacht. Andererseits erscheint es ausgeschlossen, daß etwa nur der für beide Körperseiten als gleichartig anzunehmende direkte Ernährungseinfluß allein den in beiden Corneae gleichartigen Zellteilungsrhythmus bedingt. Dies wird schon durch den im Verhältnis zu dem schnellen Verlaufe der einzelnen Mitosen außerordentlich langsam wirkenden Einfluß der Ernährung unwahrscheinlich gemacht, ferner durch die Tatsache, daß die charakteristische Kurvenform im Einzelfalle bei meinen bisherigen Untersuchungen nur selten und undeutlich mit dem durch die Ernährungsverhältnisse bedingten $\mathrm{Zu}$ - oder Abnehmen der Mitosenzahl in Zusammenhang gebracht werden konnte. Zwischen die durch Ernährungsbedingungen gesetzten langsam veränderlichen Beeinflussungen der Lebhaftigkeit der mitotischen Vorgänge und die Regelung des mitotischen Geschehens am Einzelorgan selbst scheinen spezifische Faktoren eingeschaltet zu sein, welche den Ablauf der zellulären Entwicklungsvorgänge beherrschen und regeln. All dies steht in Einklang mit den Anschauungen, welche in den Veröffentlichungen Uhlenhuths sowie zum Teile in meiner Arbeit über Kiementransplantationen auf Grund experimenteller Ergebnisse und theoretischer Erwägungen bezüglich der Regelung der metamorphotischen Entwicklungsvorgänge bei Amphibien vertreten wurden.

5. Gerade jene Fälle aber, bei welchen der Zellteilungsrhythmus in den beiderseitigen Corneaepithelien keine oder nur eine unvoll- 
kommene Ủbereinstimmung aufweist, lassen uns auch Gesetzmäßigkeiten erkennen oder doch wenigstens vermuten, deren vollständige Aufklärung allerdings noch weiteren eingehenden Untersuchungen über die Zellteilungsbiologie vorbehalten bleibt. Schon jetzt aber können wir sagen, daß die Fülle von ungleichen Verteilungskurven der mitotischen Phasen in gleichartigen Zellkomplexen in verschiedene gut charakterisierbare Gruppen eingeteilt werden können, aus deren Eigentümlichkeiten wir auf verschiedenartige Zellteilungsfaktoren schließen können. Als solche Faktoren möchte ich im Anschluß an Gurwitsch eine gewisse allgemeine Teilungsbereitschaft einerseits, auslösende innere, vielleicht aber auch äußere Reize andererseits unterscheiden. Dabei wäre daran zu denken, die Teilungsbereitschaft mit dem Ernährungszustande des betreffenden Zellkomplexes, mit seinem Reichtum an verfügbaren Assimilaten in Zusammenhang zu bringen. Für ein wachsendes Gewebe stellt reichliche Nahrungszufuhr gewiß einen adäquaten funktionellen Reiz dar. Als auslösende Faktoren könnte man dagegen vor allem Einflüsse der inneren Sekretion annehmen, wie wir solche als den Stoffwechsel regulierende, Wachstum einerseits, Differenzierungsvorgänge andererseits beherrschende Faktoren von der experimentellen Organbiologie her kennen gelernt haben. In diesem Zusammenhange erschienen die Untersuchungen Haberlandts über Zellteilungshormone im Pflanzenreiche von Interesse.

Weitere Untersuchungen werden der Klärung des Zusammenhanges zwischen dem Zellteilungsrhythmus in verschiedenen Organen eines Individuums, sowie zwischen Zellteilungsrhythmus und Tageszeit, Belichtung, Fütterungsstunde usf. dienen müssen, endlich auch der Untersuchung des Einflusses von Hormonen auf die Zellteilungstätigkeit. Es erscheint selbstverständlich, daß wir von weiteren Forschungen auf dem in diesen Richtungen noch verhältnismäßig wenig bearbeiteten Gebiete der Zellteilungsbiologie sowohl Aufschlüsse 'über Fragen von allgemein biologischer Bedeutung erwarten dürfen, als auch die Schaffung festerer und breiterer Grundlagen für die Beurteilung wichtiger pathologischer Probleme.

Nachtrag bei der Korrektur:

Während der Drucklegung der vorliegenden Arbeit erhalte ich Kenntnis von sehr interessanten Ergebnissen einer Arbeit von F. R. Sabin (Studies on the origin of blood vessels and red blood corpuscles as seen in the living blastoderm of chicks during the second day of incubation, Carnegie Institution Washington, Pub.272, Contributions to Embryology, vol. 1920). Sabin findet bei der Entwicklung des Blutgefäßsystems in jungen Hühnerkeimscheiben Zellteilungszyklen - ebenso wie im Nervensystem und im Entoderm(?) - . Es sollen alle Angioblasten oder 
alle primitiven Blutzellen einer bestimmten Zone. zu gleicher Zeit in Teilung angetroffen werden. Als Folge derartiger, von den äußeren Gebieten der Zona opaca allmählich gegen den Embryo vordringender Zellteilungswellen schreite die Differenzierung der Blutgefäße und des Blutes in der gleichen Richtung, von außen nach innen, fort, so daß man bei Keimscheiben von der zweiten Hälfte des zweiten Tages der Bebrütung nebeneinander den ganzen Verlauf der Gefäßentwicklung an einem Schnitte beobachten könne. Ein derartiges wellenförmiges Fortschreiten einer Zellteilungsepidemie würde sich gut unter die oben erwähnten ähnlichen Befunde (S. 546 u. 587) einreihen lassen.

\section{Literaturverzeichnis.}

Adler, L., Metamorphosestudien an Batrachierlarven. I. Exstirpation endocriner Drüsen. Arch. f. Entw.-Meoh. Bd. 39 u. 40. 1914. - Aschoff, L., Patho* logische Anatomie. IV. Aufl. 1919. - Bae r, K. E. v., Uber Entwicklungsgeschichte der Tiere. Königsberg 1828. - Born, G., Uber Verwachsungsversuche mit Amphibienlarven. Arch. f. Entw.-Mech. Bd. 4. 1897. - Child, C. M., A study of senescence and rejuvenescence, based on experiments with Planarians. Arch. f. Entw.-Mech. Bd. 31. 1911. - Dahlgren, O., Zur Embryologie der Kompositen mit besonderer Berücksichtigung der Endospermbildung. Zeitschr. f. Botanik. 12. Jahrg. 1920. - Driesoh, H., Philosophie des Organischen. Leipzig 1909. - F ischel, A., Uber Variabilität und Wachstum des embryonalen Körpers. Morph. Jahrb. Bd. 24. 1896. - Ders., Die Bedeutung der entwicklungsmechanischen Forschung für die Embryologie und Pathologie des Menschen. In: Vortr. u. Aufs. üb. Entw.-Mech. Heft 16. 1912. - Foá, Arch. ital. d. Biol. 34. 1900, zitiert nach Asch off 1919. - Gudernatsch, J. F., Feeding Experiments on Tadpoles. I. Arch. f. Entw.-Mech. Bd. 35. 1913. - Gurwitsch, A., Über Prämissen und anstoßgebende Faktoren der Furchung und Zellvermehrung. Arch. f. Zellforsch. Bd. 2. 1909. - Ders., Uber Determination, Normierung und Zufall in der Ontogenese. Arch. f. Entw.-Mech. Bd. 30. 1910. - Ders., Untersuchungen über den zeitlichen Faktor der Zellteilungen. 2. Mittcilung: Über das Wesen und das Vorkommen der Determination der Zellteilung. Arch. f. Entw.-Mech. Bd. 32. 1911. - Haberlandt, G., Kulturversuche an isolierten Pflanzenzellen. Sitzungsber, d. Akad. d. Wiss. Wien, math.-nat. Kl. Bd. 111. 1902. - Ders., Zur Physiologie der Zellteilung. Sitzungsber. d. Preuß. Akad. d. Wiss. 1913. - Ders., Zur Physiologie der Zellteilung. II. Mitteil. Ebenda. 1914. Ders., Zur Physiologie der Zellteilung. V. Mitteil. Ebenda. 1920. - Ders., Wundhormone als Erreger von Zellteilungen. Beiträge zur allgem. Botanik. Bd. 2. 1921. - Häcker, V., Praxis und Theorie der Zellen- und Befruchtungslehre. Jena 1899. - Ders., Entwicklungsgeschichtliche Eigenschaftsanalyse. Jena 1918. - Heilbrunn, L. V., An experimental study of cell division. I. The physical conditions, which determine the appearence of the spindle in sex urohin eggs. Journ. of Exp. Zool. Vol. 30. 1920. - Held, H., Úber experimentelle Reifung des Nervenmarks. Arch. f. Anat. u. Physiol., Anat. Abt. 1896. - Hertwig, O., Lehrbuch der Entwicklungsgesohichte. 10. Aufl. Jena 1915. - Hertwig, R., Uber Korrelation von Zell- und Kerngröße und ihre Bedeutung für die geschleohtliche Differenzierung und die Teilung der Zelle. Biol. Zentralbl. Bd. 23. 1903. - His, W., Unsere Körperform und das physiologische Problem ihrer Entstehung. Leipzig 1874. - Juel, H. O., Die Kernteilungen in den Pollenmutterzellen von Hemerocallis fulva und die bei denselben auftretenden Un- 


\section{Werner Kornfeld: Cber den Zellteilungsrhythmus und seine Regelung.}

regelmäßigkeiten. Jahrb. f. Botanik. Bd. 30. 1897. - Kahn, R. H., Zur Frage der Wirkung von Schilddrüse und Thymus auf Froschlarven. Pflügers Arch. f. d. ges. Physiol Bd. 163. 1916. - Karsten, G., Ober embryonales Wachstum und seine Tagesperiode. Zeitsohr. f. Bot. Bd. 7. 1915. - Ders, Uber die Tagesperiode der Kern- und Zellteilungen. Zeitschr. $f$. Bot. Bd. 10. 1918. Keibel, F., Uber den Entwicklungsgrad der Organe in den verschiedenen Stadien der embryonalen Entwieklung der Wirbeltiere. In: Hertwigs Handbuch der Entwicklungslehre. Bd. III, 3. Teil. 1903. - Kniep, H., Beiträge zur Kenntnis der Hymenomyceten. V. Zeitschr. f. Bot. Bd. 9. 1917. - Kopeé, St., Untersuchungen über Kastration und Transplantation bei Schmetterlingen. Arch. f. Entw.-Mech. Bd. 33. 1911. - Kornfeld; W., Abhängigkeit der metamorphotischen Kiemenrückbildung vom Gesamtorganismus bei Salamandra maculosa. Arch. f. Entw.-Meoh. Bd. 40. 1914. - Lamprecht, W., Uber die Kultur und Transplantation kleiner Blattstückehen. Beiträge zur allgem. Botanik. 1. 1918. - Maas, O., Einführung in die experimentelle Entwicklungsgeschichte. Wiesbaden 1903. - Mehnert, E., Die individuelle Variation des Wirbeltierembryo. Morphol. Arbeiten. Bd. 5. 1895. - Meisenheimer, J., Ergebnisse einiger Versuchsreihen über Exstirpation und Transplantation der Geschlechtsdrüsen bei Schmetterlingen. Zoolog. Anzeiger. Bd. 32. 1907. - Ders., Uber den Zusammenhang von Geschlechtsdrüsen und sekundären Geschlechtsmerkmalen bei Arthropoden. Verhandl. d. D. zool. Ges. 1908. - Meyns, R., Transplantation embryonaler und jugendlioher Keimdrüsen auf erwachsene Individuen bei Anuren usw. Areh. f. mikr. Anat. Bd. 79. 1912. - Mottier, Beitrïge zur Kenntnis der Kernteilungen in den Pollenmutterzellen einiger Dicotylen und Monocotylen. Jahrb. f. wiss. Bot. Bd. 30. 1897. - Oppel, A., Vergleichung des Entwicklungsgrades der Organe zu verschiedenen Entwicklungszeiten bei Wirbeltieren. Jena 1891. - Peter, K., Normentafel zur Entwicklungsgeschichte der Zauneidechse. Jena 1904. - Przibram, H., u. Megas̆ar, F., Wachstumsmessungen an Sphodromantis bioculata. I. Länge und Masse. Arch. f. Entw.Mech. Bd. 34. 1912. - Rabl, C., Bausteine za einer Theorie der Extremititen der Wirbeltiere. Leipzig 1910. - Rehn, E., a. Wakabayaschi, Die homöoplastische Transplantation im Tierexperiment. Arch. f. klin. Chirurgie. Bd. 97. 1912. Ribbert, H., Uber Transplantation von Ovarium, Hoden und Mamma. Aroh. f. Entw.-Meoh. Bd. 6. 1897. - Roux, W., Über Mosaikarbeit und neuere Entwicklungshypothesen. Merkel-Bonnet, Anat. Hefte. Bd. 2. 1892/93. - Sorokina, M., Über Synchronismus der Zellteilungen. Arch. f. Entw.Mech. Bd. 35. 1912. - Sttern, H., Waohstnmsmessungen an Sphodromantis bioculata. II. Länge, Breite und Höhe. Arch. f. Entw.-Mech. Bd, 40. 1914. - Uhlenhuth, F., Die synchrone Metamorphose transplantierter Salamanderaugen. Arch. f. Entw.Meeh. Bd. 36. 1913. - Ders., A further Contribution to the Metamorphosis of Amphibian Organs. (The Metamorphosis of grafted Skin and Eyes of Amblystoma punctatum.) Journ. of Exp. Zool. Vol. 24. 1917. - Ders., Relation between Thyroid Gland, Metamorphosis and Growth. Journ. of General Physiology. Vol. i. 1919a. - Ders., Relation between Metamorphosis and other developmental Phenomena in Amphibians. Journ. of General Physiology. Vol. i. 1919 b. - Vöchting, H., Über Transplantation am Pflanzenkörper. Tübingen 1892. Wacker, L., u. Schmincke, A., Experimentelle Untersuchungen zur kausalen Genese atypischer Epithelwucherungen. Münch. med. Wochenschr. Bd. 58. 1911. - Weigl, R., Über homöoplastisohe und heteroplastische Hauttransplantation bei Amphibien mit besonderer Berücksichtigung der Metamorphose. Arch. $f$. Entw.-Mech. Bd. 36. 1913. - Winkler, H. (Referat über die Arbeit von Haberlandt, 1902) in Botan. Zejtg. II. Abt. 1907. 